\title{
Nationwide implementation of medical skills training laboratories in a developing country
}

Citation for published version (APA):

Tran, T. Q. (2020). Nationwide implementation of medical skills training laboratories in a developing country: studies from Vietnam. [Doctoral Thesis, Maastricht University]. Maastricht University. https://doi.org/10.26481/dis.20201209qt

Document status and date:

Published: 01/01/2020

DOI:

10.26481/dis.20201209qt

Document Version:

Publisher's PDF, also known as Version of record

\section{Please check the document version of this publication:}

- A submitted manuscript is the version of the article upon submission and before peer-review. There can be important differences between the submitted version and the official published version of record.

People interested in the research are advised to contact the author for the final version of the publication, or visit the DOI to the publisher's website.

- The final author version and the galley proof are versions of the publication after peer review.

- The final published version features the final layout of the paper including the volume, issue and page numbers.

Link to publication

\footnotetext{
General rights rights.

- You may freely distribute the URL identifying the publication in the public portal. please follow below link for the End User Agreement:

www.umlib.nl/taverne-license

Take down policy

If you believe that this document breaches copyright please contact us at:

repository@maastrichtuniversity.nl

providing details and we will investigate your claim.
}

Copyright and moral rights for the publications made accessible in the public portal are retained by the authors and/or other copyright owners and it is a condition of accessing publications that users recognise and abide by the legal requirements associated with these

- Users may download and print one copy of any publication from the public portal for the purpose of private study or research.

- You may not further distribute the material or use it for any profit-making activity or commercial gain

If the publication is distributed under the terms of Article $25 \mathrm{fa}$ of the Dutch Copyright Act, indicated by the "Taverne" license above, 


\section{Nationwide implementation of}

medical skills training laboratories

in a developing country:

studies from Vietnam

\section{Trung Quang Tran}


Nationwide implementation of medical skills training laboratories in a developing country: studies from Vietnam 
The research reported here was carried out at

\section{Daastricht University 4 Maastricht UMC+}

in the School of Health Professions Education

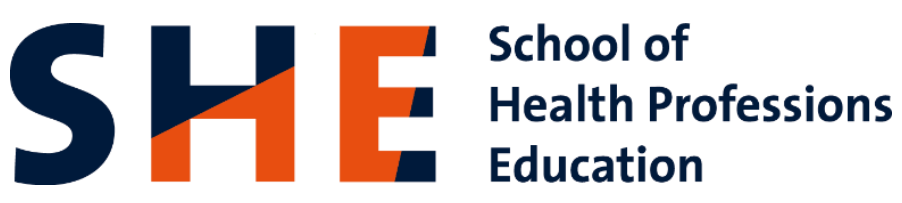

In collaboration with eight Vietnamese Medical faculties/universities in the project: NPT/VNM/UMP/MUNDO/Strengthening Medical Skills Training Funded by:

Project NPT/VNM/UMP/MUNDO/Strengthening Medical Skills Training

(C) Trung Quang Tran, HoChiMinh City 2020

Layout: Mai-Huyen Thi Pham

Cover design: Trung Quang Tran

Printing info

ISBN 


\section{Nationwide implementation of medical skills training laboratories in a developing country: studies from Vietnam}

\section{DISSERTATION}

To obtain the degree of Doctor at the Maastricht University, on the authority of the Rector Magnificus,

Prof. Dr. Rianne M. Letschert

in accordance with the decision of the Board of Deans, to be defended in public on Wednesday 09th December 2020, at 10:00 hours 

Supervisor:

Prof. Dr. A.J.J.A. Scherpbier

Co-Supervisors:

Dr. E.P. Wright (VU Amsterdam)

Dr. J.V. Dalen

Assessment committee:

Prof. Dr. E. Driessen (Chair)

Prof. Dr. D.H.J.M. Dolmans

Dr. K.B. Giang, MD, PhD (HMU, Vietnam)

Prof. Dr. A.D.C. Jaarsma (UMC Groningen)

Dr. A.P. Susilo, MD, PhD (UBAYA, Indonesia) 


\section{Contents}

$\begin{array}{ll}\text { Chapter 1: Introduction } & 6\end{array}$

Chapter 2: Validation of skill list for skillslab training based on responses 26 from students and general practitioners

Chapter 3: Implementing a Skillslab Training Program in a Developing 44 Country

Chapter 4: Nationwide survey of patients' and doctors' perceptions of what 58 is needed in doctor - patient communication in a Southeast Asian context

Chapter 5: Teacher-made models: the answer for medical skills training 79 in developing countries?

Chapter 6: Discussion 92

Chapter 7: Valorisation 109

Chapter 8: Summary

Samenvatting (Dutch)

Curriculum Vitae

Acknowledgements

SHE dissertations series 
Chapter 1

Introduction 


\section{Introduction}

At the time of graduation, students of medicine are required to have learned a number of essential competencies, which are often described in national standards [1-4]. With regard to training in clinical skills, traditional medical curricula rely primarily on clerkships; during the preclinical years there is little exposure to clinical situations $[1,5,6]$. One result of using this curriculum structure can be that while students are transiting from their preclinical to clinical training, they may experience difficulties in acquiring and applying the skills required during the clinical rotations [7]. This is not only stressful for them but also not good for the patients [8]. Henceforth, we will use the term "clinical skills" to encompass not only manual skills used in clinical work but also history-taking, physical examination, diagnostic reasoning, effective communication, and teamwork [2].

Early introduction of clinical skills training has received increasing attention during the past decades [2, 6, 9-16]. It should facilitate the integration of clinical and basic science knowledge, and help students to develop their clinical competence [17, 18]. Published reports suggest that students feel more prepared for their clinical rotations when clinical skills are introduced early in the curriculum $[8,19]$. Their performance is improved and their confidence is increased; the training makes them "feel" like doctors, as it helps them to prepare for their clerkship phase [20].

An important development in medical education was the design, construction and application of the clinical skills laboratory (Skillslab) $[2,6]$. The Skillslab approach was first presented by the Medical Faculty of the University of Maastricht in 1975. They demonstrated the benefits of letting students experience the practical side of patient contact in a more controlled, laboratory-like situation. The Skillslab method includes systematic practice on models, or on and with other students. Later, when a certain level of expertise has been acquired, they can work with simulated patients, and after that, on especially selected real patients who have been hired and trained to work with the students [21]. A Skillslab is a dedicated institution equipped with a range of teachers, facilities and equipment that provides the appropriate simulated environment to conduct the history taking, interview, physical examination, and diagnostic and therapeutic procedures in which it is essential for students to gain experience and expertise before they are allowed to practice on real patients $[22,23]$. Practicing in a Skillslab enables students to acquire the necessary clinical skills through hands-on training in a safe and zero-risk environment, because they are not directly exposed to patients nor patients to them [23, 24]. 
Teaching clinical skills in a Skillslab was found to have many advantages [25]:

$>$ In a laboratory situation, complex practical situations that graduates will face in health care services can be unraveled into simpler, teachable skills. The complexity of the learning situation can thus to a certain extent be controlled.

Skills can be repeated as often as necessary to master the skill, which would be unacceptable with patients.

$>$ In the Skillslab, mistakes are allowed; students can learn from these mistakes until their skills become good enough and they become confident and can avoid those mistakes.

$>$ Direct feedback is possible during supervised or supported practice.

$>$ Patient problems that in reality develop over time can be acted out in a short period in a laboratory situation.

$>$ Teaching of skills in the Skillslab requires the standardization of the procedures, which makes them easier to learn and to teach and assess.

Additional reasons for establishing a Skillslab include the following. In many medical schools, there may not be enough patients available at any one time for all students to have equal opportunities to learn and to practice the skills safely and competently [26]. Inexperienced students are also known to have anxieties about practice, often related to their lack of practical skills, fear of failure and fear of making mistakes [27]. Skillslabs, with their controlled environment, play a key role in the quality assurance of the medical training. In the Skillslab, many of the necessary skills can be demonstrated, then repeatedly practiced and evaluated, until the required minimum standard for patient treatment is ensured [28]. Furthermore, learning clinical skills on real patients raises many ethical concerns [29].

Currently many medical schools around the world are using a variety of simulators for hands-on health care training for medical, nursing, and allied health students. Skillslabs have been successfully developed in Western and high-income countries [13,30,31] and have started to appear in low- and middle-income countries [6, 11]. These Skillslabs vary in the accommodation provided and the resources available, from one room with one manikin to purpose-built structures that simulate different clinical settings, with a vast assortment of equipment [32]. Because of the recognized advantages of the Skillslabs, many medical schools have come under pressure to provide them for their students during the past several years [13].

It is generally true that using simulation, medical students can safely learn, practice, and repeat the skill or procedure over and over until basic proficiency is achieved without 
touching a real patient; improving their skills and confidence without compromising patient safety $[13,32,33]$. However, it is not always appropriate to transfer this model directly to medical and healthcare schools in low-income countries, as the capital cost may be far in excess of local budgets [26]. Cultural differences may also influence the most suitable content of the training. To set up and implement a medical skills training system as standard for a whole country requires great effort and investment, especially where resources are limited.

In Vietnam, medical students were traditionally sent to hospitals to practice from the second semester of the second year until they graduated at the end of the sixth year. However, as reported in Growing Healthy: A Review of Vietnam's Health Sector, in 2001, "All agree that too much of the teaching for most health professionals is theoretical and that graduates have too little experience." [34]. Although the curriculum allocated a maximum time for clerkships, graduating students still felt that their clinical skills were insufficiently developed [35]. The growing number of students and shorter hospital stays [36] could limit the availability of patients for students' practice opportunities.

The project "Strengthening medical skills training at 8 medical faculties/universities in Vietnam", funded by the Government of the Netherlands and started in 2004, aimed to set up and implement a medical skills training program in the form of Skillslabs in medical schools throughout Vietnam [37]. The project involved all eight of the publicly-funded and non-military medical faculties and universities in Vietnam at that time, and provided a great opportunity for innovating skills training in Vietnam. The technical support was provided by Maastricht University in the Netherlands, where the Skillslab approach originated.

The Skillslab approach has been impressively successful at Maastricht University [25] , but its implementation across Vietnam, a developing country, was a major challenge and the results were uncertain.

Everett M. Rogers, an American communication theorist and sociologist, who originated the Diffusion of Innovations Theory, claimed that uncertainty is an important obstacle to the adoption of innovations. To reduce that uncertainty, innovators striving to stimulate change should know the advantages and disadvantages and the possible consequences of introducing change [38].

The Diffusion of Innovations Theory has been widely applied for intervention development [39], also for investigating the adoption of new approaches in higher education and educational environments $[40,41]$, and in the adoption of innovative health care programs [42-44]. Rogers' theory mentions a variety of concepts. His five-stage adoption process is applied as a framework with which to track the nationwide implementation of medical skills training laboratories in Vietnam (adoption of the innovative Skillslab approach in Vietnam). 
For Rogers [38], the adoption process involves five stages: (1) knowledge, (2) persuasion, (3) decision, (4) implementation, and (5) confirmation.

1) Knowledge stage: The team introducing the Skillslabs in Vietnam had a study tour to Maastricht Skillslab to visit the existing Skillslabs, received training from the Maastricht facilitators, and participated in a version of the Master of Health Professions Education program at Maastricht University, tailor-made to address the issues relevant for the project. Two project members per Vietnamese university participated in this program to ensure that there would be appropriate awareness-knowledge, how-to-knowledge, and principles-knowledge in each university to implement the project.

2) Persuasion stage: Staff training was organized alternately in each of the participating institutions to provide an opportunity to get the attention of staffs and students outside the project at each site, which helped to create a good environment for the persuasion stage. Rogers described five perceived characteristics important for the persuasion stage:

- Relative advantage: the degree to which an innovation is perceived as better than the former practice. The Skillslab approach has a lot of advantages [8, 17-19, 23-25] as evidenced by the existing Skillslabs, and by literature review.

- Compatibility: the degree to which an innovation is perceived as being compatible with existing values, past experiences, and the needs of potential adopters. The Skillslab approach is not intended instead of training with patients, but rather an additional preclinical skills training before students practice on real patients. Skillslab training has to be integrated into the curriculum and needs extra facilities, models and equipment. Therefore, the implementation of the skills training program requires more resources and revision of the curriculum to fit the new teaching practices. Innovators in developing countries have to prepare to be faced with resource limitations. At the very beginning, there were a lot of difficulties for the very first Skillslab. Since in Vietnam, universities have to follow the national curriculum, curriculum reform for a single university was considered illegal. Innovation therefore needed to be a nationwide endeavor. When starting the nationwide implementation of medical skills training laboratories, the leadership of the Ministry of Health and the Ministry of Education and Training ensured that the program was consistent with government policies and had strong commitment from university leaders. The new skills training program should therefore be integrated into the national medical curriculum.

- Complexity: This is the degree to which an innovation is perceived as difficult to understand and use. With international financial and technical support, we could easily understand and use the Skillslab methodology. In the long run, after the financial support stopped, the sustainability of the Skillslabs needed to be considered. Locallymade models could help the sustainability of the innovation but the quality of these 
models needed to be evaluated. Cultural differences between the local setting and international examples can also be challenging, especially in training on communication skills, since the applicability of the available doctor-patient communication models from other parts of the world needed to be considered.

- Trialability: This is the degree to which the innovation can be trialed and modified. We could pilot and modify the skills training program in each university. The training mentioned in the Knowledge stage ensured that we could try the Skillslab approach and have appropriate methods and tools to evaluate the results of our pilot activities.

- Observability: This is the degree to which the results of the innovation are visible to others. The results of the skills training program were observable from existing Skillslabs, and from pilot activities. To have an objective observation, we need appropriate methods, tools, and procedures. The international, national, and institutional training and workshops for trainers helped to have an appropriate method as well as tools to accurately assess the results of Skillslab training.

The persuasion stage is very important for the decision stage. Innovators must critically consider how best to persuade people to adopt the innovation, because overestimating the difficulty could lead to rejection of the innovation, however good it is. Conversely, underestimating the difficulties could lead to indiscriminate acceptance of innovation but also to facing obstacles when implementing the innovation correctly and effectively.

3) Decision stage: Each university could develop a part of the skills training program based on their own situation, which helped the universities to adopt the innovations more quickly [45]. The decision phase is also influenced by government policy, and the participation of other universities. Also important is international financial and technical assistance, which can be a powerful motivator, but in some cases, could also force universities to be too ambitious in their planning or to make decisions they would later regret.

The studies in this dissertation were implemented when eight state universities agreed to participate in the innovation to strengthen medical skills training at eight medical faculties/universities in Vietnam by establishing medical skills training laboratories.

4) Implementation stage: Rogers warned that any innovation is likely to bring some degree of uncertainty and suggested the implementer may need technical support [38]. We received technical support from Maastricht University. Moreover, we had very strong commitment of the eight state universities under Ministry guidance. Experts from the universities worked together and helped each other. There were also experiences from two medical universities which had already established Skillslabs to a certain extent, which helped all of the above steps towards adoption. However, we also had disadvantages, especially the constrained resources encountered in any developing country, differences 
among the eight faculties in the numbers and quality with regard to staff, infrastructure, budget and priority-setting. Therefore, differences developed in the speed and quality of the set-up and implementation of the skills training program in each participating university.

5) Confirmation stage: In this stage, the innovator looks for supportive information to confirm the innovation and ensure its maintenance. We have to evaluate the results of the nationwide implementation of the medical skills training laboratories to provide critical information to confirm the results of the innovation.

In the Discussion chapter, we will review the contribution of our studies with the assistance of this framework of Rogers' Theory of the Diffusion of Innovation. 
Table 1: Summary information on the influence of the setting

\begin{tabular}{|c|c|}
\hline Characteristic of the setting & Advantages and disadvantages \\
\hline \multirow{6}{*}{$\begin{array}{l}\text { Eight state universities } \\
\text { participated in setting up and } \\
\text { implementing a system of } \\
\text { Skillslabs, of which two } \\
\text { universities already had } \\
\text { Skillslabs. }\end{array}$} & $\begin{array}{l}\text { - Experts from the universities worked together and } \\
\text { helped each other }\end{array}$ \\
\hline & $\begin{array}{l}\text { - Easier to change the national curriculum when most } \\
\text { medical schools participate }\end{array}$ \\
\hline & $\begin{array}{l}\text { - A consistent Skillslab system throughout the whole } \\
\text { country with shared approaches and tools }\end{array}$ \\
\hline & $\begin{array}{l}\text { - The strengths or weaknesses of existing Skillslabs } \\
\text { provided lessons for others }\end{array}$ \\
\hline & $\begin{array}{l}\text { - Differences existed in faculty, staff, infrastructure, } \\
\text { budget and priority-setting among participating } \\
\text { universities }\end{array}$ \\
\hline & $\begin{array}{l}\text { - Differences developed in speed and quality of the } \\
\text { set-up and implementation of skills training in } \\
\text { Skillslabs }\end{array}$ \\
\hline \multirow[t]{2}{*}{$\begin{array}{l}\text { The Ministry of Health led the } \\
\text { project and the Ministry of } \\
\text { Education and Training } \\
\text { participated as needed }\end{array}$} & $\begin{array}{l}\text { - Strong commitment of the eight state universities } \\
\text { under Ministry guidance } \\
\text { - Easier to change and improve the national } \\
\text { curriculum }\end{array}$ \\
\hline & $\begin{array}{l}\text { - Easier to formulate requests for and to secure } \\
\text { further support from government and other sources }\end{array}$ \\
\hline \multirow{2}{*}{$\begin{array}{l}\text { Limited resources in a low to } \\
\text { middle-income country (staff, } \\
\text { infrastructure) }\end{array}$} & $\begin{array}{l}\text { - Pressure to select priority skills to be trained in each } \\
\text { Skillslab }\end{array}$ \\
\hline & $\begin{array}{l}\text { - Sustainability of Skillslab system needs to be } \\
\text { considered }\end{array}$ \\
\hline $\begin{array}{l}\text { International financial and } \\
\text { technical support in set-up } \\
\text { and to some extent in } \\
\text { implementation }\end{array}$ & $\begin{array}{l}\text { - Easier to set up and implement during the project } \\
\text { period } \\
\text { - Easier to plan for continued development and } \\
\text { implementation }\end{array}$ \\
\hline $\begin{array}{l}\text { Cultural differences between } \\
\text { local setting and international } \\
\text { examples }\end{array}$ & $\begin{array}{l}\text { - Appropriateness of applying available doctor- } \\
\text { patient communication models from other parts of } \\
\text { the world needs to be considered }\end{array}$ \\
\hline
\end{tabular}


This dissertation presents research that describes and assesses the establishment and implementation of the Skillslab system in the eight selected universities throughout Vietnam.

Objective: In the context of the program to set up and implement medical skills training laboratories following the Skillslab approach in Vietnam, the research in this dissertation aimed to:

1) identify which skills need to be trained in the Skillslab approach,

2) find out whether these skills could all be trained effectively under conditions of limited resources, and

3) evaluate specific aspects of using the Skillslab approach in the conditions of Vietnam: quality of locally made models and adapting a communication model used in Western countries.

The results of these studies could help Vietnamese, and possibly other universities in the region and around the world, to have the most appropriate and sustainable skills training programs.

\section{Study methods}

We used diverse research methods including surveys, interviews, observation, focus group discussions, self-reporting, reviews, and controlled experiments. For each study, we tried to have the largest possible sample size at each study site. 
Table 2: Methods used for the research

\begin{tabular}{|c|c|c|}
\hline Research objective & Research design & Participants \\
\hline \multirow{2}{*}{$\begin{array}{l}\text { 1) To identify which } \\
\text { skills need to be trained } \\
\text { in the Skillslab approach }\end{array}$} & $\begin{array}{l}\text { survey using structured } \\
\text { questionnaires }\end{array}$ & $\begin{array}{l}\text { general doctors from all parts of } \\
\text { the country }\end{array}$ \\
\hline & $\begin{array}{l}\text { observation using } \\
\text { observation checklist }\end{array}$ & $\begin{array}{l}\text { students practicing in a district } \\
\text { health center }\end{array}$ \\
\hline \multirow{4}{*}{$\begin{array}{l}\text { 2) To find out whether } \\
\text { these skills could all be } \\
\text { trained effectively } \\
\text { under conditions of } \\
\text { limited resources }\end{array}$} & self-reporting & $\begin{array}{l}8 \text { faculties/universities } \\
\text { participating in the project }\end{array}$ \\
\hline & review & $\begin{array}{l}\text { results of student assessment on } \\
\text { selected skills in the largest } \\
\text { university }\end{array}$ \\
\hline & $\begin{array}{l}\text { survey using structured } \\
\text { questionnaire }\end{array}$ & $\begin{array}{l}\text { 1) } 100 \text { students after a training } \\
\text { session of each selected skill and } \\
\text { after Skillslab assessment } \\
\text { 2) all trainers involved in training } \\
\text { and/or assessment of related skills } \\
\text { in the largest university }\end{array}$ \\
\hline & focus group discussions & $\begin{array}{l}\text { all trainers involved in training } \\
\text { and/or assessment of related skills } \\
\text { in the largest university }\end{array}$ \\
\hline \multirow{2}{*}{$\begin{array}{l}\text { 3) To evaluate specific } \\
\text { aspects of using the } \\
\text { Skillslab approach in the } \\
\text { conditions of Vietnam: } \\
\text { quality of locally made } \\
\text { models and adapting a }\end{array}$} & $\begin{array}{l}\text { survey using structured } \\
\text { questionnaire }\end{array}$ & $\begin{array}{l}\text { doctors from all parts of the } \\
\text { country }\end{array}$ \\
\hline & $\begin{array}{l}\text { Face-to-face survey using } \\
\text { structured questionnaire }\end{array}$ & $\begin{array}{l}\text { patients from all parts of the } \\
\text { country }\end{array}$ \\
\hline $\begin{array}{l}\text { models and adapting a } \\
\text { communication model } \\
\text { used in Western } \\
\text { countries. }\end{array}$ & $\begin{array}{l}\text { experiment using control and } \\
\text { intervention groups }\end{array}$ & $\begin{array}{l}\text { all students to be trained in related } \\
\text { skills in the largest university }\end{array}$ \\
\hline
\end{tabular}


For studies related to patients or/and doctors, we employed a nationwide stratified sample of participants, made possible by the collaboration among the eight medical schools around the country. Participants were invited in all parts of the country: North, Center, and the South, from major cities, rural provinces, and the highlands. We mobilized different levels of health facilities as study sites, from provincial and city hospitals to district health centers.

For controlled experiments, all students who were going to be trained in the relevant skills participated in the survey. In reviewing the results of student assessment on selected skills, all students in one (the largest) university, who were trained in these skills were recruited for the study.

To elicit information on students' satisfaction after a Skillslab training session, we invited around 100 students for each skill. We also invited the same number of participants to collect information after the Skillslab assessment had been done.

To collect trainers' opinions after a training session and after Skillslab assessment, in focus group discussions, we invited all trainers involved in training or/and assessment of the related skills.

Researchers from the eight main medical universities participated in implementing several of the studies, recruited from the collaboration in establishing the Skillslabs in each university.

\section{Based on the research objectives, four studies were carried out}

The first study is presented in Chapter 2; it aimed to validate the national list of recommended skills for training in a Skillslab. We investigated to what extent practicing general practitioners were actually using the skills that were included on the national list, and when they were not, to find out their reasons for not using those skills.

Setting priorities for content is a significant challenge for all medical schools $[4,46]$. Many issues need to be considered in the curriculum development process, such as responding to the requirements of guidelines, and giving due attention to the rapid advances in medicine and to the views of stakeholders [47]. For medical education, the stakeholders include not only students and faculty members but also residents, practitioners, healthcare teams, the general public [48] and consumers [47]. The literature suggests empirical methods for deciding on the content of the medical curriculum $[4,47]$.

In Vietnam, to develop a national list of skills suitable for training in a Skillslab, a national panel was recruited, with technical assistance of experts from Maastricht University, and 
both group discussion and a Delphi process were used to draw up a list of priority skills. The panel finally reached consensus on a list of 56 basic skills that the Skillslabs in Vietnamese medical schools should offer as part of the training of prospective general practitioners: the national list of recommended skills.

Setting priorities through expert panels is a very good way to respond to the requirements of guidelines and rapid advances in medicine. However, earlier medical education research in Vietnam found that working doctors only infrequently used several skills that had been proposed by experts as necessary for the curriculum [49]. The national list of recommended skills needed to be validated.

A cross-sectional study was set up to collect self-reports from practicing physicians on their use of the different clinical skills. In addition to the questionnaires completed by the general practitioners (GPs), final year medical students were recruited to observe GPs practicing in district general hospitals. The students used the same questionnaire as completed by the GPs, but answered the questions based on their observations of the skills being used by the GPs they worked with at the hospitals. The results of this study, described in Chapter 2, would help to confirm which skills should have priority for training in the Skillslabs.

The research presented in Chapter 3 explored how a national skills training program in a developing country worked in actual practice in the Vietnamese universities. Having the list of skills identified as suitable for training in the Skillslab, the universities planned and implemented their Skillslab curriculum. However, limited resources and limited experience/capacity for skills training will affect the choices made by each university. For low- and middle-income countries, fully equipped Skillslabs are expensive to set up and to maintain [26]. To set up and implement skills training for all of the skills on the list in eight medical schools at the same time was a big challenge for most of the universities.

It was therefore of interest to investigate how close the eight medical schools came to implementing training on all of the recommended skills, and to identify the facilitating factors and barriers to Skillslab training. While we looked into the capacity of the eight schools to implement training of the whole list of skills, a more intensive assessment of the program was done in one school, the largest one. There, we consulted both students and teachers about their satisfaction with the way the Skillslab was being used and whether it was effective.

The study presented in Chapter 4 aimed to identify the essential items in communication with patients that doctors should perform during a consultation. The results of the study would act as a guide for developing the training curriculum on doctor-patient 
communication. In Vietnam, the available material on this topic came mostly from Western countries. That material favors the partnership model, in which the patient is actively involved in the consultation, and doctor and patient have equal status [50]. This model has been effectively applied in Western countries. A few Asian countries have begun efforts to move their doctor-patient communication model toward the partnership model. However, before a Western model is applied in Asian countries, it may need adaptations [51-54] because of the influence of culture on communication.

In Vietnam, a version of the partnership model of doctor-patient communication is reflected in the competency standards for general practitioners [55] and the government regulations on communication in medical facilities [56]. Implementing these standards and regulations in training on doctor-patient communication is, however, still a challenge, partly because of the lack of a formal model adapted to the Vietnamese context. Based on the government regulations on communication in medical facilities and the available educational material from Western countries, each university developed its training and assessment material on its own. A typical Vietnamese doctor-patient communication model is needed to guide and standardize such training throughout the country.

Working towards an appropriate model, we developed a standard tool that listed required communication skills based on tools used to assess communication in Western medical schools, adapted to be consistent with local legislation. Using this tool, we investigated the perceptions and expectations of patients and doctors on the communication between them. Since patients are the customers of the service, in this study we paid attention to patients' perceptions as well and explored factors that potentially affect patients' perceptions and expectations, in addition to items related to their actual satisfaction. The results of the study provide information that trainers can use to select key items to be included in doctor-patient communication training.

In Chapter 5 we report a study of the effectiveness of a teacher-made model (that is, a model made locally of easily available materials by teachers) in training and assessing students, in comparison with a commercially available model. This research aimed to check whether teacher-made models could be an alternative for more expensive commercially available models for medical skills training in developing countries.

Although the Skillslabs were introduced and established in Vietnam with the support of internationally funded programs, they have to be used and maintained within the locally available budget. The purchase of commercially available equipment and manikins is very expensive [13]. The maintenance and running costs may prove prohibitive in the long term and the equipment might not be repaired or maintained [26]. Since the school fees in Vietnam are very low, the universities could not generate enough income to buy simulation 
models to replace the broken ones or to keep up with modern developments of new models.

One of the solutions for sustainability is to make the model locally. Locally produced learning materials are likely to be less expensive than commercial models. Furthermore, we could increase the number of models available for each training session, thereby increasing the practicing opportunities for the students. However, even an inexpensive model will be too expensive and wasteful if it does not function well in training and assessment. Therefore, we investigated whether there were differences in the effectiveness of using a teacher-made model compared to a commercially available model in training and assessing students.

To answer this question, we conducted an experimental study to compare the results of skills assessment on three groups of students who practiced with a commercially available model, with a teacher-made model, or with an increased number of teacher-made models. In this study, each group of students was assessed three times in the training process, using the same assessment procedure and rating scale each time. Pre-practice assessment was designed to provide a "baseline" of the student's competency before practicing on the models and to check whether the procedure (skill) really needs to be trained using a model. Post- practice assessment served to check direct effects of training on the model, and finally, assessment with a real patient was conducted to check the effect on practice in the real clinical situation.

In Chapter 6, the objectives and the results of these investigations are discussed in the light of the progress in medical education and continued implementation of skills training in Vietnam and other resource-limited settings, and in comparison with the original ideas that generated the Skillslab approach more than 40 years ago. 


\section{List of chapters published or submitted for publication in international peer-reviewed journals}

\section{Chapter 2:}

Trung Q Tran, Albert Scherpbier, Jan Van Dalen, Do van Dung, Elaine Pamela Wright, Validation of skill list for Skillslab training based on responses from students and general practitioners, International Journal of Clinical Skills, 8 (2014): 54-64.

\section{Chapter 3:}

Trung Q Tran, Albert Scherpbier, Jan Van Dalen, Dung van Do, E. Pamela Wright, Implementing a skillslab training program in a developing country, Education for Health, 27 (2014): 243-248.

\section{Chapter 4:}

Trung Q Tran, Albert Scherpbier, Jan Van Dalen, Do Van Dung, E. Pamela Wright, Nationwide survey of patients' and doctors' perceptions of what is needed in doctor patient communication in a Southeast Asian context. BMC Health Services Research 20 (2020): 946

\section{Chapter 5:}

Trung Q Tran, Albert Scherpbier, Jan Van Dalen, E. Pamela Wright, Teacher-made models: the answer for medical skills training in developing countries? BMC Medical Education 12 (2012): 98 


\section{References}

1. D.P. Lofaso, P.M. DeBlieux, R.P. DiCarlo, C. Hilton, T. Yang, S.W. Chauvin, Design and effectiveness of a required pre-clinical simulation-based curriculum for fundamental clinical skills and procedures, Med Educ Online 16 (2011) 10.3402/meo.v16i0.7132.

https://www.ncbi.nlm.nih.gov/pubmed/22190848 https://www.ncbi.nlm.nih.gov/pmc/articles/PMC3234100/

2. Al-Elq, H. Abdulmohsen, Medicine and clinical skills laboratories, J Family Community Med 14 (2007) 59-63.

https://www.ncbi.nlm.nih.gov/pubmed/23012147 https://www.ncbi.nlm.nih.gov/pmc/articles/PMC3410147/

3. L.N. Hoat, N.B. Yen, E.P. Wright, Participatory identification of learning objectives in eight medical schools in Vietnam, Med Teach 29 (2007) 683-90. https://doi.org/10.1080/01421590701361189

4. G. Bordage, I. Harris, Making a difference in curriculum reform and decision-making processes, Medical Education 45 (2011) 87-94. https://onlinelibrary.wiley.com/doi/abs/10.1111/j.1365-2923.2010.03727.x

5. L. Mileder, T. Wegscheider, H.P. Dimai, Teaching first-year medical students in basic clinical and procedural skills--a novel course concept at a medical school in Austria, GMS Z Med Ausbild 31 (2014) Doc6-Doc6.

https://www.ncbi.nlm.nih.gov/pubmed/24575157 https://www.ncbi.nlm.nih.gov/pmc/articles/PMC3935167/

6. N. Upadhayay, Clinical training in medical students during preclinical years in the skill lab, Adv Med Educ Pract 8 (2017) 189-194.

https://www.ncbi.nlm.nih.gov/pubmed/28280405 https://www.ncbi.nlm.nih.gov/pmc/articles/PMC5338839/

7. M. Swamy, T.C. Bloomfield, R.H. Thomas, H. Singh, R.F. Searle, Role of SimMan in teaching clinical skills to preclinical medical students, BMC medical education 13 (2013) 20.

https://www.ncbi.nlm.nih.gov/pubmed/23394435 https://www.ncbi.nlm.nih.gov/pmc/articles/PMC3572432/

8. B. O'Brien, M. Cooke, D.M. Irby, Perceptions and Attributions of Third-Year Student Struggles in Clerkships: Do Students and Clerkship Directors Agree?, Academic Medicine 82 (2007) 970-978.

https://journals.Iww.com/academicmedicine/Fulltext/2007/10000/Perceptions and Attributions of Third Year Student.16.aspx

9. M. Wenrich, M.B. Jackson, A.J. Scherpbier, I.H. Wolfhagen, P.G. Ramsey, E.A. Goldstein, Ready or not? Expectations of faculty and medical students for clinical skills preparation for clerkships, Med Educ Online 15 (2010) 10.3402/meo.v15i0.5295. 
https://www.ncbi.nlm.nih.gov/pubmed/20711483

https://www.ncbi.nlm.nih.gov/pmc/articles/PMC2919534/

10. D.M. Windish, P.M. Paulman, A.H. Goroll, E.B. Bass, Do Clerkship Directors Think Medical Students Are Prepared for the Clerkship Years?, Academic Medicine 79 (2004) 56-61.

https://journals.Iww.com/academicmedicine/Fulltext/2004/01000/Do Clerkship Dire ctors Think Medical Students Are.13.aspx

11. J. Amanya, Innovative Application of Skills Lab Methodology for Effective Teaching of Clinical Medicine at the Kenya Medical Training College, Greener Journal of Medical Sciences 7 (2017).

12. W. McGaghie, B. Issenberg, E. Petrusa, R. Scalese, A critical review of simulation-based medical education research: 2003-2009, Medical Education 44 (2010) 50-63.

13. T. Kozu, Medical Education in Japan, Academic Medicine 81 (2006) 1069-1075. https://journals.Iww.com/academicmedicine/Fulltext/2006/12000/Medical Educatio $\underline{\mathrm{n} \text { in Japan.10.aspx }}$

14. A. Boker, Setup and Utilization of Clinical Simulation Center, Faculty of Medicine, King Abdulaziz University, Saudi Arabia, Life Science Journal 10 (2013) 1079-1085.

15. H. Khaja, Quadri, M., Rahim, M.F., Alam, A.Y., Jaffery, T., Zaidi, Z., \& Iqbal, M., The structure and function of a new Clinical Skills and Medical Informatics Laboratory (SCIL) in a developing country-a two year institutional experience, Journal Of Pakistan Medical Association 58 (2008) 612-15.

16. H. Kim, Experience of Simulation-Based Training in a Developing Country, Simulation in Healthcare 12 (2017) 202.

https://journals.Iww.com/simulationinhealthcare/Fulltext/2017/06000/Experience of Simulation Based Training in a.10.aspx

17. A.I. AlHaqwi, W.S. Taha, Promoting excellence in teaching and learning in clinical education, Journal of Taibah University Medical Sciences 10 (2015) 97-101. http://www.sciencedirect.com/science/article/pii/S165836121500027X

18. P.K. Sahu, V.K. Chattu, A. Rewatkar, S. Sakhamuri, Best practices to impart clinical skills during preclinical years of medical curriculum, J Educ Health Promot 8 (2019) 57-57. https://www.ncbi.nlm.nih.gov/pubmed/31008124 https://www.ncbi.nlm.nih.gov/pmc/articles/PMC6442250/

19. T.P. Lam, M. Irwin, L.W.C. Chow, P. Chan, Early introduction of clinical skills teaching in a medical curriculum - factors affecting students' learning, Medical Education 36 (2002) 233-240. https://doi.org/10.1046/i.1365-2923.2002.01142.x

20. M. Zafar, Medical students' perceptions of the effectiveness of integrated clinical skills sessions using different simulation adjuncts, Advances in Physiology Education 40 (2016) 514-521. https://doi.org/10.1152/advan.00097.2016 
21. P. Bartholomeus, The skillslab methods, University of Medicine and Pharmacy at HoChiMinh City, HoChiMinh City, 2004.

22. N.H. Al-Yousuf, The clinical skills laboratory as a learning tool for medical students and health professionals, Saudi medical journal 25 (2004) 549-51.

23. T.J. Bugaj, C. Nikendei, Practical Clinical Training in Skills Labs: Theory and Practice, GMS J Med Educ 33 (2016) Doc63. https://www.ncbi.nlm.nih.gov/pubmed/27579363

24. S.J. Matson CC, Defer T, Greenberg L, Ullian JA., Prerequisite competencies for thirdyear clerkships: An interdisciplinary approach. , Fam Med 39 (2007) 38-42.

25. Skillslab Faculty of Health, Medicine and Life Sciences., 2012. https://skl.mumc.maastrichtuniversity.nl/sites/intranet.mumc.maastrichtuniversity.nl /files/skl mumc maastrichtuniversity $\mathrm{nl} /$ skillslab brochure 2012.pdf. (Accessed 03 March 2020).

26. P. Stark, F. Fortune, Teaching Clinical Skills in Developing Countries: Are Clinical Skills Centres the Answer?, Education for Health 16 (2003) 298-306. http://www.educationforhealth.net/text.asp?2003/16/3/298/109015

27. O. Sarikaya, M.M. Civaner, S. Sakarya, The anxieties of medical students related to clinical training International journal clinical practice 60(11):1340-1 (2006).

28. P. Bradley, K. Postlethwaite, Setting up a clinical skills learning facility, Medical Education 37 (2003) 6-13. https://onlinelibrary.wiley.com/doi/abs/10.1046/i.13652923.37.s1.11.x

29. M.R. Moon, M.T. Hughes, J.-Y. Chen, K. Khaira, P. Lipsett, J.A. Carrese, Ethics Skills Laboratory Experience for Surgery Interns, Journal of Surgical Education 71 (2014) 829838. http://www.sciencedirect.com/science/article/pii/S1931720414000956

30. G. Peeraer, A. Scherpbier, R. Remmen, B. De Winter, K. Hendrickx, P. Van Petegem, J. Weyler, L. Bossaert, Clinical Skills Training in a Skills Lab Compared with Skills Training in Internships: Comparison of Skills Development Curricula, Education for health (Abingdon, England) 20 (2007) 125.

31. P. Bradley, K. Postlethwaite, Setting up and running clinical skills learning programmes, The Clinical Teacher 1 (2004) 53-58. https://doi.org/10.1111/i.1743-498X.2004.00039.x

32. J.A. Dent, Current trends and future implications in the developing role of clinical skills centres, Medical Teacher 23 (2001) 483-489. https://doi.org/10.1080/01421590120075724

33. R.J. Davies, J.M. Hamdorf, Surgical skills training and the role of skills centres, BJU International 91 (2003) 3-4. https://onlinelibrary.wiley.com/doi/abs/10.1046/i.1464410X.2003.04002.x

34. V.C.U. Human Development Sector Unit, Growing Healthy: A Review of Vietnam's Health Sector, East Asia and Pacific Region, the World Bank, 2001. 
35. L.N. Hoat, N.M. Son, E.P. Wright, Perceptions of graduating students from eight medical schools in Vietnam on acquisition of key skills identified by teachers, BMC medical education 8 (2008) 5.

https://www.ncbi.nlm.nih.gov/pubmed/18205954

https://www.ncbi.nlm.nih.gov/pmc/articles/PMC2248186/

36. A. Sebiany, New trends in medical education. The clinical skills laboratories, Saudi medical journal 24 (2003) 1043-7.

37. Dutch Ministry of Foreign Affairs, The case of Vietnam: report of a field investigation. Final Report, 2007.

http://www.government.nl/./reports/./evaluation.pt.nfp-the-case-of-vietnam.(Access ed 01 May 2013 ).

38. E.M. Rogers, Diffusion of Innovations, 5th ed., Free Press, New York, 2003.

39. J.W. Dearing, Applying Diffusion of Innovation Theory to Intervention Development, Res Soc Work Pract 19 (2009) 503-518. https://pubmed.ncbi.nlm.nih.gov/20976022 https://www.ncbi.nlm.nih.gov/pmc/articles/PMC2957672/

40. B.D. Medun, The factors that may influence a faculty members' decision to adopt electronic technologies in instruction, 2001.

41. D. Cohen, D. Ball, Educational innovation and the problem of scale, in: S. Barbara, S.-K. McDonald (Ed.), Scale-up in education, Rowman \& Littlefield, the United States of America, 2017, pp. 19-36.

42. E.H. Bradley, T.R. Webster, D. Baker, M. Schlesinger, S.K. Inouye, M.C. Barth, K.L. Lapane, D. Lipson, R. Stone, M.J. Koren, Translating research into practice: speeding the adoption of innovative health care programs, Issue brief (Commonwealth Fund) (2004) 1-12.

43. X. Zhang, P. Yu, J. Yan, I. Ton A M Spil, Using diffusion of innovation theory to understand the factors impacting patient acceptance and use of consumer e-health innovations: a case study in a primary care clinic, BMC Health Services Research 15 (2015) 71. https://doi.org/10.1186/s12913-015-0726-2

44. R.W. Sanson-Fisher, Diffusion of innovation theory for clinical change, The Medical journal of Australia 180 (2004) S55-6.

45. I. Sahin, Detailed review of Rogers' diffusion of innovations theory and educational technology-related studies based on Rogers' theory, The Turkish Online Journal of Educational Technology 5 (2006) 14-23.

46. G. Maccarrick, Curriculum reform: A narrated journey, Medical education 43 (2009) 979-88.

47. I. Rolfe, S. Pearson, R. Sanson-Fisher, C. Ringland, Identifying Medical School Learning Needs: A Survey of Australian Interns, Education for Health 14 (2001) 395-404. http://www.educationforhealth.net/text.asp?2001/14/3/395/109113 
48. M. D'Eon, R. Crawford, The elusive content of the medical-school curriculum: A method to the madness, Medical teacher 27 (2006) 699-703.

49. L.N. Hoat, D.V. Dung, E.P. Wright, Practicing doctors' perceptions on new learning objectives for Vietnamese medical schools, BMC Medical Education 7 (2007) 19. https://doi.org/10.1186/1472-6920-7-19

50. G. Makoul, M.L. Clayman, An integrative model of shared decision making in medical encounters, Patient Education and Counseling $60 \quad$ (2006) 301-312. http://www.sciencedirect.com/science/article/pii/S0738399105001783

51. R. Mudiyanse, M, G. Weerasinghe, S,M, M. Piyasinghe, K, J. Jayasundara, M,H, Patient's Expectations during Doctor Patient Communication and Doctors Perception about Patient's Expectations in a Tertiary Care Unit in Sri Lanka, Archives of Medicine, iMedPub Journals, 2015. https://www.archivesofmedicine.com/medicine/patientsexpectations-during-doctor-patient-communication-and-doctors-perception-aboutpatients-expectations-in-a-tertiary-care-unit-in-sri-lanka.php?aid=7716

52. M. Moore, What does patient-centred communication mean in Nepal?, Medical Education 42 (2008) 18-26. https://onlinelibrary.wiley.com/doi/abs/10.1111/i.13652923.2007.02900.x

53. M. Claramita, Y. Prabandair, J. van Dalen, C. van der Vleuten, Developing and validating a guideline on doctor-patient communication for Southeast Asian context, Southeast Asian Journal of Medical Education 4 (2010) 23-30.

54. M. Claramita, M.D. Nugraheni, J. van Dalen, C. van der Vleuten, Doctor-patient communication in Southeast Asia: a different culture?, Adv Health Sci Educ Theory Pract 18 (2013) 15-31. https://doi.org/10.1007/s10459-012-9352-5

55. Ministry of Health, Decision on approval for document about competence standards for general practitioners, in: M.o. Health (Ed.) Vietnam, 2015. https://vanbanphapluat.co/decision-no-1854-qd-byt-2015-document-aboutcompetence-standards-for-general-practitioners

56. Ministry of Health, Regulations on communication in medical examination and treatment facilities, in: M.o. Health (Ed.) Vietnam, 2001. https://thukyluat.vn/vb/quyet-dinh-4031-2001-qd-byt-che-do-giao-tiep-trong-cac-coso-kham-chua-benh-15cf6.html 


\section{Chapter 2}

\section{Validation of skill list for skillslab training based on responses from students and general practitioners}

A full text version was published as:

T.Q. Tran, A. Scherpbier, J. van Dalen, D. van Do, E.P. Wright, Validation of skill list for Skillslab training based on responses from students and general practitioners, International Journal of Clinical Skills, 8 (2014): 54-64. 


\section{Abstract}

Objective: To validate the list of priority basic skills to be trained in the skills lab of a medical schools using practicing General Practitioners' (GP) reported experience and students' observation of GP's practice

Method: A national list of 56 basic skills to be trained in skills labs had been formulated by an expert panel of faculty members from all the medical faculties/ universities in the country with advice from Dutch experts in a Delphi process. It was then validated by checking against skills commonly used in practice through self-reporting by general practitioners and observation by final year medical students.

Results: The results revealed gaps between the skills on the list formulated by the university expert panel and the actual use of these skills by graduate doctors in their daily work. The gaps were related to specific skills as well as to the region and the practice setting. The results suggest that the tendency of GPs to focus on certain areas of medicine and not on others could account for their not using some of the skills that according to the expert panel should be offered for training of prospective general practitioners. 


\section{Introduction}

Previous studies indicate that we cannot rely on the clerkship experience alone to provide adequate basic clinical skills to medical students [1]. To gain competence in key medical skills students require opportunities to practice skills safely without risks to themselves or to patients. Skills laboratory training can be a good solution to this issue [2]. Skills laboratories (Skillslabs) have been successfully developed in higher resourced countries [38]. These Skillslabs vary in the accommodation provided and the resources available, from one room with one manikin to purpose-built structures with a vast assortment of equipment $[5,6,9,10]$.

In developing skills laboratory training programs, consideration needs to be given as to which skills should be trained. Learners must acquire the essential competencies that the profession as well as society expect from a competent and effective doctor [11]. But the constantly increasing body of knowledge in medicine creates a problem in the development of curricula for medical schools: what content should be added to the curriculum, and what should be removed? D'eon and Crawford suggested that it is easier to add content to a curriculum than it is to remove it [12]. Thus, the content of programs increases as the knowledge base expands, which results in a growing curriculum in which there will not be enough time to learn skills.

Setting priorities for content is a significant challenge for all medical schools $[11,13]$. Many issues need to be considered in the curriculum development process, such as responding to the requirements of guidelines, giving due attention to the rapid advances in medicine and to the views of stakeholders [14]. For medical education, stakeholders include faculty, residents, practitioners, students, healthcare teams, the general public [12] and consumers [14]. The literature suggests empirical methods for deciding on the content of the medical curriculum $[11,14]$.

In 1999, Rolfe et al. conducted a survey to identify medical school learning needs in Australia. By reviewing relevant medical literature and consulting stakeholders, the researchers generated a list of core skills required of a graduate from medical school; the list of core skills was then sent to interns practicing in New South Wales. The interns were able to discriminate between their needs for different skills and identified further training needs for many core skills [14].

Setting priorities through expert panels is a very good way to respond to the requirements of guidelines and rapid advances in medicine. However, an earlier study in Vietnam found that working doctors only infrequently used several skills suggested by experts as necessary for the curriculum [15]. Furthermore, because a skills lab cannot provide training in all of 
the skills required of a medical school graduate, it is necessary to select those skills that could and should be trained in a Skillslab. After students have gained the necessary level of skills from the lab training, real clinical practice is still needed. The first step is to identify in which skills medical students need to be trained, and then plan how to provide that training in a Skillslab. Moreover, manikins and other equipment are very expensive. Some Japanese medical colleges invest up to 600,000 USD for the necessary equipment to set up a clinical skills laboratory [5]. Scarcity of resources and facilities in limited resource countries creates extra pressure to prioritize skills for Skillslab training.

In contrast, an Australian study identified 20 skills needing more medical school preparation [14] and an American team found that more than $10 \%$ of residents in each specialty reported that they felt unprepared to undertake one or more tasks relevant to their disciplines [16].

To improve skills training, a project involving all of the civil (non-military) medical faculties and universities in Vietnam was launched in 2004. The project, "Strengthening medical skills training at 8 medical faculties/universities in Vietnam", funded by the Government of the Netherlands, aimed to set up and implement medical skills training systems using the "Skillslab method" in medical schools throughout Vietnam [17]. The project provided an opportunity for innovating skills training in Vietnam.

In Vietnam, most medical universities mainly train general practitioners (GPs). A GP in Vietnam is a medical doctor who has completed successfully the six years of basic medical training. Most GPs practice in district and provincial/city general hospitals; their practice covers a variety of medical problems in patients of all ages.

To develop a national list of skills that training in a Skillslab should provide to prospective general practitioners in Vietnam, a national panel was formed, with over 40 experts from clinical, laboratory, psychological, public health and medical education departments from all eight Vietnamese medical faculties and universities. There is no specific department in the medical schools for general practice and the panel comprised only university experts; GPs were not represented in the panel. With technical assistance of experts from Maastricht University, the national expert panel collaborated during one year in several national meetings, using group discussion and a Delphi process to draw up a list of priority skills. Between these national meetings, members of the national expert panel discussed the results with their faculties and prepared for the next meeting. Through this approach, most of the medical educators in the eight faculties/universities participated in the process. The panel finally developed a list of 56 basic skills that the Skillslabs in Vietnamese medical schools should offer for the training of prospective general practitioners: the national list of recommended skills. 
The current study aimed to validate the national list of recommended skills. We therefore investigated to what extent practicing GPs were actually using the skills on the national list, and when they were not, to find out their reasons for not using those skills.

\section{Methods}

\section{Setting}

In the Vietnamese healthcare system, most GPs practice in district or city general hospitals. The main differences between these two levels are presented in Table 1 below.

A district general hospital is supposed to be the very first hospital that patients come to while a city/provincial general hospital is supposed to be the referral hospital to which patients are transferred if needed. In reality, patients often go directly to city/provincial general hospitals or even to hospitals specialized in pediatrics, infectious diseases or other areas, when they are nearby. The district general hospitals have fewer GPs who have less opportunity to specialize than do doctors working in city/province general hospitals. GPs working in district general hospitals might, therefore, be expected to use a broader range of skills than GPs practicing in city/province general hospitals.

Table 1: Main differences between district and city/province general hospitals

\begin{tabular}{ll}
\hline District General Hospital & City/Province General Hospital \\
\hline $\begin{array}{l}\text { First level hospital, supposed to be the } \\
\text { very first hospital to which patients come }\end{array}$ & $\begin{array}{l}\text { Second level hospital, supposed to be } \\
\text { the referral hospital to which patients } \\
\text { are transferred }\end{array}$ \\
\hline The only hospital in a district & $\begin{array}{l}\text { One of several hospitals in the city or } \\
\text { province; other urban hospitals are } \\
\text { specialized in one area such as pediatrics } \\
\text { or dermatology } \\
\text { Have few specialties and specialists }\end{array}$ \\
\hline Have fewer GPs and equipment & specialists \\
\hline Have fewer patients & Have more GPs and equipment \\
\hline
\end{tabular}




\section{Context}

GPs who graduate from one of the eight medical faculties or universities mainly practice in district and city/province general hospitals all over the country. For this study, we selected seven provinces/cities to represent the different geographic and economic regions: three in the north including Hanoi, the capital city; three in the south including Ho Chi Minh City, the economically most developed city; and one in Daklak, a remote province in the Central Highlands. In each study site, we selected the provincial general hospital(s) and district general hospitals that had previously collaborated in research.

Additional data came from Thai Binh, a northern coastal province where sixth (final) year medical students practice their final six-week internships at district general hospitals. The students answered a questionnaire based on their observations of GPs' practice in the district general hospital (not on what they had actually done themselves).

\section{Research design}

This cross-sectional study was set up to elicit self-reports from GPs on their use of skills, based on a questionnaire. Universities and local health departments introduced the researchers to the hospitals; at a routine meeting of GPs the researchers presented the objectives of the research and invited GPs to participate by completing the questionnaire. The majority of the GPs (90\%) were willing to participate in the research. They stayed in the meeting room, where the researchers introduced and explained the questionnaire which was then completed by the respondents. Respondents who completed the questionnaires could receive a modest compensation for their time (approximately 3 USD).

In addition to the questionnaires completed by the GPs, final year medical students were recruited to observe GPs practicing in district general hospitals. The students used the same questionnaire as did the GPs, but answered the questions based on their observations of the use of the skills by any of the GPs they worked with. The GPs who were observed were not necessarily the same individuals who completed the survey.

\section{Participants:}

The questionnaires were completed by 647 GPs at district and city general hospitals in seven selected provinces/cities and by 146 sixth year medical students from Thai Binh Medical University who observed practice at district level hospitals.

The researchers in charge of data collection were staff from the eight medical faculties/universities. 


\section{Questionnaire:}

For the GP survey:

Based on the national list of recommended skills, we developed a questionnaire in which 56 basic skills were presented in four groups: 7 communication skills, 22 physical examination skills, 23 procedure skills and 4 diagnostic skills. This study is limited to the physical examination, procedure and diagnostic skills and will not further address communication skills.

For each skill the GPs were asked whether they used that particular skill or not, initially on a dichotomous scale. If a skill was not used, then GPs had three further options to identify their reasons for not using it: (1) Do not have patients; (2) Refer to a specialist for this skill; (3) Other reasons.

1) By "Do not have patients" we meant that the GP did not receive patients that needed them to perform that specific skill. If many GPs choose this option for a skill, then that skill could be removed from the skills list.

2) By "Refer to specialist for this skill" we meant that the GP may have patients needing this specific skill but the GP thought that the skill should be performed by a specialist or at least another doctor. If many GPs were to choose this option, the skill in question needs to be reconsidered for inclusion on the list because it aims to prepare general doctors for their practice.

3) "Other reasons" would mean that GPs have patients needing this specific skill but for one of many possible reasons they did not perform it. Possible reasons could be, for example, lack of skills, lack of confidence, lack of assistance, or lack of equipment/facilities. If GPs chose this option, the training in that related skill might need strengthening.

We did not ask how frequently they used the skills. Such information is very important for a needs assessment, but it would have made the questions more complex which in turn would yield a lower response and/or less reliable answers. Finally, the questionnaire also asked GPs to write down any skills that they used frequently but that were not mentioned in the questionnaire.

As the research was conducted nationwide, in each selected city/province we did a small pilot study to correct for the local language or dialect if needed. 
For students reporting on skill use by GPs:

To standardize the observations, we supplied final-year students spending six weeks in hospitals with an observation check list that contained the same items as the questionnaire for GPs. They observed the GPs they worked with and noted which skills they saw being used at least once. We also asked students to write down any skills they saw GPs use, that were not mentioned in the questionnaire.

Data analysis:

We used SPSS 13 to analyze the answers from the GPs' questionnaires and compare them to the national list. A p-value of 0.05 was considered the threshold value for significance. We also used cluster analysis to classify the skills into clusters depending on the number of GPs reporting using or observed using the skills [18]. Additional skills noted by GPs or students that were not on the national list were also reported.

\section{Results}

The results presented in the following sections are based on the data collected from the whole country, by practice setting (district or city/province general hospital) and by respondent group (GPs or students). In the cluster analysis we focused on the cluster of skills which had the lowest reported percentage use by GPs. We named this cluster the "lowest cluster".

General information on responding GPs

Of the 647 GPs who participated in the research, 326 were practicing in district hospitals and 321 in city/provincial hospitals. The responding GPs reported that their main practice was in the following fields: internal medicine (49\%); family medicine (11\%); surgery (9\%); pediatrics (9\%); and obstetrics and gynecology (6\%). Four per cent did not reveal their main area of practice.

Most of the respondents had considerable clinical experience: $50 \%$ had more than 12 years' experience and the most experienced one had been working for 43 years. 
Examination skills

GPs self-reported use of examination skills

All of the 22 examination skills listed in the questionnaire were practiced frequently and consequently need to be included in training for GPs. However, cluster analysis showed that four examination skills (listed in Table 2) belong to the "lowest cluster" of skills (i.e. used by the lowest percentage of GPs, in this case fewer than half of the GPs). Table 2 also shows the reasons given for not using these skills. Gynecological examination and antenatal examination were used least frequently; only 33\% of GPs reported using them.

Table 2: Four examination skills in the lowest cluster

\begin{tabular}{lcccc}
\hline \multirow{2}{*}{ Skill } & \multicolumn{5}{c}{ Do not use because: } \\
\cline { 5 - 6 } & \begin{tabular}{l} 
Use \\
\cline { 5 - 6 }
\end{tabular} & $\begin{array}{c}\text { Do not have } \\
\text { patients } \\
\text { (\%) }\end{array}$ & $\begin{array}{c}\text { Refer to } \\
\text { specialist for } \\
\text { this skill (\%) }\end{array}$ & $\begin{array}{c}\text { Other } \\
\text { reasons } \\
\text { (\%) }\end{array}$ \\
\hline Gynecological examination & 33 & 24 & 33 & 10 \\
\hline Antenatal examination & 33 & 25 & 33 & 10 \\
\hline Newborn examination & 37 & 26 & 29 & 9 \\
\hline Infant examination & 40 & 25 & 28 & 8 \\
\hline
\end{tabular}

Practice setting also influenced which skills were used. Table 3 shows that the percentage of GPs using newborn examination and infant examination skills at district level was significantly higher than at city/province level. Looking at the reasons for not using these two skills, GPs who practiced in city/provincial general hospitals reported that they left the skills to a specialist more often than did GPs practicing at district level. The proportion of GPs at district level who reported not using these two skills for other reasons was significantly higher than for those at city/province level. 
Table 3: Four examination skills in the lowest cluster according to practice setting: district or city/provincial hospital

\begin{tabular}{|c|c|c|c|c|c|}
\hline \multirow[b]{2}{*}{ Skills } & \multirow[b]{2}{*}{ Level } & \multirow[b]{2}{*}{$\begin{array}{l}\text { Use } \\
\text { (\%) }\end{array}$} & \multicolumn{3}{|c|}{ Do not use because: } \\
\hline & & & $\begin{array}{c}\text { Do not have } \\
\text { patients } \\
(\%)\end{array}$ & $\begin{array}{c}\text { Refer to } \\
\text { specialist } \\
\text { (\%) }\end{array}$ & $\begin{array}{c}\text { Other } \\
\text { reasons } \\
(\%)\end{array}$ \\
\hline \multirow{2}{*}{$\begin{array}{l}\text { Gynecologica } \\
\text { I examination }\end{array}$} & District & 33 & 21 & 29 & $16^{*}$ \\
\hline & Province/City & 33 & 27 & 37 & $3 *$ \\
\hline \multirow{2}{*}{$\begin{array}{l}\text { Antenatal } \\
\text { examination }\end{array}$} & District & 33 & 21 & 30 & $16^{*}$ \\
\hline & Province/City & 33 & 29 & 36 & $2 *$ \\
\hline \multirow{2}{*}{$\begin{array}{l}\text { Newborn } \\
\text { examination }\end{array}$} & District & $43^{*}$ & 20 & 25 & $13^{*}$ \\
\hline & Province/City & $33^{*}$ & 32 & 33 & $3 *$ \\
\hline \multirow{2}{*}{$\begin{array}{l}\text { Infant } \\
\text { examination }\end{array}$} & District & $45^{*}$ & 19 & 25 & $11^{*}$ \\
\hline & Province/City & $36^{*}$ & 30 & 31 & $3 *$ \\
\hline
\end{tabular}

$* p<0.05$ (Levene's test for Equality of Variances)

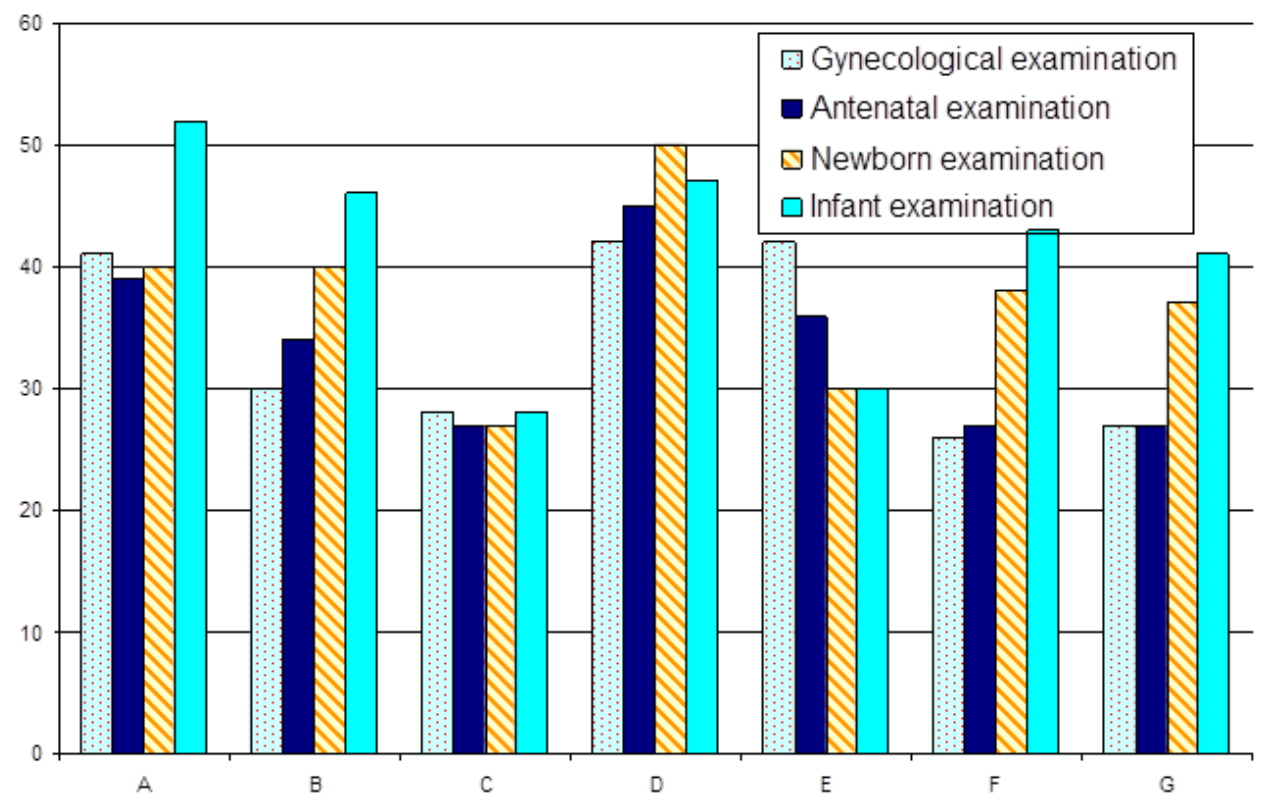

Figure 1: Four examination skills in the lowest cluster, according to study site

Not only the setting but also the region within the country influenced the use of the skills in the lowest cluster. As can be seen in Figure 2, the percentages of GPs practicing these less used skills were low in all regions. For specific skills, the proportions of GPs using them 
could rise to $50 \%$, but most were between 25 and $40 \%$. The two sites with the highest rate of use of these skills were the more remote provinces, where GPs may have to deal with more types of patients, having less opportunity to refer them to more specialized doctors.

Student reports on the observed use of examination skills in district hospitals

Cluster analysis of students' observation on GPs practicing at a district general hospital showed that no items on the list of 22 examination skills fell in the lowest cluster of overall skills (which were seldom used). That means that most of the students observed at least one GP performing every examination skill at least once. For example, although gynecological examination fell in the lowest cluster according to practicing GPs, $96 \%$ of students reported observing GPs using these skills. Although some skills were reported as never used by the GPs in the survey, the students observed groups of doctors over time during practice, providing more opportunities to record the use of the skills. If students did not observe a skill, it would mean that skill was rarely used by GPs.

Procedure skills

GP self-reporting on use of procedure skills

Cluster analysis revealed that five of the procedure skills in the list of $23(22 \%)$ fell in the lowest cluster of skills, reported to be used by less than $35 \%$ of GPs. Table 4 lists the five procedure skills in the lowest cluster and the reasons given for not using them.

Table 4: Five procedure skills in the lowest cluster of skills

\begin{tabular}{lcccc}
\hline \multicolumn{1}{c}{ Skill } & Use & \multicolumn{3}{c}{ Do not use } \\
\cline { 3 - 5 } & & $\begin{array}{c}\text { Do not have } \\
\text { patients }\end{array}$ & $\begin{array}{c}\text { Refer to specialist } \\
\text { for this skill }\end{array}$ & $\begin{array}{c}\text { Other } \\
\text { reasons }\end{array}$ \\
& $\mathbf{( \% )}$ & $\mathbf{( \% )}$ & $\mathbf{( \% )}$ & (\%) \\
\hline Pap smear & 24 & 26 & 38 & 12 \\
\hline Intrauterine device insertion & 25 & 27 & 36 & 13 \\
\hline Acupuncture & 30 & 28 & 30 & 12 \\
\hline Episiotomy/suture & 30 & 27 & 32 & 11 \\
\hline Delivery techniques & 34 & 27 & 29 & 11 \\
\hline
\end{tabular}

The influence of the practice setting in these results is seen in Table 5. It becomes clear that the percentage of GPs using Pap smear and intrauterine device insertion technique at 
city/province level was significantly higher than at district level ( $27 \%$ vs. $21 \%$ and 28 vs. 23 $\%$ respectively). Table 5 also shows that GPs practicing in city/provincial general hospitals tended to leave the skills for specialists more than did GPs in district general hospitals. The percentage of GPs at district level who did not use these skills for other reasons was significantly higher than the corresponding data for city/province level ( $18 \%$ to $20 \%$ vs. $3 \%$ to $4 \%)$.

Table 5: Five procedure skills in the lowest cluster of skills by practice setting

\begin{tabular}{|c|c|c|c|c|c|}
\hline \multirow[t]{3}{*}{ Skill } & \multirow[t]{3}{*}{ Level } & \multirow{3}{*}{$\begin{array}{l}\text { Use } \\
\text { (\%) }\end{array}$} & \multicolumn{3}{|c|}{ Do not use } \\
\hline & & & $\begin{array}{l}\text { Do not have } \\
\text { patients }\end{array}$ & $\begin{array}{l}\text { Refer to } \\
\text { specialist }\end{array}$ & $\begin{array}{l}\text { Other } \\
\text { reasons }\end{array}$ \\
\hline & & & $(\%)$ & (\%) & (\%) \\
\hline \multirow{2}{*}{ Pap smear } & District & $21^{*}$ & 24 & 36 & $19 *$ \\
\hline & Province/City & $27^{*}$ & 29 & 40 & $4^{*}$ \\
\hline \multirow{2}{*}{$\begin{array}{l}\text { Intrauterine device } \\
\text { insertion }\end{array}$} & District & $23^{*}$ & 24 & 34 & $20 *$ \\
\hline & Province/City & $28 *$ & 30 & 38 & $4^{*}$ \\
\hline \multirow{2}{*}{ Acupuncture } & District & 29 & 26 & 27 & $18^{*}$ \\
\hline & Province/City & 30 & 32 & 35 & $4^{*}$ \\
\hline \multirow{2}{*}{ Episiotomy/suture } & District & 30 & 23 & 29 & $18^{*}$ \\
\hline & Province/City & 32 & 30 & 35 & $3^{*}$ \\
\hline \multirow{2}{*}{ Delivery technique } & District & 34 & 24 & 25 & $18^{*}$ \\
\hline & Province/City & 34 & 30 & 33 & $3^{*}$ \\
\hline
\end{tabular}

$* p<0.05$ (Levene's test for Equality)

Students' reports on observed use of procedure skills

Cluster analysis of student reports revealed that five of the procedure skills in the list of 23 (22\%) belonged to the cluster of least performed skills ( $27 \%$ to $40 \%$ of students observed them). They were Pap smears, lumbar puncture, endotracheal intubation, peritoneal puncture and pleural puncture techniques. Regarding the other 18 procedure skills, most of the students (61\% to $100 \%$ ) reported having seen GPs use them; for example, $96 \%$ of students observed GPs doing deliveries. 
Diagnostic skills

GPs self-reporting on use of diagnostic skills

The national recommended list of skills to be trained in a Skillslab includes four diagnostic skills. Self-reporting by GPs confirmed that all four diagnostic skills were frequently used. Three were used by $89-95 \%$ of GPs; only hemogram analysis was slightly lower at $81 \%$ of GPs performing this skill.

Students' reports on the use of diagnostic skills

All of the students reported observing GPs reading radiogram of the bones and radiogram of the lungs; $97 \%$ saw GPs reading normal ECG and 77\% observed GPs using hemogram analysis skills.

Additional skills:

GPs and students provided a long list of skills which GPs frequently used but were not included in the questionnaire. The extra skills were usually mentioned by 15-24 GPs each, although a few were mentioned by lower numbers of GPs. The suggested extra skills were in the categories of examination (e.g. lymph node examination, assessing level of dehydration), procedure (e.g. first aid, gastric lavage, foreign body removal from the eye) and diagnostic skills (e.g. interpreting urine test, abdominal ultrasound or pulmonary function test).

GP reports versus students' reports on skills used at a district hospital

The reported use of skills by GPs was in some cases confirmed by the reports from student observations and in other cases contradicted. For the Pap smear, not only did a low percentage (17\%) of GPs at district hospitals in Thai Binh report using that technique, but also only $27 \%$ of the students had ever seen GPs perform it. While $68 \%$ of GPs at district hospitals reported using peritoneal puncture, during six weeks in the hospital, only $41 \%$ of students actually saw GPs perform that procedure. On the other hand, only $32 \%$ and $48 \%$ of the GP at district hospitals in Thai Binh reported using gynecological examination skills and doing deliveries, respectively, but $96 \%$ of students observed GPs in the same locations using both of these skills.

\section{Discussion}

The gap between the list of skills recommended by an expert committee and their actual use by graduate doctors in their daily work presents a common problem for any educational system, but the extent of this difference needs to be considered. In this study, we sought 
to validate a national list of skills to be taught in Skillslabs by checking how often the selected skills were actually used by practicing GPs, according to self-reporting and according to observation of GPs by medical students.

Four examination skills appeared to be used infrequently by many GPs: gynecological, antenatal, newborn and infant examination, all in obstetrics and gynecology. GPs who practiced in city/provincial general hospitals tended to leave these skills for a specialist to perform more than did GPs in at district level. Therefore, GPs practicing in more remote areas used these skills more often than did those in the large cities. These results suggest that the proportion of GPs using a specific skill depends not only on the skill but also on the location and the practice setting. It could depend on the availability of specialists in each hospital and/or in nearby hospitals, as well as the availability of facilities for performing the skill, or on management policies, or the attitudes of individual GPs. If the facilities for performing certain skills are not available, the nurses in reception may direct patients elsewhere and GPs at that hospital will not use those skills due to lack of patients. Or they may send the patients to a specialist or to another GP who does have the facilities. If this situation persists, GPs would gradually become more specialized in some skills and be increasingly likely to practice those skills.

For example, gynecological examination skills were not used frequently by doctors according to their own reports, but almost all of the students observed GPs in the same locations using such skills. It is possible that a small proportion of GPs were using the skills but using them frequently enough that most of the students had a chance to observe them doing so.

All five procedure skills on the list were used infrequently, according to the GPs; this finding needs to be examined carefully. Only half of GPs at district hospitals in Thai Binh reported doing deliveries but almost all students observed GPs at the same place using such skills. This data suggests that half of the GPs there account for nearly all of the deliveries. This reinforces our picture of a trend to informal specialization among GPs.

Not only did a low percentage of GPs at district hospitals in Thai Binh report using Pap smear techniques, but also only about a third of the students had ever seen GPs perform Pap smears. The finding that $68 \%$ of GPs at district hospitals in Thai Binh reported using peritoneal puncture techniques, while uring six weeks only $41 \%$ of students actually saw GPs perform the skill, suggests that this skill is also rarely used.

The results from the present study are comparable to those from an earlier study in Vietnam, which found that selected skills suggested by experts as necessary in the curriculum were reportedly used very infrequently by doctors working in all areas [15]. 
In contrast with examination and procedure skills, all four of the diagnostic skills on the list were used by most of the GPs. However, GPs as well as students suggested a long list of additional skills that they used regularly. This list is valuable for the course organizers and trainers to consider how to address training in these necessary skills. These findings are consistent with the results of an Australian study [14], as well as an American study asking similar questions with regard to use of skills learned in medical school [16].

One interesting finding was that when the GPs were the only doctor in a clinical setting, they seemed to perform a wide range of examination, procedure, and diagnostic skills. However, when there was more than one doctor, the GPs tended to specialize in several or just one skill area. In Vietnam, most doctors work in a team [15] and when the team includes several GPs, each one may tend to work mainly in selected areas of practice. This does not necessarily mean that they become formal specialists; rather that they divide the tasks of a GP into smaller groups of tasks and each GP commonly practices a few in that group tasks. This kind of informal specialization by GPs could be an explanation for the low percentage of GPs using certain skills, because they refer such activities to "specialized" GPs. For example, intrauterine device insertion is widely used in Vietnam, as a result of the National Family Planning program giving technical and financial support. Many women have intrauterine devices but only $25 \%$ of GPs reported ever using intrauterine device insertion techniques. In one big city (C) general hospital the proportion was as low as $5 \%$. There are many possible reasons why such a small number of GPs were using this specific technique at this hospital: there may be few patients requesting a device; GPs may not have mastered the technique; facilities may be lacking, or they may have other health workers to do that. For a big city like " $C$ ", the choice "have other health workers do it" seems the most obvious explanation. This tendency to specialization was reported in a previous study in Vietnam, in which only $34 \%$ of GP were still working as general doctors five years after graduation [15].

In comparison with the city/province level, the district level has more limitations in personnel, facilities, equipment and financing. There may also be limitations in the competence of the GPs at district level, which could result in differences in performing skills in certain special or highly technical procedures or laboratory investigations and in the types of treatment offered. However, the observed differences in performing the basic skills expected from all doctors are not acceptable and measures to fill the gaps need to be identified

The results of this study demonstrate that the list prepared by the experts did not fit exactly with the everyday practice of medical skills. The experts are all specialists, and some of the skills may be more suited to specialist rather than general practice [19]. This finding re- 
emphasizes the role of other stakeholders in determining what is needed in training for medical practice $[12,14-16,20]$.

As do all studies, this study had some limitations which could influence the results or their interpretation. The restricted number of options for the GPs to give reasons for not using skills led to many choosing "other reasons", so the amount of information was less than if more options had been offered. For medical education, stakeholders include faculty, residents, practitioners, students, healthcare teams, the general public [12] and consumers [14]. However, we could not find an appropriate way to ask non-medical stakeholders about the use of specific medical skills. Those stakeholders could better participate in a survey on satisfaction with the quality of the health care service.

\section{Conclusions and Recommendations}

Combining self-reporting by GPs with student observations of their practice gave a more objective picture of the skills actually used by GPs. Further research on the relation between the training and the skills that were seldom used by most GPs use is needed. If the reason for not using a basic skill is because the doctors have not been trained well in that skill, and consequently do not feel confident to use it, then training institutions must take heed and reconsider their training programs or methods.

With the increasing number of GPs in hospitals at all levels, they appeared to be tending to specialize in selected areas. We therefore recommend that in parallel with the existing national GP training program, which is based on local needs, medical faculties consider developing a "specialty oriented" training program, in which selected groups of students could be trained in specialty-oriented skills. This could be done intensively in the last semester of the training program, and skills not directly related to their orientation specialty could be optional. This approach would be better than using very limited resources to train skills that fewer than $50 \%$ of GP will actually use in practice.

The remarkable difference in the percentage of GPs not using basic medical skills for "other reasons" between central and district general hospitals needs to be explored in more depth.

In a developing country, with limited resources, high-tech and expensive equipment may be considered non-essential, but the facilities and equipment to perform basic medical skills are vital and should be available everywhere. 


\section{References:}

1. Remmen R, Derese A, Scherpbier A, Denekens J, Hermann I, Van der Vleuten C, Van Royen P, Bossaert L.(1999). Can medical schools rely on clerkships to train students in basic clinical skills? Medical Education. 33(8):600-5.

2. Kneebone R, Nestel D (2005). Learning clinical skills- the place of simulation and feedback. The Clinical Teacher. 2(2): 86-90.

3. Hao J, Estrada J, and Tropez-Sims S. (2002). The Clinical Skills Laboratory: a cost effective venue for teaching clinical skills to third-year medical students. Academic Medicine. $77(2): 152$.

4. Bligh J. (1995). The clinical skills unit. Postgraduate Medical Journal. 71(842):730-32.

5. Kozu T. (2006). Medical Education in Japan. Academic Medicine. 81(12):1069-75.

6. Dent JA. (2001). Current trends and future implications in the developing role of clinical skills centers. Medical Teacher. 23(5):483-89.

7. Bradley P, Postlethwaite K. (2004). Setting up and running clinical skills learning programmes. The Clinical Teacher. 1(2):53-58.

8. Peeraer G, Scherpbier A, Remmen R, De winter BY, Hendrickx K, Van Petegem P, Weyler J, Bossaert L. (2007). Clinical skills training in a skillslab compared with skills training in internship: comparison of skills development curricula. Education for Health. 20(3):125.

9. Sierra R, Bajka M, Székely G. (2006). Tumor growth models to generate pathologies for surgical training simulators. Medical Image Analysis. 10(3):305-16.

10. Davies RJ, Hamdorf JM. (2003). Surgical skills training and the role of skills centres. British Journal of Urology International. 91(1):3-4.

11. Bordage G, Harris I. (2011). Making a difference in curriculum reform and decisionmaking processes. Medical Education. 45(1):87-94.

12. D'eon M, Crawford R. (2005). The elusive content of the medical - school curriculum: a method to the madness. Medical Teacher. 27(8):699 - 703.

13. MacCarrick G. (2009). Curriculum reform: a narrated journey. Medical Education. 43(10): :979-988.

14. Rolfe IE, Pearson S, Sanson-Fisher RW-, Ringland C. (2001). Identifying Medical School Learning Needs: A Survey of Australian Interns. Education for Health. 14 (3):395- 404.

15. Hoat LN, Dung DV, and Wright EP. (2007). Practicing doctors' perceptions on new learning objectives for Vietnamese medical schools. BMC Medical Education. 7(19) 
16. Blumenthal D, Gokhale M, Campbell EG, Weissman JS (2001): Preparedness for clinical practice: reports of graduating residents at academic health centers. Journal of the American Medical Association, 286:1027-1034.

17. University of Medicine and Pharmacy, Ho Chi Minh City, Vietnam. Strengthening Medical Skill straining at eight universities in Vietnam (2004). http://www.maastrichtuniversity.nl/web/Misc/MUNDO/Projects1/ProjectList.htm

18. Norusis M. J. (2005) Cluster analysis. PASW Statistics 18 Statistical Procedures Companion Prentice Hall: 361-391. Available from: www.norusis.com

19. Turner SR, Hanson J, de Gara CJ. (2007) Procedural skills: What's taught in medical school, what ought to be? Education for Health. 20(1) Available from: http://www.educationforhealth.net

20. Ringsted C., Schroeder T. V., Henriksen J., Ramsing B., Lyngdorf P., Jonsson V. and Scherpbier A. (2001) Medical students' experience in practical skills is far from stakeholders' expectations. Medical teacher. 23(4):412-416. 


\section{Chapter 3}

\section{Implementing a Skillslab Training Program in a Developing Country}

A full text version was published as:

T.Q. Tran, A. Scherpbier, J. van Dalen, D. van Do, E.P. Wright, Implementing a Skillslab training program in a developing country, Education for Health 27 (2014) 243-8. 


\begin{abstract}
Background: Eight skills laboratories (Skillslabs) were established by consensus of Vietnamese medical universities, with international support. A national list of basic skills needed for medical practice and suitable for Skillslab training was developed; models, medical and teaching equipment were supplied; learning material was developed, and core staff and teachers were trained. This study was designed to assess how closely eight schools in Vietnam came to implementing all recommended skills on list developed by educators of that country and identify the facilitating factors and barriers to Skillslab use within the country's largest school.
\end{abstract}

Methods: Data were collected from reports from the eight Skillslabs. Students and trainers from the largest university were surveyed for their perceptions of the quality of training on eight selected skills. Results of students' skill assessments were gathered, and focus group discussions with trainers were conducted. SPSS 16 was used to analyze the quantitative data and cluster analysis was used to test for differences.

Results: Only one medical school was able to train all 56 basic skills proposed by consensus among the eight Vietnamese medical universities. Deeper exploration within the largest school revealed that its Skillslab training was successful for most skills, according to students' postprogram skills assessment and to students' and trainers' perceptions. However, through focus group discussions we learned that the quantity of training aids was perceived to be insufficient; some models/manikins were inappropriate for training; more consideration was needed in framing the expected requirements of students within each skill; too little time was allocated for the training of one of the eight skills investigated; and further curriculum development is needed to better integrate the skills training program into the broader curriculum.

Discussion: The fact that one medical school could teach all skills recommended for Skillslab training demonstrates that all Vietnamese schools may be similarly able to teach the basic skills of the national consensus list. But as of now, it remains challenging for most schools in this developing country to fully implement a national Skillslab training program.

Keywords: Skillslab, training program, training aids 


\section{Background}

Before graduating and starting their work as doctors, medical students must gain competence in a number of skills. The number and selection of skills required will depend on the local context.[1] Since the 1970s, dedicated skills training centers known as skills laboratories (Skillslabs) have been developed. [2-5]

Although Skillslabs have been effective in Western countries [3-8], it cannot be assumed that they will work as well in all settings. Schools in developing countries often adopt Western teaching and learning methods, which may not meet the needs of their individual healthcare systems and cultural norms.[9] In recent years, Skillslabs have been established in many countries. However, because limited resources and experience will affect the choices made by each university regarding Skillslab teaching, challenges will arise in training all students to the level required for graduating doctors. Skillslabs vary in their accommodations and resources available, ranging from one.

room with one manikin to purpose-built structures with a vast assortment of equipment.[7] For developing countries, fully equipped Skillslabs are expensive to set up and to maintain.[10] In Vietnam, international projects supported the establishment of Skillslabs in the country's eight principal state medical schools. Models and medical and teaching equipment were supplied by the projects. Maastricht University provided technical assistance and trained core staff and teachers. A national list of basic skills needed for medical practice and suitable for Skillslab training was developed using a Delphi method [11] among 40 senior teachers of all eight schools based on required standard practice for graduates. Dedicated learning materials were developed, including skills books, videos and self-made models.[12] These eight state schools, which together produce most of the medical doctors in Vietnam and participated in developing the list, are not yet obliged to use Skillslabs in their programs.

Based on self-evaluation of capacity to provide Skillslab training, a core team in each university submitted a list of skills that they expected to be able to teach. One way to check whether the skills have been learned is to review the results of Skillslab student assessments. However, these results depend on the reliability and validity of the assessment, which is influenced by facilities and the capacity of teaching staff. The students' scores could only be interpreted in relation to the quality of training, which is a result of inputs by both teachers and students.

This study was designed to assess how closely eight schools in Vietnam came to implementing all recommended skills on list developed by educators of that country, and identify the facilitating factors and barriers to Skillslab use within the country's largest school. 


\section{Methods}

\section{Skills taught in eight medical universities}

The staff in charge of the Skillslab in each of the eight participating medical universities provided a list of the skills taught there. The eight schools include all the principal state schools offering medical study in Vietnam; they range from large, long-established schools (such as Hanoi, Ho Chi Minh City) and smaller, younger, regional schools (such as Cantho, Thai Nguyen). The eight lists were compared against the national list of skills expected to be taught in the Skillslab, which was developed jointly by the same eight schools, to identify the extent to which this nationally agreed training program has been implemented.

\section{Quality of training in Skillslab of the largest school}

The second part of this study was conducted at the Skillslab of the largest medical school, where students' postcourse assessments and the opinions of students and trainers about Skillslab training and assessment were collected. From the national list of skills recommended for training in Skillslabs, eight skills were selected to cover a range of disciplines and to represent the weight of each discipline in the curriculum. The skills selected were: Heart examination; abdomen examination; ear, nose and throat (ENT) examination; gynecological examination; taking blood pressure; suture technique; lumbar puncture and Pap smear.

First, we analyzed the student's postcourse skills assessment. Then we used questionnaires to investigate the main stakeholders' opinions about the perceived quality of the teaching and of the assessment itself. Finally, we conducted focus group discussions (FGDs) with teachers to deepen our understanding of their opinions of the teaching and assessment processes.

\section{Skillslab assessment}

The routine Skillslab assessments of students' performance on the eight selected skills were recorded. The assessments consisted of direct observation of performance using a rating scale and a detailed observation guideline. The way of setting up the skills assessment and rating followed standard protocols used in the schools that provided technical assistance to set up the skills training in Vietnamese schools, as previously documented. ${ }^{[12-14]}$ The interrater reliability of assessments of students by various raters reached 0.77 after rater training, including expert discussions. Questionnaires were developed based on literature review and finalized after discussion with trainers and students. The content validity was checked with experts; reliability of each item was improved through trials, revisions, and pilot studies. ${ }^{[15]}$ 
For all questionnaires, a five-point Likert scale ( 1 = strongly disagree, 2 = disagree, $3=$ uncertain, 4 = agree, 5 = strongly agree) was used to rate the opinions on statements about the training/assessment. Scores below 3 were considered negative, while scores of 3 and above were considered positive.

\section{Students' opinions after a training session}

Each cohort of medical students is divided into 30 groups, each with about 10 students. After the training sessions for each selected skill, 11 groups were randomly selected using a list randomizer; all students of the selected squads were asked to answer a 30-item questionnaire covering students ( 3 items), Skillslab training process (13), training aids (8), trainers (5) and difficulty (1). A total of 949 individual student ratings of skills were received, which includes more than one skills rating for some students. The response rate was $90 \%$ of 1054 students invited to contribute.

\section{Students' opinions after Skillslab assessment}

After the sessions to assess learning in the Skillslab, we recruited approximately 100 student respondents per skill to complete a questionnaire. Because in skills assessment the number of students assigned for each station (skill) varied, for some skills we surveyed all students and for skills training for larger groups we only surveyed the first completers. The questionnaire included 12 items, 4 about students, 4 about the assessment tools and fo4ur on assessment conditions. We received a total of 801 skill evaluations from students, again with some students providing an evaluation for more than one skill. The response rate was $91 \%$ of 880 invited students

\section{Address for correspondence:}

\section{Trainers' opinions after training sessions}

After the training sessions on each selected skill, all trainers were invited to answer a 35item questionnaire on students (4 items), Skillslab training conditions (10), training aids (8), trainer (12) and difficulty (1). All invited trainers agreed to answer, making a total of 74 questionnaires completed by trainers after a training session

\section{Trainers' opinions after Skillslab assessments}

After a Skillslab assessment session, all trainers who had assessed the selected skills were invited to answer a questionnaire with seven items, on assessment tools (4 items) and assessment conditions (3). All of the 53 trainers invited to participate completed these questionnaires. 


\section{Focus group discussions with trainers}

FGD with Skillslab trainers, led by the researcher, provided deeper insights into their views on the quality of the training as revealed by the survey results. The results from the questionnaires were presented to the FGD participants along with the assessment results, and both were discussed and recommendations made.

The FGD discussions were recorded and the verbatim text was made available to three reviewers. The reviewers independently coded the verbatim and identified emerging themes and concepts, as well as representative quotes. Differences of opinion were discussed until consensus about interpretation was reached. As a member checking procedure, a report of the focus group findings was sent to the focus group members and they were invited to submit corrections.

\section{Data analysis}

SPSS 16 was used to analyze the quantitative data. For each skill, the mean and standard deviation of the scores of the students' assessment and the percentage of failed students are presented. The mean and standard deviation of the Likert scores on perceptions of students after skill training and after skill assessment are presented. Cluster analysis was used to test for differences in student perceptions of training across the eight different skills, and the scree plot was used to discriminate skills with high scores and skills with low scores. Perceptions of students and trainers of the difficulties of each skill are presented by means and standard deviations. Because perceptions of students are clustered data, the generalized estimating equation was used to compare the perceptions of students and trainers about difficulty.

Ethical approval of the project including both scientific and ethical aspects was provided by the University of Medicine and Pharmacy Ho Chi Minh City.

\section{Results}

Skills on the national list to be trained in Vietnamese Skillslab system

Each of the eight medical universities involved in the project reported how many and which skills it felt confident to teach in the Skillslab among the 56 skills on the national list [Figure 1]. One medium-sized university was able to train 56 skills in the national list. Among the other seven schools, four felt confident in the teaching of two-thirds to three-quarters of the skills on the national list, while three Skillslabs were confident in their training of fewer than $50 \%$ of the basic skills. 


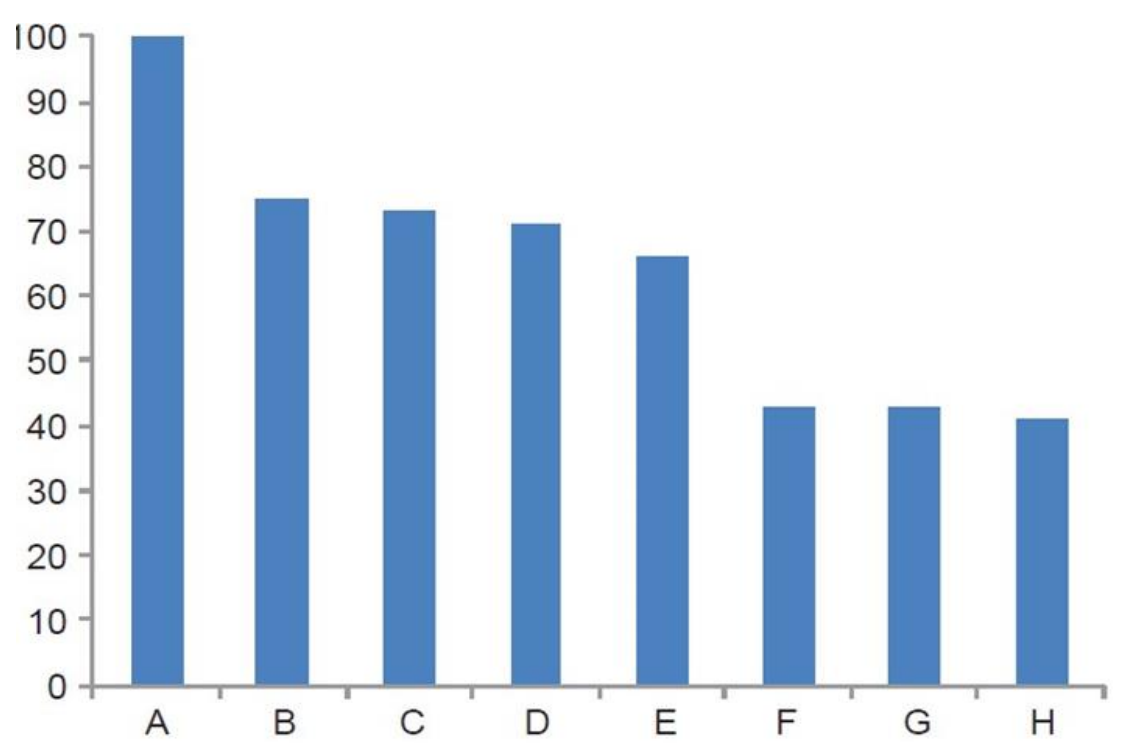

Figure 1: Percentage of skills in the national list of basic skills that are actually trained in the Skillslabs of eight Vietnamese medical schools

\section{Results of Skillslab assessment in the largest medical university}

Assessment of students' performance on the eight selected skills used a standard scoring system with a 11 -point scale ( 0 = lowest mark; $10=$ highest mark, and $5=$ pass) [Table 1 ]. Students' overall mean score across stations was 7.9 (SD 1.61). On average, 4\% (65/1629) of students failed any given station.

Table 1: Result of Skillslab assessment for eight selected skills*

\begin{tabular}{lcccc}
\hline Skill & $N$ & $\begin{array}{c}\text { Mean } \\
\text { score/10 }\end{array}$ & SD & $\begin{array}{c}\text { Failures } \\
\text { Number of students (\%) }\end{array}$ \\
\hline Heart examination & 53 & 6.64 & 1.62 & $7(13.2)$ \\
Taking blood pressure & 342 & 7.16 & 1.88 & $38(11.1)$ \\
Abdominal examination & 100 & 7.55 & 1.25 & $0(0)$ \\
ENT examination & 181 & 7.71 & 1.09 & $1(0.6)$ \\
Lumbar puncture & 259 & 7.77 & 1.59 & $15(5.8)$ \\
Gynecological examination & 196 & 8.13 & 1.30 & $2(1.0)$ \\
Suture technique & 319 & 8.45 & 1.54 & $1(0.3)$ \\
Pap smear & 179 & 8.83 & 1.18 & $1(0.6)$ \\
Totals & 1629 & 7.88 & 1.61 & $65(4)$ \\
\hline
\end{tabular}

*Possible scores, 1 to 10

The lowest mean score was found for "heart examination". High failure rates were seen with "heart examination", "taking blood pressure" and "lumbar puncture". The skills "Pap smear" and "suture technique" produced high marks and almost no failures. 


\section{Students' perceptions after Skillslab training sessions}

Immediately after training sessions, students were asked to evaluate the session. Out of 29 items, students gave 26 a mean score over 3.0, which suggest that on average the students were satisfied with the skill training sessions. There were, however, three items with significantly lower mean scores, all related to the quantity of training aids: Models/manikins (mean score, 2.72), simulated patients (2.82) and medical equipment (2.85).

All three items in which students rated something about themselves received just satisfactory scores, on average. The mean scores for the five items about the trainer ranged from 3.65 to 4.04 , indicating general satisfaction with the role of the trainers.

Students identified weaknesses in the training for certain skills compared with others [Table 2]. Training on " heart examination skills" was evaluated significantly lower than other skills in six items. For three skills, the issue of the adequate time for theory and practice teaching was noted.

Table 2: Students' perception on various aspects of Skillslab instruction on the eight selected skills

\begin{tabular}{|c|c|c|}
\hline Aspect of training program & $\begin{array}{l}\text { Mean } \\
\text { Likert } \\
\text { score of } \\
\text { all } 8 \text { skills }\end{array}$ & $\begin{array}{l}\text { For this aspect of training, the } \\
\text { particular skills for which mean } \\
\text { perception scores were lower } \\
\text { than for at least five other skills }\end{array}$ \\
\hline $\begin{array}{l}\text { Related theory was taught before } \\
\text { skillslab training }\end{array}$ & 3.65 & $\begin{array}{l}\text { Pap smear, } 2.95^{*} \\
\text { Lumbar puncture } 3.13^{*} \\
\text { Gynecological examination } 3.37^{*}\end{array}$ \\
\hline $\begin{array}{l}\text { Students have enough related } \\
\text { knowledge before practicing in skillslab }\end{array}$ & 3.23 & Heart examination, $2.89^{*}$ \\
\hline $\begin{array}{l}\text { Time to teach practical theory of this } \\
\text { skill is sufficient }\end{array}$ & 3.55 & Heart examination $3.17^{*}$ \\
\hline $\begin{array}{l}\text { I have the opportunity to practice the } \\
\text { skill in training session }\end{array}$ & 4.02 & Heart examination $3.66^{*}$ \\
\hline Time for practice was enough & 3.42 & Heart examination, $2.72^{*}$ \\
\hline $\begin{array}{l}\text { Students were checked at end of } \\
\text { training session }\end{array}$ & 3.53 & Heart examination $2.93^{* *}$ \\
\hline $\begin{array}{l}\text { Model/manikin appropriate for } \\
\text { training }\end{array}$ & 3.18 & $\begin{array}{l}\text { Gynecological examination } 2.91^{*} \\
\text { Pap smear } 3.00^{*}\end{array}$ \\
\hline $\begin{array}{l}\text { I can perform all the steps of the skill } \\
\text { at the end of the training session }\end{array}$ & 3.57 & $\begin{array}{l}\text { Heart examination } 3.12^{*} \\
\text { ENT examination } 3.20^{*}\end{array}$ \\
\hline
\end{tabular}




\section{Students' perception after Skillslab assessment}

Students provided responses not only after training sessions but also after assessment sessions. We received 96-115 completed questionnaires after each of the eight skill test sessions, with the exception of assessment of "heart examination", for which only 53 students were in the available group, of whom 48 completed the questionnaire. For all aspects of the training program for all eight skills, overall means ranged from 3.37 to 4.15 , indicating a positive perception from the students about both training and assessment.

\section{Trainers' perceptions skills training and assessment}

Trainers were asked their perceptions on Skillslab training after the training sessions and about Skillslab assessment after assessment sessions. The mean scores of all aspects of the training program for all skills were above 3 ; the trainers were positive about their training and the assessment.

The trainers were also asked their perception on the difficulty of each skill they led in the Skillslab. The mean scores of item "level of difficulty" for heart examination and lumbar puncture skills were significantly higher than other skills, suggesting that trainers considered those skills more difficult for the students to learn than other skills. For other skills, the trainers considered them not very difficult to learn.

\section{Comparing students' and trainers' perceptions on difficulty of skills}

Comparing the rating for difficulty of the eight selected skills between the trainers and students, only for the Pap smear technique were the difficulty scores given by students significantly higher than those given by trainers. For other skills, the levels of difficulty as perceived by students and trainers were similar.

Correlation between the difficulty of skills as rated by students and the students' mean score on assessment

Another consideration is the relation between the perceptions that students have on the difficulty of a technique they are learning and their assessment of their skill on that technique. The equation to predict the assessment results and the difficulty rating by student shows an inverse relation: For each unit increase in difficulty the average score was 1.3 lower [Figure 2]. The coefficient is not significant $(P=0.06)$. 


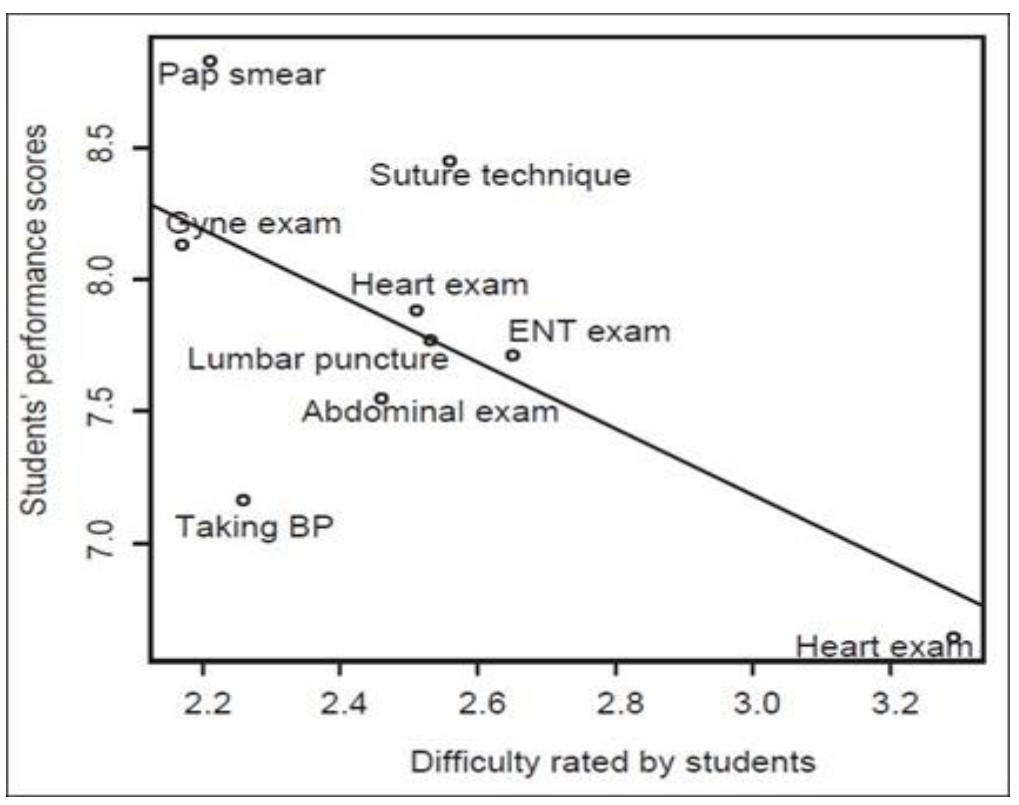

Figure 2: Relation between difficulty rating and students' performance scores on assessment for eight selected skills (Gyne exam: Gynecological examination; BP: blood pressure; ENT: Ear, Nose, Throat)

\section{Focus group discussions with trainers}

A deeper investigation of training in this one university Skillslab was conducted with FGDs, when the participants discussed the above-described survey results. One point was that the lowest mean score for "heart examination" and high failure rates for "taking blood pressure" and "lumbar puncture" may be related to the specific result required when students are assessed on those skills. As one trainer noted: "For heart examination students have to recognize a specific heart sound." Another said, "Having to read the blood pressure of the simulated patient, and to draw spinal fluid (on a model) for lumbar puncture could contribute to students' low scores". In contrast, for other skills, "Students have to perform all steps in the rating scale but there is no specific result to be measured".

Both trainers and students considered heart examination to be the most difficult skill; training in heart examination skills was also evaluated significantly lower than other skills for six items. The trainers suggested that "increasing the training time for this skill would strengthen the weaknesses mentioned by the students and improve their performance".

The trainers also agreed with the students' perception of insufficient medical equipment and models/manikins and suggested that there should be increased opportunity for selfpractice. The FGD also had a explanation for the satisfactory score by trainers for those items. "Recent improvements in quality and quantity of the training equipment, 
models/manikins satisfied the trainers, but in fact, both quality and quantity are still far from meeting the training requirements". The models/manikins were not fully appropriate for training but in assessment they could help students to perform the skills more easily to give better results in assessment.

Regarding the frequency of low scores for learning theory before practice, the trainers also mentioned that, " The Skillslab training program was an addition to the existing curriculum; in some cases, the scheduling of the related theory teaching did not completely fit with the Skillslab training program". The trainers suggested that, "We need a full curriculum reform to integrate the skills training program in to the existing curriculum".

\section{Discussion}

This study was designed to investigate the capacity of a Skillslab in a developing country to train the skills assigned by consensus among eight medical universities. The fact that one university could teach all 56 skills suggests that Skillslab training the entire national list of basic skills is possible in this country. That particular university was the first in Vietnam to establish a Skillslab, with international support, and has the longest experience, with better trained and experienced teachers running it. It is a medium-sized regional school. The school in which the in-depth study reported here was done is the largest in the country and was the second to set up a Skillslab; it was the second highest in number of skills taught using the Skillslab. Resource constraints may be one reason for the low proportion of recommended skills being taught in other schools. This interpretation is supported by the students' opinion that the quantity of training aids available even in one of the largest universities was insufficient to meet their learning requirements. Insufficient investment for Skillslabs in a developing country is understandable and stands in contrast with the often strong investments in developed countries. [5] Stark and Fortune $\stackrel{[10]}{~ s u g g e s t e d ~ t h a t ~}$ in a first phase of setting up a Skillslab in developing countries, it may be easier to let students continue to learn in the clinical environment. However, Hoat et al. [16] reported the results of an earlier study on skills learning in Vietnamese medical schools; new graduates from schools that already had a Skillslab expressed more confidence about skills they had learned than students from schools without one. One way to overcome resource constraints is to use self-made models; $[121,[17]$ greater availability and relevance as well as lower cost makes such models very useful in a resource-limited setting. The three schools that taught less than $40 \%$ of recommended skills were smaller. Younger schools, where human and other resources are limited, may need a longer time to develop sufficient capacity. When capacity to provide training becomes available, all 56 skills in the national list should be trained in Skillslabs in all the medical universities.

Training in the Skillslab in the one university was apparently successful for most skills, according to the results of student assessment after training and to the students' and the trainers' perceptions. However, based on focus group feedback, curriculum renovation is 
still needed to integrate the skills training program within the existing curriculum. Also, time allocated for training of one of the eight skills investigated needs to be increased. The issues of inappropriate models/manikins for training could be a problem for any university; the differences between models and human beings have also been a point of criticism of Skillslabs in other countries. [17],[18] It might, however, be a more serious problem in resource-limited settings where the quality of the manikins might be lower.

Students and trainers in the one examined school were satisfied with the role of the trainer. This might reflect a good selection process and training for the trainers. But this praise for instructors might also be a halo effect $[19]$ and reflect the reluctance within the Southeast

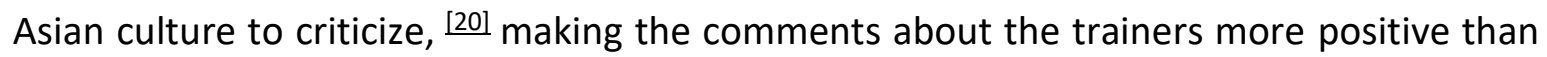
students' actual assessments. A deeper evaluation of the quality of the trainers' work still needs to be performed.

The study does have limitations. The focus group participants' openness to respond may have been influenced by their professional relationship with the moderator, who was their senior. We report on the perception of stakeholders and immediate results of skills training but not at the longer term effectiveness of the training. That will require a future, longitudinal study. The data consist of the impressions and opinions of students compared with their performance, while the teachers' performance has not been directly evaluated. Most of the results came from in-depth research of one university, where the data collection and analysis could be controlled by the researchers. From the section reporting the review of Skillslab training in the eight schools, it is clear that Skillslab training is not yet optimal in some of them. We make the assumption that if Skillslab training can be implemented successfully in one university, there is potential for the others to do the same, if they also identify the barriers and obstacles in their particular situations.

\section{Conclusions}

It remains a challenge to implement fully a national Skillslab training program in a developing country, at least in the startup phase. In spite of great efforts to establish such a program, there are still many barriers to full implementation. The biggest obstacle recognized by students and trainers was the limited quantity of training aids, providing fewer opportunities for each student to practice. The main issues identified to improve the contribution of the Skillslab to the training of medical students of this particular school were to integrate the Skillslab training program into the existing curriculum, increase time allocated for training certain skills, ensuring models/manikins were appropriate for the training, and reconsidering the requirements of students for each skill in the skill assessment. Further efforts are needed if the medical schools in this developing country are to make the best use of the Skillslabs to improve the quality of their graduates. 


\section{References}

1. Metz JCM, Verbeek WA. Blueprint 2001: Training of Doctors in the Netherlands: Adjusted Objectives of Undergraduate Medical Education in The Netherlands. University of Nijmegen, Nijmegen, The Netherlands.

2. Bouhuijs PA, Schmidt HG, Snow RE, Wijnen WH. The Rijksuniversiteit Limburg, Maastricht, Netherlands: Development of Medical Education. Public Health Pap 1978;70:133-51.

3. Peeraer G, Scherpbier AJ, Remmen R, De winter BY, Hendrickx K, Van Petegem P, et al. Clinical skills training in a Skillslab compared with skills training in internship: Comparison of skills development curricula. Educ Health (Abingdon) 2007;20:125.

4. Bligh J. Clinical skills unit. Postgrad Med J 1995;71:730-2.

5. Kozu T. Medical Education in Japan. Acad Med 2006;81:1069-75.

6. Hao J, Estrada J, Tropez-Sims S. The Clinical Skills Laboratory: A cost effective venue for teaching clinical skills to third year medical students. Acad Med 2002;77:152.

7. Dent JA. Current trends and future implications in the developing role of clinical skills centers. Med Teach 2001;23:483-9.

8. Bradley $P$, Postlethwaite $K$. Setting up and running clinical skills learning programmes. Clin Teach [2004];1:53-8.

9. Bajaj JS. Multiprofessional education as an essential component of effective health services. Med Educ 1994;28:86-91.

10. Stark P, Fortune F. Teaching Clinical Skills in Developing Countries: Are Clinical Skills Centres the Answer? Educ Health (Abingdon) 2003;16:298-306.

11. Linstone HA, Turoff M. (2002) The Delphi Method, Techniques and Applications. In: Linstone HA, Turoff $M$, editors. Available from:

http:// www.is.njit.edu/pubs/delphibook/. [Last accessed in 2013 May 01].

12. Tran TQ, Scherpbier A, Dalen J van, Wright PE. Teacher-made models: The answer for medical skills training in developing countries? BMC Med Educ 2012;12:98.

13. Dutch Ministry of Foreign Affairs (2007) Evaluation NPT/NFP The case of Vietnam report of a field investigation-final report. Available from:

http://www.government.nl/./reports/./evaluation. npt.nfp-the-case-of-vietnam. [Last accessed on May 01, 2013].

14. Duvivier R, Dalen JV, Bartholomeus $P$, Verwijnen $M$, Scherpbier A. Skills training. In: Van Berkel $H$, Scherpbier A, Hillen $H$, Van der Vleuten $C$, editors. Lessons from problem-based learning. Oxford: Oxford University Press; 2010. p. 87-96. 
15. Siniscalco MT, Auriat N. Questionnaire design. In: Ross KN, editor. Quantitative research methods in educational planning: International Institute for Educational Planning/UNESCO; 2005. p. 22-79. Available from:

http://www.unesco.org/iiep/PDF/TR Mods/Qu Mod8.pdf [Last accessed on April 01, 2013].

16. Hoat LN, Son NM, Wright EP. Perceptions of graduating students from eight medical schools on acquisition of key skills identified by teachers. BMC Med Educ 2008;8:5.

17. Akaike $M$, Fukutomi $M$, Nagamune $M$, Fujimoto $A$, Tsuji $A$, Ishida $K$, et al. Simulation-based medical education in clinical skills laboratory. J Med Invest 2012;59:28-35.

18. Widyandana D, Majoor G, Scherpbier A. Transfer of Medical Students' clinical skills learned in a clinical laboratory to the care of real patients in the clinical setting: The challenges and suggestions of students in a developing country. Educ Health (Abingdon) 2010;233:339.

19. Nisbett RE, Wilson TD. The halo effect: Evidence for unconscious alteration of judgments. J Pers Soc Psychol 1977;35:250-6.

20. Hofstede G. National-culture. The Hofstede Centre. Available from: http://geert-hofstede.com/national-culture.html. [Last accessed on May 01, 2013]. 


\section{Chapter 4}

Nationwide survey of patients' and doctors' perceptions of what is needed in doctor - patient communication in a Southeast Asian context

A full text version was published as:

T.Q. Tran, A. Scherpbier, J. van Dalen, D. van Do, E.P. Wright, Nationwide survey of patients' and doctors' perceptions of what is needed in doctor - patient communication in a Southeast Asian context. BMC Health Services Research 20 (2020): 946 


\begin{abstract}
Background

Asian countries are making efforts to apply the partnership model in doctor-patient communication that has been used effectively in Western countries. However, notable differences between Western and Asian cultures, especially the acceptance of a hierarchical order and little attention to individuality in Asian cultures, could mean that the application of the partnership model in Vietnam requires adaptation.

The study aimed to investigate whether communication models used in the Western world are appropriate in Southeast Asia, and to identify key items in doctor-patient communication that should be included in a doctor-patient communication model for training in Vietnam.
\end{abstract}

\title{
Methods
}

In six provinces, collaborating medical schools collected data from 480 patients using faceto-face surveys with a structured guideline following a consultation session, and from 473 doctors using a cross-sectional survey on how they usually conduct consultation sessions with patients. Data collection tools covered a list of communication skills based on Western models, adapted to fit with local legislation. By means of logistic regression we examined whether doctor patient communication items and other factors were predictors of patient satisfaction.

\section{Results}

Both patients and doctors considered most elements in the list necessary for good doctorpatient communication. Both also felt that while actual communication was generally good, there was also room for improvement. Furthermore, the doctors had higher expectations than did the patients. Four items in the Western model for doctor-patient communication, all promoting the partnership relation between them, appeared to have lower priority for both patients and doctors in Vietnam.

\section{Conclusion}

The communication model used in the Western world could be applied in Vietnam with minor adaptations. Increasing patients' understanding of their partner role needs to be considered. The implications for medical training in universities are to focus first on the key skills perceived as needing to be strengthened by both doctors and patients. In the longer term, all of these items should be included in the training to prepare for the future.

\section{Key words}

doctor-patient communication, partnership model, perception, culture, Asia, training, Vietnam 


\section{Background}

Doctor-patient communication is one of the most essential dynamics in health care, affecting the course of patient care and patient satisfaction [1-5]. Although technical skills may receive more attention in physician training, communication plays an essential role in practice.

A standard communication structure for a medical interview is described in the CalgaryCambridge Observation Guide [2], which has been an effective model for communication skills in medical interviews and has strongly influenced the development of medical communication skills training programs $[6,7]$. In this "partnership" model, which has been effectively applied in Western countries, the patient is actively involved in the consultation, and doctor and patient are equal [8].. Some Asian countries are trying to shift their doctorpatient communication model toward this partnership model; however, application of a Western model to Asian communities may require it to be adapted to fit local context [912].

The Western communication model improves patient care and patient satisfaction. Patient participation in medical encounters depends on a complex interplay of influencing factors, including ethnicity [11, 13-16]. Hofstede, a pioneering researcher on crosscultural communication and organization, who developed the Cultural Dimensions Theory and Country Comparison Tool [17], reported notable differences between Western and Asian cultures. Using this tool, Vietnam scores highest on the dimension "Power distance" and lowest on the dimension "Individualism," showing that Vietnamese people accept a hierarchical order in which everybody has a place without further justification, and pay less attention to the individual than to the group. In contrast, in Western countries the "Individualism" score is higher than "Power distance," meaning that equal respect and individual rights are expected and deserved [18].

In a strongly hierarchical society, the respect for someone who is perceived to be of higher social status strongly influences communication [19]. Doctors are considered to have a higher position than their patients and they recognize that $[19,20]$. In addition, patients accept their lower social position; they do not have expectations beyond that [18], and do not think of doctors as their partners [10].

A society with a low score on individualism is a collectivist society where there is a high preference for a strongly defined social framework in which individuals are expected to conform to the ideals of the society [18]. In collectivist societies, self-control is a core value. Vietnamese people tend to be reserved and modest; emotions are typically kept to oneself, whereas expressions of disagreement that may irritate or offend are avoided [20] With such cultural characteristics, applying the partnership communication model in Vietnam may require compromise. For example, a study in Sri Lanka found that fewer than $50 \%$ of patients expected doctors to introduce themselves, to thank them, or to discuss available treatment options with them [9]. 
Although Hofstede's theories are often seen as the most comprehensive and relevant study of cultural differences [21], there has been criticism of his approach, such as assigning the results from one company to their entire nation's overall scores, and using nations as units to examine cultural differences [22]. A study replicating Hofstede's approach with a student population at Stenden University [23] showed that the dimensions "Power Distance" and "Individualism" of Chinese students did differ from Western students, but the differences were smaller than in Hofstede's report. It was also suggested that workrelated cultural values in a specific culture can change over time [24].

In Vietnam, there is not yet a list of required clinical communication skills for medical doctors. The competency standards for general practitioners state: "General practitioners shall have the ability to communicate effectively with patients, their family and the community," and note two related standards: "Have the ability to create a friendly, cooperative and trustful relationship with patients, their family and the community," and "Effective communication." These two standards have nine criteria which reflect the partnership model in doctor-patient communication [25].

There are also Government regulations on communication in medical facilities [26] which guide activities of health workers and include most but not all standard activities in doctorpatient communication. The regulations reflect the partnership model, with the general regulation: "Communication in medical examination and treatment facilities is expressed verbally and by cultural attitudes and behaviors; visiting people are the consumers of services of medical examination and treatment facilities and are treated equally and politely." Implementing these standards and regulations in training for doctor-patient communication is a challenge in Vietnam, because of the lack of a formal Vietnamese doctor-patient communication model.

Based on these government regulations and the available material on doctor-patient communication (mostly from Western countries), each university had developed its training and assessment material in its specific way. A typical Vietnamese doctor-patient communication model is needed to provide a mandate to introduce the partnership model more systematically into medical education throughout the country.

This study aimed to identify the essential items in communication that doctors should perform during a consultation applying the partnership model; the results will guide the application of the partnership model in training doctor patient communication. We expected that doctors and patients would value most of activities from the Western doctorpatient communication model, but that selected activities related to building a relationship (but not directly related to the patient's health) may have lower priority for patients and/or doctors. 


\section{Methods}

Doctors and patients are both partners in the communication. When investigating which parts of the Western communication model may be applicable in Asia, both the patients' expectations and the doctors' willingness and capacity to meet those expectations should be explored. Gender, age, employment, setting, and time available for the consultation may influence patients' expectations and satisfaction [10, 12, 19, 27-30]. Because they may influence the communication, we recorded these potentially confounding variables, to support interpretation of the results.

\section{Study design}

The data were collected using face-to-face surveys with 480 patients and a cross-sectional survey among 473 doctors in six Vietnamese cities, involving six of the eight oldest medical schools in Vietnam. To reduce bias caused by patients' life experience, we asked patients about the consultation they had just finished, not doctor-patient communication in general. Because we invited doctors to complete the questionnaire when they had time, we could only ask them about doctor-patient communication in general. Therefore, answers from patients and doctors could not be directly compared.

\section{Study participants and data collection process}

The study employed a nationwide stratified sample of participants. Teaching staff in six medical universities in six provinces/cities with universities implemented it: two in the North, two in the Center and two in the South. One in the North and one in the South are in major cities, while the others are in rural provinces. The data were collected from both urban hospitals and district health centers, none linked directly with the universities. Since district health centers have fewer doctors and patients than do city hospitals, we selected one urban hospital and two district health centers in each province/city as research sites, based on their order in the list of health facilities and using random number lists generated in Excel. We also used random number lists to select 40 medical doctors and 40 patients at each hospital and 20 medical doctors and 20 patients at each district health center to participate in this study. The doctors worked in outpatient services where they would be expected to use all the communication activities. The patients had just finished a consultation at an outpatient service. Patients and doctors were compensated for their time, receiving around two euros. The research assistants were six groups of four medical teaching staff who had participated in developing the questionnaires and a guide for the face-to-face survey. They were trained in a 3-hour session to ensure consistent use of the guide. Research assistants performed the face-to-face surveys and recorded patients' responses, but did not probe for further qualitative information, so that information from 
the different locations could be standardized.

\section{Materials}

Representatives from the six medical universities involved in communication skills training had collaborated during a workshop to reach consensus on a questionnaire, based on the theoretical background of Kurtz et al. and the Calgary-Cambridge Observation Guide [2, 31]. The MAAS Global checklist to assess communication skills [32] was used as a reference, as were regulations on communication from the Ministry of Health in Vietnam [26]. Working towards an appropriate model for teaching, we developed a standard tool that listed required communication skills. Using this tool, we investigated the perceptions and expectations of patients and doctors on the communication between them. Since patients are the customers of the service, in this study we paid attention to patients' perceptions, and explored factors that could potentially affect patients' perceptions and expectations, as well as items related to their satisfaction. We aimed to obtain information that would guide trainers in selecting key items to be included in doctor-patient communication training.

The doctor also has a crucial role as a partner in the communication. We compared the expectations of patients and doctors to identify any differences that could be addressed during doctors' training.

\section{Doctors}

\section{Doctors were asked to complete a two-part questionnaire:}

$>$ Part 1 included 22 activities that may be used by the doctor in communication with patients in the categories: Introduction, Exploration, Examination, Information, Discussion, and Closure. For each activity, doctors were asked first whether they usually performed it, and second, whether they thought they should perform it and would plan to in future for a better communication model. Each question had Yes and No as answer categories.

$>$ Part 2 related to demographic information. Doctors were also asked how much time they used for an average consultation and how much they would need under ideal conditions.

Patients

As described, this questionnaire served as a guide for a face-to-face survey with patients exiting a consultation; teaching staff of local medical universities conducted the survey.

To eliminate any hesitation to be critical, which might negatively impact their treatments, and to encourage patients to participate, the research assistants emphasized that they were not hospital staff and that patients' responses would remain anonymous. The study 
was verbally introduced to participants as a national research to explore the perceptions of doctors and patients on their communication at the present time, and their expectations of better communication in the future. By responding, the participants would help the medical universities improve their training quality. The research did not aim to evaluate either the individual doctor or the individual health facility.

Patients were asked to give verbal consent to participate. If they agreed, information on their gender, age, and employment were recorded, as well as the level of the facility. Then patients were asked about their satisfaction with the consultation in general as well as with their communication with the doctor. For each question, patients were asked to choose one of four choices, ranging from very unsatisfied to very satisfied. Additionally, they were asked their opinion on each item of communication on the list of activities in the questionnaire for doctors.

The data collection instruments were pre-tested in a population near a medical university. The pilot revealed that results were unreliable if patients completed the forms without guidance, because they may misunderstand the wording. Some questions were reformulated to be clearer, and the revised questionnaire was administered by research assistants who recorded patients' responses after making sure that the question was understood. During pilot testing, we found that patients did not clearly understand two of the doctors' activities on the list: item 12: "doctor asks patient about their knowledge and attitude concerning their disease before giving information" and item 16: "doctor considers patient's reaction to information provided." Therefore, these two activities were excluded from the final question list for patients. The reliability of the face-to-face survey form for patients using the test-retest method was 0.73 (Pearson correlation coefficient).

The questionnaire was developed and administered in Vietnamese. The final version was translated into English and edited by the native English-speaking author in consultation with the Vietnamese author.

\section{Data analysis}

The data from both sets of questionnaires were first analyzed descriptively using SPSS. The categorical variables were reported as frequencies and percentages and compared by age group, sex, employment, or level of health facility using regression analysis. Normally or near-normally distributed variables were expressed as means with standard deviations and compared by Student's t-test. Non-normally distributed variables were reported as medians with interquartile ranges and compared using the Kruskal-Wallis test and McNemar's test for paired nominal data. In this study, a threshold p-value of 0.05 indicates significance, and a frequency higher than $50 \%$ was considered as majority. Stepwise multivariate logistic regression analysis was used to find the most independent items in the doctor-patient communication affecting patient satisfaction. The inclusion and exclusion 
threshold of the stepwise method were set at $p$-value of 0.10 .

\section{Ethical considerations}

The patients were recruited by invitation, and most invitations (95.4\%) were accepted. The face-to-face survey took place in private spaces in the hospitals. Patients were presented verbally with the aim of the study and were informed that they could refuse any questions or could stop the face-to-face survey at any time if they wished without giving an explanation. All participants gave verbal consent to participation.

More than $98 \%$ of doctors invited to complete the survey agreed; forms were returned to the Director of Nursing in the outpatient clinic, who forwarded them to the researchers.

The research protocol was approved by the Scientific Committee of the Ho Chi Minh City University of Medicine and Pharmacy, covering both technical and ethical aspects. The relevant authorities in each health facility also agreed to host the study.

\section{Results}

\section{Patients' perceptions of doctors' communication}

Most of the patients reported finding their consultation satisfactory (75.2\%). While onefifth of the respondents were very satisfied (20.6\%), only $4.2 \%$ were not satisfied and none was very unsatisfied. When asked about their general satisfaction with the doctors' communication, nearly all patients were satisfied (75.6\%) or very satisfied (19.2\%), and no one was very unsatisfied.

The patients were then asked about a list of specific activities that may be performed by the doctor during the consultation. For each activity, patients were asked first whether their doctors had performed that activity during the consultation just completed. Then they were asked about their expectations - whether they would like or expect their doctors to perform those specific activities in future consultations.

The patients' perceptions are presented in Table 1 . The items are listed in the order they appeared on the face-to-face survey form. For each activity, the percentages of patients reporting the doctor "performed during last consultation" and the percentages of patients who "expect doctor perform in future" are presented in the same row. 
Table 1: Patients' perceptions on performance and need for communication skills ( $N=480)$

\begin{tabular}{|c|c|c|c|}
\hline & Activities & $\begin{array}{c}\text { Performed during } \\
\text { the last } \\
\text { consultation } \\
\% \\
\end{array}$ & $\begin{array}{c}\text { Expect to be } \\
\text { Performed in the } \\
\text { future } \\
\% \\
\end{array}$ \\
\hline 1 & Doctor greets patient & 65.6 & 73.3 \\
\hline 2 & Doctor introduces him/herself & 10.4 & 37.4 \\
\hline 3 & Doctor uses the patient's name in communication & 38.4 & 46.2 \\
\hline 4 & Doctor listens attentively while patient talks & 93.3 & 98.5 \\
\hline 5 & Doctor expresses sympathy with patient & 86.0 & 97.1 \\
\hline 6 & $\begin{array}{l}\text { Doctor expresses a positive and encouraging attitude } \\
\text { towards patient's efforts in taking care of health }\end{array}$ & 30.2 & 60.6 \\
\hline 7 & $\begin{array}{l}\text { Doctor check whether he/she understood exactly what } \\
\text { patient said/would like to say }\end{array}$ & 52.9 & 83.5 \\
\hline 8 & $\begin{array}{l}\text { Doctor asks if there is anything else that patient would } \\
\text { like to share. }\end{array}$ & 44.6 & 81.6 \\
\hline 9 & Doctor informs the patient what he/she is going to do & 63.3 & 90.6 \\
\hline 10 & Doctor explains the needs for examination/ test & 57.3 & 89.8 \\
\hline 11 & Doctor conducts examination in respectful manner & 91.9 & 98.3 \\
\hline 12 & Doctor informs patient about results of examination & 76.9 & 98.3 \\
\hline 13 & Doctor informs patient about diagnosis, hypothesis. & 62.9 & 91.2 \\
\hline 14 & $\begin{array}{l}\text { Doctor informs patient about possible prognosis of the } \\
\text { disease }\end{array}$ & 58.5 & 92.1 \\
\hline 15 & $\begin{array}{l}\text { Doctor discusses with patient about treatment } \\
\text { methods with advantages and disadvantages of each } \\
\text { method }\end{array}$ & 39.4 & 81.2 \\
\hline 16 & Doctor summarizes what he/she and patient agreed & 46.0 & 77.7 \\
\hline 17 & $\begin{array}{l}\text { Doctor asks if the patient has any difficulty to follow } \\
\text { the treatment course described by the doctor }\end{array}$ & 31.0 & 77.3 \\
\hline 18 & $\begin{array}{l}\text { Doctor asks patient to repeat main issues in treatment } \\
\text { course }\end{array}$ & 26.7 & 59.6 \\
\hline 19 & Doctor asks if patient is satisfied with the consultation & 15.6 & 41.2 \\
\hline 20 & Doctor thanks the patient & 12.1 & 33.5 \\
\hline
\end{tabular}


For half of the activities, fewer than $50 \%$ of patients reported "doctor performed during last consultation." For all items, the percentage of patients expecting to see those items in future was significantly higher than the percentage reporting that they had been done during their consultation, suggesting that patients wanted doctors to improve on all items. There were four items that less than $50 \%$ of patients expected doctors to perform: Doctor introduces him/herself; Doctor uses the patient's name in communication; Doctor asks if patient is satisfied with the consultation; Doctor thanks the patient.

\section{Doctors' perceptions on doctor-patient communication}

Doctors answered a questionnaire that was very similar to questions given to patients, with the addition of the two points that patients had found difficult in pre-testing. They were asked first whether they performed these activities routinely, then whether they thought they should in future. The doctors' perceptions are presented in Table 2 . The items are listed in the same order as they appeared in the questionnaire. For each activity, the percentage of doctors who reported "routinely perform" in the consultations and "expect to perform in the future" are reported in the same row. 
Table 2: Doctors' perception of performance of and need for communication activities

\begin{tabular}{|c|c|c|c|c|c|}
\hline & \multirow[t]{2}{*}{ Activities } & \multicolumn{2}{|c|}{$\begin{array}{l}\text { Routinely } \\
\text { perform }\end{array}$} & \multicolumn{2}{|c|}{$\begin{array}{l}\text { Expect to } \\
\text { perform in the } \\
\text { future }\end{array}$} \\
\hline & & $\mathrm{N}$ & (\%) & $\mathrm{N}$ & $(\%)$ \\
\hline 1 & Doctor greets patient & 469 & 89.3 & 468 & 98.7 \\
\hline 2 & Doctor introduces him/herself & 467 & 30.4 & 468 & 74.4 \\
\hline 3 & Doctor uses the patient's name in communication & 468 & 41.0 & 463 & 60.0 \\
\hline 4 & Doctor listens attentively while patient talks & 467 & 98.3 & 464 & $99.6^{*}$ \\
\hline 5 & Doctor expresses sympathy with patient & 469 & 97.2 & 468 & 99.6 \\
\hline 6 & $\begin{array}{l}\text { Doctor expresses a positive and encouraging attitude towards } \\
\text { patient's efforts in taking care of health }\end{array}$ & 470 & 81.3 & 468 & 99.6 \\
\hline 7 & $\begin{array}{l}\text { Doctor check whether he/she understood exactly what } \\
\text { patient said/would like to say }\end{array}$ & 467 & 78.4 & 466 & 98.7 \\
\hline 8 & $\begin{array}{l}\text { Doctor checks if there is anything else that patient would like } \\
\text { to share. }\end{array}$ & 469 & 88.9 & 465 & 98.9 \\
\hline 9 & Doctor informs the patient what he/she is going to do & 469 & 91.7 & 467 & 97.9 \\
\hline 10 & Doctor explains the needs for examination/test & 469 & 92.8 & 466 & 98.5 \\
\hline 11 & Doctor conducts examination in respectful manner & 467 & 97.9 & 467 & 99.6 \\
\hline 12 & $\begin{array}{l}\text { Doctor asks patient about their knowledge and attitude } \\
\text { concerning their disease before giving information } * *\end{array}$ & 467 & 67.2 & 469 & 95.5 \\
\hline 13 & Doctor informs patient about results of examination & 467 & 89.1 & 467 & 95.3 \\
\hline 14 & Doctor informs patient about diagnosis, hypothesis. & 469 & 80.2 & 467 & 92.9 \\
\hline 15 & $\begin{array}{l}\text { Doctor informs patient about possible prognosis of the } \\
\text { disease }\end{array}$ & 467 & 81.8 & 466 & 92.5 \\
\hline 16 & Doctor consider patient's reaction to information provided $* *$ & 465 & 79.6 & 465 & 97.6 \\
\hline 17 & $\begin{array}{l}\text { Doctor discusses with patient about treatment methods with } \\
\text { advantages and disadvantages of each method }\end{array}$ & 467 & 73.7 & 463 & 92.7 \\
\hline 18 & Doctor summarizes what he/she and patient agreed & 469 & 72.3 & 466 & 94.6 \\
\hline 19 & $\begin{array}{l}\text { Doctor asks if the patient has any difficulty to follow the } \\
\text { treatment course }\end{array}$ & 466 & 74.7 & 465 & 97.4 \\
\hline 20 & Doctor asks patient to repeat main issues in treatment course & 466 & 30.9 & 462 & 77.3 \\
\hline 21 & Doctor asks if patient is satisfied with the consultation & 467 & 41.3 & 464 & 85.1 \\
\hline 22 & Doctor thanks the patient & 466 & 45.9 & 465 & 86.0 \\
\hline \multicolumn{6}{|c|}{$\begin{array}{l}\text { * NO significant difference; all other differences between performed and expect to perform were } \\
\text { significantly different. }\end{array}$} \\
\hline$* *$ । & ems not included in the patients' questionnaire & & & & \\
\hline
\end{tabular}


Table 2 shows that five of the 22 activities were not routinely performed by fewer than half of the doctors. For all but one item (number 4, "Doctor listens attentively while patient talks"), the percentage of doctors expecting to perform them in the future was significantly higher than the percentage of those routinely performing them. That one item was reported as routinely done by nearly all doctors and could hardly be improved. On all other items, doctors apparently thought they should improve their communication.

\section{Time for each consultation}

Doctors' communication may be influenced by the time available per consultation. They were asked how much time they had for an average consultation and what would be ideal. While doctors said they would need an average of $17.6(+/-9.1)$ minutes per patient, they estimated that they only had $10.8(+/-6.6)$ minutes.

\section{Comparison of patients' and doctors' expectations}

Patients expected improvement on all 20 items, while doctors expected to improve $21 / 22$. However, patients' expectations for all the items were lower than doctors were. Table 3 shows the five items for which both patients and doctors had the lowest expectations.

Table 3: Five items for which both patients and doctors had low expectations

\begin{tabular}{lll}
\hline Activities & $\begin{array}{l}\text { Patients } \\
\text { expected } \\
\%\end{array}$ & $\begin{array}{l}\text { Doctors } \\
\text { expected } \\
\%\end{array}$ \\
\hline Doctor thanks the patient & 33.5 & 86 \\
\hline Doctor introduces him/herself & 37.4 & 74.4 \\
\hline Doctor asks if patient is satisfied with the consultation & 41.2 & 85.1 \\
\hline Doctor uses the patient's name in communication & 46.2 & 60 \\
\hline Doctor asks patient to repeat main issues in treatment course & 59.6 & 77.3 \\
\hline
\end{tabular}

Although the patients had low expectations on all four items, for one ('Doctor asks patient to repeat main issues in treatment course'), it was above the $50 \%$ cutoff for importance. The other four items that most patients did not expect from doctors were still considered important by doctors, but were among the five rated lowest by them.

\section{Factors potentially affecting patients' perceptions}

To check for potential confounding factors, additional data were collected from patients about their gender, age, and employment. Responses from men and women were similar. Women reported higher frequencies of "doctor performed" than men, but the difference 
was significant only for the activity "greets patient". Significantly higher satisfaction scores were seen among respondents over 55 years of age. For employment, few differences were noted. Farmers more often responded "very satisfied", and industrial workers were more "unsatisfied" with both the consultation and the doctor's communication. For "doctor greets patient", retired persons reported the highest frequency, while students reported the lowest. Housewives said that they felt that the doctor "expresses sympathy with patient" more than did students.

The responses from patients exiting a provincial hospital were significantly higher than from a district facility for "Doctor informs the patient what he/she is going to do". For "Doctor expresses a positive and encouraging attitude towards patient's efforts in taking care of health", the results were reversed.

For patients' expectations of future consultations, no significant differences were found among different groups related to gender, age, employment, or level of facility.

\section{Items related to patients' satisfaction}

Analysis of the association between the patients' perception about the communication actions and their satisfaction with their consultation can clarify what is important to the patients. Logistic regression analysis showed a significant relationship between patients' general satisfaction with the consultation in general, and with four of the items that were performed by the doctor (Table 4).

Table 4: Four items of doctors' communication significantly related to patients' general satisfaction with the consultation

\begin{tabular}{lll}
\hline $\begin{array}{l}\text { Communication activities performed by doctors strongly related to } \\
\text { patients' general satisfaction with the consultation }\end{array}$ & Sig. & Odds Ratio \\
\hline Doctor expresses sympathy with patient & $.018^{*}$ & 3.837 \\
\hline Doctor informs the patient what he/she is going to do & $.046^{*}$ & 2.745 \\
\hline Doctor conducts examination in respectful manner & $.020^{*}$ & 3.692 \\
\hline Doctor asks patient to repeat main issues in treatment course & $.020^{*}$ & 0.283 \\
\hline
\end{tabular}

*significantly related

In Table 4, the odds ratio (OR) for the item "Doctor expresses sympathy with patient" was 3.837, which means that patients who reported that their doctor performed this item were 3.837 times more likely to report being satisfied with their consultation than those reporting that the doctor did not perform it. Similarly, the OR were 2.745 and 3.692 times for the items "Doctor informs the patient what he/she is going to do" and "Doctor conducts examination in respectful manner" respectively. For the item, "Doctor asks patient to repeat main issues in treatment course", the OR of .283 means that this item was inversely related to overall satisfaction with the consultation. 
Regarding the relation between the doctors' performance and the patients' satisfaction with the doctors' communication, the results of logistic regression analysis are presented in Table 5.

Table 5: Items performed by doctors and significantly related to patients' satisfaction with doctors' communication

\begin{tabular}{lll}
\hline $\begin{array}{l}\text { Items performed by doctors that were significantly related } \\
\text { to patients' satisfaction with doctors' communication }\end{array}$ & Sig. & Odds Ratio \\
\hline Doctor introduces him/herself & $.043^{*}$ & 0.267 \\
\hline Doctor listens attentively while patient talks & $.002^{*}$ & 5.582 \\
\hline Doctor conducts examination in respectful manner & $.029^{*}$ & 3.363 \\
\hline
\end{tabular}

*significantly related

Table 5 shows that two items, "Doctor listens attentively while patient talks", and "Doctor conducts examination in respectful manner" were significantly related to the patients' satisfaction with doctors' communication, while the item "Doctor introduces him/herself" was inversely related with their satisfaction.

\section{Discussion}

Communication between doctor and patient is a key part of a clinical experience [33]. Discussions arise about potential differences in communication practice and expectations in different cultures [13]. When first asked about their satisfaction with the consultation, nearly all patients were either satisfied or very satisfied with both the overall consultation and the doctor's communication. Robbins et al. reported that patients are most satisfied with consultations when they talk about specific therapeutic interventions, are examined, and receive health education [34]. In our research, most patients reported being satisfied or very satisfied with both the overall consultation as well as with their doctor's communication. However, when asked about specific communication activities, fewer than $50 \%$ of them reported the doctors having performed half of the activities on the list at most. This result suggests that Vietnamese patients were perhaps easily satisfied, and/or had low expectations for the communication with the doctor. On the other hand, the result may have been influenced by putting those questions at the beginning of the face-to-face survey. If we had asked these questions at the end of the survey, after the patients had had an opportunity to review what the doctor had done and what should be done in the future, their overall satisfaction might have been lower.

The four items that less than half of the patients expected the doctor to perform were among the five items that doctors had lowest expectation of performing in future. These 
items may reflect the relatively little attention to the individual in Asian culture and the acceptance of hierarchy [18]. The patients may place themselves in a lower position than the doctors and limit their expectations. A similar result was found in Sri Lanka (a South Asian country) where less than $50 \%$ of patients expected doctors to introduce themselves and to thank the patients [9]. But there were also differences between the Sri Lankan results and the current study results. In Sri Lanka, patients also expected the doctor to decide the most appropriate treatment modality instead of discussing the available treatment options with them. They wanted precise instructions instead of explanations about the disease and the treatment [9]. This may reflect an even stronger hierarchy in Sri Lanka than in Vietnam. This is in support of the findings of Hofstede who reported that the power distance score was higher in Sri Lanka than in Vietnam [18].

Verlinde et al. [35] noted that social differences between doctors and patients could affect communication. Many still follow traditional social rules in which doctors dominate and patients remain passive [36]. Together with better communications training for doctors, increasing the patient's understanding of their partner role needs to be considered.

The variable "gender" was found to affect only one item: women reported that their doctors "greet patients" more than did men. Women may pay more attention to the greeting, or doctors may be more attentive to women. A few differences were found in satisfaction level and perception by different age groups, employment and with facility level, but expectations were similar for all groups at both facility levels.

Most patients in our quantitative study gave low priority to four communication aspects, perhaps because of cultural differences or perhaps because the study methods did not allow for probing to obtain qualitative information.

In a similar hospital-based study among patients in Yemen, patients rated the doctors' basic communication skills as good, while higher social skills like involving patients in decisionmaking were considered weak [30]. Among their patients, those above 45 were grouped as "older" and were also more accepting of the doctors' communication skills, while the younger people were more demanding, similar to the results in our study. Unlike the patients in our study, they found that gender played no significant role in the rating of doctors' skills [30].

All doctors said they needed more time for consultations. The high SD in their estimates of needed time may be related to specialty or personal speed; however, it could result from the bias of the estimates, since each doctor may have their own way of estimating the average consultation times. In any case, the average perception of the amount of time needed was significantly higher than the time allocated, indicating a time pressure that 
may force doctors to choose priorities during the consultation.

When we looked at overall patient satisfaction with the consultation or with the doctor's communication, and its relation to specific items on the communication list, it was revealed that satisfaction was significantly related to items of attentiveness and respect, but two items were notably inversely related to satisfaction. Those were "Doctors introduces him/herself" and "Doctor asks patient to repeat main issues in treatment course."

"Doctor who introduced him / her" did not seem to harm the patient in communication but if linked with the fact that all doctors said they needed more time for consultations, the patient may think that such activities could waste the valuable but limited time of the consultation especially in the condition of most of the consultation rooms have the name of the doctor and the nurse.

In contrast, because it is not easy for patients to "repeat major problems during treatment", patients may feel uncomfortable when their doctor asks them to do this. However, by doing this, doctors know for sure whether the patient understands and can remember what to do. The healthcare system must raise patient awareness about the importance of checking mutual understanding and help them get used to it.

It seems that clinicians (and patients) in Vietnam focus on clinical information and examination. However, good medical practice suggests they should maximize therapeutic effects of communication to achieve results through increasing mutual understanding and trust, associated with increased self-efficacy, adherence, social support and improved health [37]. Both doctors and patients in our study recognized a need to strengthen other aspects of communication. However, doctors and patients also agreed that four items on the Western-inspired communication model had lower priority.

The doctors in our study felt confident in their communication skills, while recognizing that they could and should improve in most of the items. The patients' expectations were less ambitious than the doctors'. An Indonesian report [14] noted that patients wanted doctors to improve their communication skills; patients' expectations about doctors' communication were very similar to those reported for Western societies. A U.S. review found that doctors and patients agreed on what constitutes competent communication with patients, but that it often did not happen as expected [37].

Implications for communication skill training in medical universities

What do these results mean for skills training in medical universities? Firstly, most activities 
on the list were considered appropriate for doctor-patient communication in Vietnam and were similarly appreciated by both doctors and patients. Also, both clearly recognized that improvements were needed. Claramita and Majoor [38] noted that although they could not detect differences in the actual practice of communication skills between doctors who had or had not been trained in a skills lab, those who had been trained were more aware of their deficiencies and the need to strengthen them.

Claramita et al. [12] considered the relevance of a Western communications approach in a Southeast Asian setting and found that not all items would be appropriate. They did find evidence of interest among patients in a more partnership-type approach. In our study, most patients gave lower priority to four items aimed at fostering the doctor-patient relation, as did most doctors. The role of the social gradient described by Verlinde et al. [35] could explain the reticence on both sides to engage in a more partnership style communication.

Claramita et al. [11] proposed a guideline for training communication skills in Southeast Asia which has similarities with our findings, such as "doctors should express equality", "invites two-way conversation", "active listening, facilitation, responding emotion, empathy". Furthermore, they emphasized the importance of checking understanding. In our study, item "Doctor asks patient to repeat main issues in treatment course", was inversely related to overall satisfaction with the consultation, but knowing the importance of this element, we have to develop ways to convince patients to become actively involved, and not to ignore that part of the consultation.

\section{Limitations}

The study was done in outpatient clinics where most patient-doctor contacts would be the first meeting. However, for each case, we do not know whether all communication items were needed, e.g., not all patients may have needed discussion about treatment methods. Some of the responses to survey items might have differed due to factors that were not included in the study, such as whether the patient knew the doctor from a previous visit, and whether these were specialty consultations or for primary care.

Because the design was a cross-sectional survey based on questionnaires, misunderstandings about terminology could lead to incorrect choice of responses. To reduce that problem, the questionnaire was developed and piloted with experts from eight universities before using it in the survey. To collect data from patients, trained research assistants read the questionnaire to each patient and recorded the results, but the doctors completed the questionnaires on their own, making undetected misunderstandings possible. To explore more deeply the expectations of doctors and patients, further studies 
should include a range of clinical specialties and qualitative research methods should be added.

Very few patients or doctors declined to participate, but those few might have had more negative experiences. Patients and doctors received payment for their time, which could create a positive bias; the amount however was very small. The study investigated communication in a Southeast Asian culture, which could have increased the positive response because of the higher desire for harmony in these cultures. To reduce such bias, participants were informed that they would remain anonymous and the research assistants emphasized that they were not hospital staff, so the patient did not need to hide any criticism.

Asking at the start of the survey about the patient's general satisfaction could have made that result more positive. If we had put these questions at the end of the survey, after having an opportunity to review in detail what the doctor did and what should be done in the future, the patient's overall satisfaction might have been lower.

Finally, it may seem a limitation that the doctors' responses are based on self-reports, which might not reliably reflect their actual performance. The intention, however, was to identify their perceptions about what a good doctor should do; we did not try to evaluate their actual performance.

\section{Conclusions}

Doctors and patients agreed that most of the activities on Western lists for training medical doctors were appropriate. Both groups had similar perceptions about what should be expected under better conditions and both gave lower priority to four skills that are considered important in a Western-style communication promoting relationship. Furthermore, the doctors had higher expectations than the patients. Training of physicians along with improving patients' understanding of their partner positions must receive attention. It will be important to convince patients to participate actively in their consultation.

The main implication for medical training in universities is that they should focus first on the key skills perceived as needing strengthening by both doctors and patients. The training can be based on Western models with minor adaptations to the local context. In the longer term, all these items should be included, to prepare for the future. If doctors for any reason must omit items during a consultation, they should choose those with lower priority.

Cultural differences affect the position of doctors and patients in doctor-patient communication but applying the partnership model could be implemented by increasing the doctors' understanding of cultural differences and by increasing patients' awareness of their partner role. 


\section{References}

1. Matusitz J, Spear J. Effective doctor-patient communication: an updated examination. Social work in public health. 2014;29(3):252-66.

2. Kurtz S, Draper J, Silverman J. Teaching and Learning Communication Skills in Medicine. 3, editor: CRC Press; 2017.

3. Belasen A, Belasen AT. Doctor-patient communication: a review and a rationale for using an assessment framework. Journal of Health Organization Management. 2018; 32(7):891-907. doi:10.1108/JHOM-10-2017-0262.

4. Norhayati MN, Masseni AA, Azlina I. Patient satisfaction with doctor-patient interaction and its association with modifiable cardiovascular risk factors among moderately-high risk patients in primary healthcare. PeerJ. 2017;5:e2983-e. doi:10.7717/peerj.2983.

5. Wang Q. Doctor-patient communication and patient satisfaction: A cross-cultural comparative study between China and the U.S. Purdure. E-Pubs: Purdue University; 2010.

6. Laidlaw TS, MacLeod H, Kaufman DM, Langille DB, Sargeant J. Implementing a communication skills programme in medical school: needs assessment and programme change. Med Educ. 2002;36(2):115-24.

7. Aspegren $\mathrm{K}$, Lonberg-Madsen $\mathrm{P}$. Which basic communication skills in medicine are learnt spontaneously and which need to be taught and trained? Med Teach. 2005;27(6):539-43. doi:10.1080/01421590500136501.

8. Makoul G, Clayman ML. An integrative model of shared decision making in medical encounters. Patient Educ Couns. 2006;60(3):301-12. doi:10.1016/i.pec.2005.06.010.

9. Mudiyanse R, Weerasinghe M, Piyasinghe GS,M, Jayasundara MK. J, M,H. Patient's Expectations during Doctor Patient Communication and Doctors Perception about Patient's Expectations in a Tertiary Care Unit in Sri Lanka. Archives of Medicine. 2015;7(6):12.

10. Moore M. What does patient-centred communication mean in Nepal? Med Educ. 2008;42(1):18-26. doi:10.1111/j.1365-2923.2007.02900.x.

11. Claramita M, Prabandair Y, van Dalen J, van der Vleuten C. Developing and validating a guideline on doctor-patient communication for Southeast Asian context. Southeast Asian Journal of Medical Education. 2010;4(2):23-30.

12. Claramita M, Nugraheni MD, van Dalen J, van der Vleuten C. Doctor-patient communication in Southeast Asia: a different culture? Adv Health Sci Educ Theory Pract. 2013;18(1):15-31. doi:10.1007/s10459-012-9352-5. 
13. Schouten BC, Meeuwesen L. Cultural differences in medical communication: a review of the literature. Patient Educ Couns. 2006;64(1-3):21-34. doi:10.1016/i.pec.2005.11.014.

14. Claramita M, Susilo AP. Improving communication skills in the Southeast Asian health care context. Perspect Med Educ. 2014;3(6):474-9. doi:10.1007/s40037-014-0121-4.

15. Street RL Jr, Gordon HS, Ward MM, Krupat E, Kravitz RL. Patient participation in medical consultations: why some patients are more involved than others. Med Care. 2005:9609.

16. Bensing J, Rimondini M, Visser A. What patients want. Patient Educ Couns. 2013;90(3):287-90. doi:10.1016/i.pec.2013.01.005.

17. Hofstede G. Country Comparison - Hofstede Insights (2018). https://www.hofstedeinsights.com/country-comparison/. Accessed 28 April 2018.

18. Hofstede G. What about Vietnam?- Country Comparison - Hofstede Insights (2018). https://www.hofstede-insights.com/country-comparison/vietnam/. Accessed 28 April 2018.

19. Claramita M, Utarini A, Soebono H, Van Dalen J, Van der Vleuten C. Doctor-patient communication in a Southeast Asian setting: the conflict between ideal and reality. Advances in health sciences education: theory practice. 2011;16(1):69-80. doi:10.1007/s10459-010-9242-7.

20. Nguyen D. Culture shock-a review of Vietnamese culture and its concepts of health and disease. The Western journal of medicine. 1985;142(3):409-12.

21. Ministry of Health, Decision on approval for document about competence standards for general practitioners, Ministry of Health, Vietnam. 2015,

https://vanbanphapluat.co/decision-no-1854-qd-byt-2015-document-aboutcompetence-standards-for-general-practitioners, Accessed 9 February 2018.

22. Ministry of Health, Regulations on communication in medical examination and treatment facilities, Ministry of Health, Vietnam. 2001, https://thukyluat.vn/vb/quyetdinh-4031-2001-qd-byt-che-do-giao-tiep-trong-cac-co-so-kham-chua-benh$15 \mathrm{cf6} 6 . \mathrm{html}$, Accessed 24 January 2018.

23. Kersnik J. An evaluation of patient satisfaction with family practice care in Slovenia. Int J Qual Health Care J Int Soc Qual Health Care ISQua. 2000;12(2):143-7.

doi:10.1093/intahc/12.2.143.

24. Sebo P, Herrmann FR, Bovier P, Haller DM. What are patients' expectations about the organization of their primary care physicians' practices? BMC Health Services Research. 2015;15(1):328. doi:10.1186/s12913-015-0985-y. 
25. Fan VS, Burman M, McDonell MB, Fihn SD. Continuity of care and other determinants of patient satisfaction with primary care. J Gen Intern Med. 2005;20(3):226-33. doi:10.1111/i.1525-1497.2005.40135.x.

26. Abadel FT, Hattab AS. Patients' assessment of professionalism and communication skills of medical graduates. BMC Med Educ. 2014;14(1):28. doi:10.1186/1472-6920-14-28.

27. Silverman J, Kurtz S, Draper J. Skills in Communicating with Patients: CRC Press 2013.

28. Van Thiel J, van Dalen j, Ram P. MAAS Global Manual 2000: Maastricht University Press 2003.

29. Deledda G, Moretti F, Rimondini M, Zimmermann C. How patients want their doctor to communicate. A literature review on primary care patients' perspective. Patient Educ Couns. 2013;90(3):297-306.

30. Robbins JA, Bertakis KD, Helms LJ, Azari R, Callahan EJ, Creten D. The influence of physician practice behaviors on patient satisfaction. Fam Med. 1993;25:17-.

31. Verlinde E, De Laender N, De Maesschalck S, Deveugele M, Willems S. The social gradient in doctor-patient communication. Int J Equity Health. 2012;11:12. doi:10.1186/1475-9276-11-12.

32. Managing the Power Dynamic Between Doctors and Patients Esposito L. Managing the Power Dynamic Between Doctors and Patients (2014). https://health.usnews.com/health-news/patientadvice/articles/2014/05/13/managing-the-power-dynamic-between-doctors-andpatients. Accessed 28 April 2018.

33. Street RL Jr, Makoul G, Arora NK, Epstein RM. How does communication heal? Pathways linking clinician-patient communication to health outcomes. Patient Educ Couns. 2009;74(3):295-301. doi:10.1016/i.pec.2008.11.015.

34. Cegala DJ, Gade C, Lenzmeier Broz S, McClure L. Physicians' and patients' perceptions of patients' communication competence in a primary care medical interview. Health Commun. 2004;16(3):289-304. doi:10.1207/s15327027hc1603 2.

35. Claramita M, Majoor G. Comparison of communication skills in medical residents with and without undergraduate communication skills training as provided by the Faculty of Medicine of Gadjah Mada University. Educ Health (Abingdon). 2006;19(3):308-20. doi:10.1080/13576280600937887. 


\section{Chapter 5}

\section{Teacher-made models: the answer for medical skills training in developing countries?}

A full text version was published as:

T.Q. Tran, A. Scherpbier, J. Van Dalen, P.E. Wright, Teacher-made models: the answer for medical skills training in developing countries?, BMC Medical Education 12 (2012) 98 


\section{Abstract}

\section{Background}

The advantages of using simulators in skills training are generally recognized, but simulators are often too expensive for medical schools in developing countries. Cheaper locally-made models (or part-task trainers) could be the answer, especially when teachers are involved in design and production (teacher-made models, TM).

\section{Methods}

We evaluated the effectiveness of a TM in training and assessing intravenous injection skills in comparison to an available commercial model (CM) in a randomized, blind, pretestposttest study with 144 undergraduate nursing students. All students were assessed on both the TM and the $\mathrm{CM}$ in the pre-test and post-test. After the post-test the students were also assessed while performing the skill on real patients.

\section{Results}

Differences in the mean scores pre- and post-test were marked in all groups. Training with TM or CM improved student scores substantially but there was no significant difference in mean scores whether students had practiced on TM or CM. Students who practiced on TM performed better on communication with the patient than did students who practiced on $\mathrm{CM}$. Decreasing the ratio of students per TM model helped to increase practice opportunities but did not improve student's mean scores. The result of the assessment on both the TM and the CM had a low correlation with the results of the assessment on real persons.

\section{Conclusions}

The TM appears to be an effective alternative to CM for training students on basic IV skills, as students showed similar increases in performance scores after training on models that cost considerably less than commercially available models. These models could be produced using locally available materials in most countries, including those with limited resources to invest in medical education and skills laboratories. 


\section{Background}

Medical simulators are revolutionizing training for the practice of medicine [ $\underline{1}-\underline{5}]$. Currently [2] thousands of schools around the world are using simulators for hands-on health care education to medical, nursing, and allied health students. Skills laboratories (Skillslabs) have been successfully developed in resource-rich countries [ $\underline{1}, \underline{6}-\underline{10}]$. These Skillslabs vary in the accommodation provided and the resources available from one room with one manikin to purpose-built structures with a vast assortment of equipment $[\underline{6}, \underline{7}, \underline{11}, \underline{12}]$. In Japan, students must pass the Common Achievement Test, which includes an objective structured clinical examination, before starting their clinical education. Many medical schools have been under pressure to provide clinical skills laboratories for their students. A range of simulators are used in skills laboratories [?]].

Using simulation, medical students can safely learn, practice, and repeat a skill or procedure over and over until proficiency is achieved, without touching a real patient. They can improve their skills and confidence without compromising patient safety $[\underline{6}, \underline{7}, \underline{11}, \underline{12}]$. But it is not always appropriate to transfer this model to medical and healthcare schools in developing countries, because the capital and maintenance costs may far exceed local budgets [13]. The equipment and manikins are very expensive, especially the more sophisticated types. Japanese medical colleges invested up to 600,000 USD for the necessary equipment of a clinical skills laboratory [7]. Once set up and equipped, the maintenance and running cost may prove prohibitive in the long term, so that the equipment cannot be repaired or maintained [13]. Moreover, even the expensive models have limited validity. For example, they do not help to prepare students for communication with their patients during procedures.

In Vietnam, we have obtained financial support from the Dutch Government and World Bank for setting up skills laboratories in most of the medical schools, but the sustainability of these skills laboratories is still a challenge. The school fee is only about 300 USD per year per student, and university funds are insufficient to buy more simulation models to replace broken ones. One solution for sustainability is to make the models ourselves. We established a unit for learning material research and development, whose main role is to motivate and support teachers to design and produce learning materials (including skills training models, or part-task trainers) using appropriate techniques and locally available resources. There are only teachers and support staff in the unit; no "special experts" are involved.

One of the very first teacher made models was a simple model for training and assessing intravenous (IV) injection procedure. We started with this model because intravenous injection is an invasive procedure and the commercial model soon breaks down. Moreover, 
we could make this model simply and cheaply (5 USD compared to 300-400 USD for a commercial IV model) and it will last longer because of its structure. These teacher-made models (TM) helped us not only in replacing the broken commercial models but also in increasing the number of models available for our students to use for practice in their training sessions. Custer et al. found that increasing the number of performances tended to increase the quality and speed of the performance [14]. By supplying more models, we expected that our students would have more opportunities for practicing and that the quality of skills training would therefore improve.

Furthermore, clinical skills include more than just the procedure. Patient-based simulation has enormous potential as learning tool, and can provide insight into the subtleties and complexities that characterize clinical practice [2]. Because our TM for IV injection is attached to a simulated patient's arm, we hoped that it could also help students learn to communicate better with the patient.

Even an inexpensive model will be too expensive and wasteful if it does not function well in training and assessment. Therefore, we investigated whether there were differences in effectiveness of using teacher made models compared to the commercially available models in our university in training and assessing students on the skill "intravenous injection".

Sub question 1: Do students reach similar levels of technical skill when trained on TM compared to $\mathrm{CM}$ ?

Sub question 2: Do students communicate better with patients when trained on TM compared to $\mathrm{CM}$ ?

Sub question 3: Do students reach a higher level of technical skills level when trained more often with TM?

To answer these questions, we conducted an experimental study to compare the results of skills assessment on three groups of students who practiced with CM, with TM or with an increased number of TM.

\section{Methods}

\section{Setting}

This study was conducted at the Faculty of Nursing and Medical Technology, University of Medicine and Pharmacy at Ho Chi Minh City (UMP HCMC), the largest health university in Vietnam. Before practicing the skill on models, all students had studied the related theory. Normally one teacher and one teaching assistant train 20-25 students during 50 minute 
sessions working with three models for intravenous injection in the arm. The Commercial Models (CM) used in this study were new plastic arms for intravenous injection training available at our university (Intravenous Training Arm, 300-400 USD, supplied by Gaumard Scientific Company, USA).

The teacher made model (TM) or part-task trainer used in this study was developed by teachers of the Skills Lab at UMP HCMC and had been tested and improved over a period of time. The TM for IV injection is a hand-made silicone bandage which has one vein, a thin protection under the vein and a blood container. The vein can be seen and palpated on the silicone "skin" surface. The model is wrapped around the forearm of a simulated patient (SP) for practicing IV placement, injection of fluids, and drawing of blood. In this study, students following the same course in IV injection played the role of simulated patients (SP). No extra training was given to these peer SP because the scenario was very simple: the student SP only had to respond to the greeting (if any) and give their name. The students practicing had to check whether they had the right client then inform and explain the steps of the procedure to the patient.

Based on our experience with the TM, our hypothesis was that there would be no difference in effectiveness between using $\mathrm{TM}$ and $\mathrm{CM}$ in training and assessment of intravenous injection practice. With the advantages of very low cost and making them ourselves, we could supply more TM for the students, thus giving students more opportunities for practice and hopefully leading to better performance. Because the TM was attached to a person, we expected that students would learn better to communicate with the patient during training on TM compared to the separate inanimate arm of the CM.

\section{Research design}

The study was set up to compare the effectiveness of the teacher made model (TM) with the available commercial model (CM) in two different training situations: using the same ratio of students per model and using different ratios of students per model. We tried to make the research fit within the routine training and assessment program. Participants: The participants in this study were the students and teachers who normally participate in training and assessing these skills. They were not recruited especially for the study; instead the study was carried out during the normal training program. The student participants were all of the 144 first year students in the primary program of nursing who were going to be trained in IV procedure. The students were divided into three groups in the order of their normal classes; the groups were comparable in age, gender and learning achievements. All of the students learned the theory together, and were trained in the skills laboratory using the same lesson plan. The same group of teachers and teaching conditions and the same group of raters for all assessments were applied under the same conditions. 


\section{Chapter 5}

The only difference in the training of the three groups was the simulation model:

Group 1 used the available commercial model with the ratio of 8 students per model;

Group 2 used the teacher made model with the ratio of 8 students per model;

Group 3 used the teacher made model with the ratio of 2 students per model.

\section{Three-step assessment process}

Students were assessed three times in the training process, using the same assessment procedure and rating scale each time. The reliability and validity of the tools had been evaluated. Pre-practice assessment was designed to provide a "baseline" of the student's competency before practicing on the models and to check if the IV injection procedure really needs to be trained using a model. Post- practice assessment served to check direct effects of training on the model and assessment with real patient was to check the effect on practice in the real clinical situation.

\section{Pre-practice assessment}

Before practicing on models, students were assessed on performance of the IV procedure on the model they were going to practice with (group 1 with CM, groups 2 and 3 with TM).

\section{Post-practice assessment}

After practicing on models, students were assessed on their performance of the IV procedure on two different kinds of model, first on the model they had used in practice (group 1 with $\mathrm{CM}$, groups 2 and 3 with TM) and later, on the other model. Because each assessment could also be considered as a practice opportunity, we designed the study such that students were assessed with the model used in practice first and then with the other model, giving the TM and CM the same opportunity to contribute to skill-building during assessment.

\section{Assessment with real patient}

When the students went to the hospital for practicing on real patients, they were evaluated while performing the intravenous injection on their first real patient, under supervision of the teacher.

\section{Objective assessment}

All of the assessments used the same assessment tools, which had been validated in national assessments. The raters (observers) were trained until the inter-rater reliability reached 0.8. Raters were the same for all groups of students and were blinded: the raters did not know which students had belonged to which study group. The rating scale had five 
points ( $0=$ does not do, $1=$ Poor; $2=$ Fair; $3=$ Good; $4=$ Excellent $)$ and included 15 items related to the IV procedure and 1 item on interaction. The maximum score for the 15 items was 60 .

The teachers who developed the TM did not participate in the student assessment, and the teachers who did student assessment did not know on which models the students had been trained. Although bias because of teachers wishing to promote the TM would have been possible it was avoided in this study (Table 1).

Table 1 Summary of the research design

\begin{tabular}{lllll}
\hline $\begin{array}{l}\text { Group } \\
\text { in training }\end{array}$ & \begin{tabular}{l} 
Model used \\
\cline { 3 - 5 }
\end{tabular} & $\begin{array}{l}\text { Models used in assessment } \\
\text { assessment }\end{array}$ & $\begin{array}{l}\text { Post-practice } \\
\text { assessment }\end{array}$ & $\begin{array}{l}\text { First real } \\
\text { patient } \\
\text { assessment }\end{array}$ \\
\hline 1 & 8 students/CM & $\begin{array}{l}\text { Commercial } \\
\text { model }\end{array}$ & $\begin{array}{l}\text { commercial model then } \\
\text { teacher-made model }\end{array}$ & real patient \\
\hline 2 & 8 students/TM & $\begin{array}{l}\text { teacher-made } \\
\text { model }\end{array}$ & $\begin{array}{l}\text { teacher-made then } \\
\text { commercial model }\end{array}$ & real patient \\
\hline 3 & 2 students/TM & $\begin{array}{l}\text { teacher-made } \\
\text { model }\end{array}$ & $\begin{array}{l}\text { teacher-made then } \\
\text { commercial model }\end{array}$ & real patient \\
\hline
\end{tabular}

\section{Ethical approval}

Ethical approval was not required for this study, which was carried out as part of the regular training of the students in the University. However, approval of the project including ethical aspects was provided by the Ho Chi Minh City University of Medicine and Pharmacy. In Vietnam, after training in a Skillslab, students practice in teaching hospitals under supervision by teachers. The students tested for this study were carrying out their normal practice supervised by teachers. The only difference was that the teachers marked the students with the same rating scale as used in the Skillslab. Before practice on patients, students asked patients' consent verbally. When patients come to teaching hospitals, they normally agree to allow students to practice, under supervision by the teachers.

\section{Statistical analysis}

Data analysis was performed using SPSS 13.0. One-way ANOVA and paired-samples tests were used. The level of significance for all comparisons was set at $P<0.05$. In the tables showing results, the significant differences are marked, and the $95 \%$ confidence intervals given. 


\section{Results}

\section{Results of pre-practice assessment}

One way-ANOVA analysis of the results of the pre-practice assessment showed no significant differences in performance scores among the students in the three groups

\section{Results of post-practice assessment using CM}

A paired-samples test comparing the results of the post-practice assessment using CM with pre-practice assessment showed that the performance of the students in all three groups increased significantly in all items of the IV procedure after the described practice sessions.

There was no significant difference in the mean score of students in group 1 (trained on $\mathrm{CM}$ ) compared with groups 2 and 3 (trained on TM). Comparing groups 2 and 3 , only for item 4 (Select the right injection site) was the mean score of group 3 (practiced more often on TM) significantly higher than that of group 2 (practiced less often on TM)

Groups 1, 2 and 3 were trained and assessed in the same conditions, except for the number of models used in practice sessions. Table 2 shows that by decreasing the student/model ratio from 8 to 2 , the mean number of practice times did differ significantly (Table 2).

Table 2 Number of times practiced on model

\begin{tabular}{llccccc}
\hline UP & & N & Minimum & Maximum & Mean & Std. Deviation \\
\hline 1 & 8 Students/1 CM & 49 & 1 & 2 & 1.14 & .35 \\
\hline 2 & 8 Students/1 TM & 48 & 1 & 2 & 1.04 & .20 \\
\hline 3 & 2 Students/1 TM & 47 & 2 & 6 & $3.77^{*}$ & 1.10 \\
\hline
\end{tabular}

* Significantly different from groups 1 and 2, $p<0.05$.

\section{Results of post-practice assessment using TM}

The results of the post-practice assessment using TM showed no significant differences in mean scores of students in groups 1 and 2 . Comparing groups 1 and 3 , the only significant difference was in item 3 (Check the right client with the physician's order, prepare patient) where group 3 performed better than group 1. Comparing groups 2 and 3 , only for item 2 (Prepare medication) was the mean score of students in group 2 significantly higher than in group 3.

\section{Results of assessment of performance on real patients}


Assessment of students' performance when carrying out the IV procedures on their first real patient revealed no significant differences in mean scores in most the items of the IV procedure. The exceptions were for item 3 (Check the right client with the physician's order, prepare patient) where groups 2 and 3 performed better than group 1 and for item 12 (Check the right position of the needle) where group 3 performed better than group 2 .

\section{Result of the assessment using TM, CM or real persons}

For the TM, the correlation between performance scores on models and on real patients was only significant for 10 of the 15 items, and the correlation for these items was low (ranging from .175 to .341). For the CM, the correlation was significant in 13 of the 15 items; correlation of these items was also low (from .176 to .466).

Differences of the three groups in assessment results

$\begin{array}{lllllll}0 & 10 & 20 & 30 & 40 & 50 & 60\end{array}$

Figure 1: Means of the total scores in the three assessments of 3 groups, where 60 is the maximum score (4/4 points on 15 items).

In Figure 1, the results are summarized. There was no significant difference in mean scores between students who practiced on TM (group 2) and students who practiced on CM (group 1) in the post-practice assessment. That result was the same whether CM or TM was used in a post-practice assessment. In assessment of the skill performance on a real patient, the results were quite comparable. Only on Item 3 (Check the right client with the physician's order, prepare patient) which is related to communication with the patient, did groups who had practiced on TM (groups 2 and 3) perform better than group 1, who practiced only on CM.

\section{Discussion}

The results of this study suggest that TM were at least equal to $\mathrm{CM}$ in providing the opportunity for students to acquire the expected IV procedure skills. The cost of CM models for schools in developing countries may be too high; the initial investment may already far exceed local budgets, and maintenance is equally important [13]. Students who practiced on the TM model outperformed their classmates who practiced on the CM on one key item related to communication skills. The TM was bandaged on the arm of a simulated patient, which encourages the student to pay attention to the person, not only the arm, and provides opportunity for the communication with the patient. This result fits with the recent attention to the benefits of attaching models to human beings to provide a more realistic experience while learning technical skills $[15,16]$. 
In Group 3, we tried to maximize the number of TM for students. As a result, the number of times that students practiced the skill increased significantly. This implies that if students are given more practice opportunities, they will use them. However, the results of their assessments were not significantly different in most of the items. This result is not consistent with the common idea of "practice makes perfect" nor with the results reported by Custers et al. [14], suggesting that increasing the number of times of practice will increase students' competence. We provided enough models so that instead of eight students per model we had only two. That meant that one student had the model bandaged to his arm while the other performed the procedure. In each of these training sessions there were 24 students with one teacher, one teaching assistant and twelve (instead of three) models. That meant that twelve students practiced simultaneously, making good supervision and feedback by the two teachers more difficult. In addition, when one student wears the model and one practices, there are no other students to use the observer checklists and provide peer feedback. If the students in Group 3 made errors, were not corrected and repeated them through practice, they may have become proficient not only in good practice but also in bad practice [17]. This is an undesirable side-effect of the teacher-student ratio. A ratio of 3 or 4 students/model might have been better, to provide peer observers during practice. Another explanation could be that although group 3 students had more chance to practice, students in groups 1 and 2 had more chances to observe which is also a good way to learn [14]. The best balance between observation and practice and therefore the optimal student/model ratio for each training condition should be investigated in further research.

The low correlation between the results of assessments on models and on real persons could arise from the differences between models (TM or CM) and real persons, but it could also arise from the limited stability of the students' performance. When we validate the result of an assessment by comparing it with the result of another assessment, we assume that the competence shown by the students will be consistent. To validate these comparisons, it would be useful to study different subjects with different levels of competence.

The relatively small sample size is a limitation of this study, and we cannot be sure that the results on this teacher-made model will apply to other TM. We have not yet investigated what the students thought and felt when learning using the different models. There is scope for further research into these questions.

\section{Conclusions}

The TM appears to be an effective and appropriate alternative to $\mathrm{CM}$ for training on basic IV skills, as students showed a similar increase in performance while being trained on models that cost considerably less than the commercially available models. This is 
especially important in settings with limited resources such as developing countries but may also be useful in developed countries. Because this TM is attached to a simulated patient, it may provide an extra benefit, increasing the learning on communication with patients while carrying out the procedure. Increasing the number of models without changing other aspects of the training setting did not improve the results of student assessment. The effectiveness of using TM or CM in assessment for predicting the students' performance on real patients remains a question.

\section{Abbreviations}

TM: Teacher made model

CM: Commercial model

IV: Intravenous injection. 


\section{References}

1. Hao J, Estrada J, Tropez-Sims S: The Clinical Skills Laboratory: a cost effective venue for teaching clinical skills to third year medical students. Acad Med. 2002, 77 (2): 15210.1097/00001888-200202000-00012.

2. Kneebone R, Nestel D: Learning clinical skills - the place of simulation and feedback. Clin Teach. 2005, 2 (2): 86-90. 10.1111/j.1743-498X.2005.00042.x.

3. Weller J, Robinson B, Larsen $P$, Caldwell C: Simulation-based training to improve acute care skills in medical undergraduates. N Z Med J. 2004, 117 (1204): U1119.

4. Paparella SF, Mariani BA, Layton K, Carpenter AM: Patient safety simulation: learning about safety never seemed more fun. J Nurses Staff Dev. 2004, 20 (6): 247-252. 10.1097/00124645-200411000-00001.

5. Kneebone R: Simulation in surgical training: Educational issues and practical implications. Medical Education. 2003, 37 (3): 267-277. 10.1046/j.13652923.2003.01440.x.

6. Dent JA: Current trends and future implications in the developing role of clinical skills centres. Medical Teacher. 2001, 23 (5): 483-489.

7. Kozu T: Medical Education in Japan. Acad Med. 2006, 81 (12): 1069-1075. 10.1097/01.ACM.0000246682.45610.dd.

8. Bligh J: Clinical skills unit. Postgrad Med J. 1995, 71 (842): 730-732. 10.1136/pgmj.71.842.730.

9. Bradley $P$, Postiethwaite $K$ : Setting up and running clinical skills learning programmes. Clin Teach. 2004, 1 (2): 53-58. 10.1111/j.1743-498X.2004.00039.x.

10. Peeraer G, Scherpbier A, Remmen R, Winter BD, Hendrickx K, Petegem PV, Weyler J, Bossaert L: Clinical skills training in a skills lab compared with skills training in internships: comparison of skills development curricula. Educ Heal. 2007, 20 (3): 1-9.

11. Sierra R, Bajka M, Székely G: Tumor growth models to generate pathologies for surgical training simulators. Medical Image Analysis. 2006, 10 (3): 305-316. 10.1016/j.media.2005.11.004.

12. Davies RJ, Hamdorf JM: Surgical skills training and the role of skills centres. British Journal of Urology International. 2003, 91 (1): 3-4. 10.1046/j.1464-410X.2003.04002.x.

13. Stark P, Fortune F: Teaching clinical skills in developing countries: Are clinical skills centres the answer?. Educ Heal. 2003, 16 (3): 298-306.

10.1080/13576280310001607433. 
14. Custer EJFM, Regehr G, McCulloch W, Peniston C, Reznick R: The effects of Modeling on learning a simple surgical procedure: See one, do one or see many, do one?. Adv Heal Sci Educ. 1999, 4 (2): 123-143. 10.1023/A:1009763210212.

15. Moulton C-a, Tabak D, Kneebone R, Nestel D, MacRae H, LeBlanc VR: Teaching communication skills using the integrated procedural performance instrument (IPPI): $A$ randomized controlled trial. Am J Surg. 2009, 197 (1): 113-118. 10.1016/j.amjsurg.2008.09.006.

16. Kneebone R, Nestel D, Yadollahi F, Brown R, Nolan C, Durack J, Brenton H, Moulton C, Archer J, Darzi A: Assessing procedural skills in context: Exploring the feasibility of an Integrated Procedural Performance Instrument (IPPI). Medical Education. 2006, 40 (11): 1105-1114. 10.1111/j.1365-2929.2006.02612.x.

17. David E, Manthey P: The Ideal Curriculum. Medical Student Educators' Handbook. Edited by: Robert L, Rogers SM. 2010, 15-24. 


\section{Chapter 6}

Discussion 
In 2004 a project funded by the Government of the Netherlands was initiated, aiming to set up and implement a medical skills training program in the form of Skillslabs in medical schools throughout Vietnam [1]. The project involved all eight of the publicly-funded and non-military medical faculties and universities in Vietnam at that time. It provided an excellent opportunity for innovative skills training in Vietnam. The technical support was provided by Maastricht University in the Netherlands, where the Skillslab approach originated.

In the Skillslab approach, clinical skills are trained in the safe environment of the laboratory, prior to learning in the hospital setting with real patients. Students can acquire the necessary skills at their own pace [2]. By using Skillslab training, medical students can safely learn, practice, and repeat the skill or procedure over and over until basic proficiency is achieved before they touch a real patient. This will help to improve their skills and confidence in their further training, without compromising patient safety [3-5]. Skillslabs have been introduced and developed in many medical schools, albeit mostly in industrialized countries $[\underline{4}, \underline{6}, \underline{7}]$. However, it is not always appropriate to transfer a model directly from high-income countries to medical and healthcare schools in low-income countries, as the capital cost and maintenance may be more than local budgets can afford [8]. Cultural differences [9] may also influence the most suitable content of the training in a different setting [10].

Setting up and implementing medical skills training laboratories following the Skillslab approach as standard for a whole country requires considerable effort and investment, especially where resources are limited. However, it also brings a lot of advantages:

$>$ The involvement and leadership of the Ministry of Health and the Ministry of Education and Training ensured that the program was consistent with government-backed policies and had strong commitment from university leaders.

$>$ Since Vietnamese universities must follow the national curriculum with only minor revisions based on the local needs, a major educational innovation such as strengthening skills training using the Skillslab approach can only be successful when undertaken collectively in conjunction with a national curriculum reform.

$>$ Chances of external financing are higher when donors recognize that the authorities support the program and commit to sustaining it in future.

$>$ Staff training can be organized alternately in each of the participating institutions so that every institution will have trained staff, who could participate in all activities. This also provides an opportunity to get the attention of other staffs and students at each site, which helps to create a good environment for setting up and implementing skills training.

$>$ Scale efficiency can be realized when a substantial number of staff members participate 
in a health professions education program that was specifically targeted to the field of skills training. In fact, sixteen Vietnamese project members (two per university) took part in a tailor-made, Vietnamese version of the Master of Health Professions Education -program at Maastricht University.

Two universities that were already using Skills labs because of previous collaboration with Maastricht when this project started could continue to develop a full skills training program. Their success as well as their difficulties could serve as lessons for other Skillslabs. Experts from the eight universities could collaborate and assist each other, thus sharing the workload in developing a national list of basic skills to be trained in Skillslabs, as well as a "Basic Medical Skills Manual," video films on skills training, direct observation assessment tools, and appropriate models.

The stronger local Skillslabs could be good examples for those still working on development of their skills training, because the differences between universities in the same country may not be as significant as the difference between universities in developed and developing countries. Success, or any improvement of any one Skillslab in Vietnam could motivate the others, as they see it in practice and want to have the same advantages in their school.

The experience of making their own models from locally available materials and to suit the needs identified by the teachers not only addresses the financial limitations faced by universities in low- and middle-income countries, but also provided extra training benefits.

In the context of the program to set up and implement medical skills training laboratories following the Skillslab approach in Vietnam, the research in this thesis aimed to:

1) identify which skills need to be trained in the Skillslab approach,

2) find out whether these skills could all be trained effectively under actual conditions of limited resources, and

3) evaluate specific aspects of using the Skillslab approach in the conditions of Vietnam: quality of locally made models and adapting a communication model used in Western countries.

The results of these studies could help Vietnamese and other universities to have the most appropriate and sustainable skills training programs.

\section{Our findings}

With the technical assistance of experts from Maastricht University, a Vietnamese national expert panel used group discussion and a Delphi process to draw up a national list of 56 basic skills. In this thesis, we validated the national list of basic skills by combining self- 
reporting by GPs with student observations of their practice. Most of the students observed GPs performing all of the skills. However, the research revealed that some of the skills on the national list were used by only a small number of GPs. The proportion of GPs using a specific skill depends not only on the skill but also on the location and setting of the practice. GPs practicing in more remote areas used certain skills more often than did those in the large cities. The highest rate of use of these skills was in the more remote provinces, where GPs may have to deal with more types of patients, having less opportunity to refer them to more specialized doctors. GPs who practiced in city/provincial general hospitals tended to leave these skills for a specialist to perform, more than did GPs at district level. GPs in all locations, as well as students, suggested a long list of additional skills that were used regularly. This list is valuable for the course organizers and trainers to consider how to address training in these necessary skills.

Based on the results of the validation and self-evaluation of the capacity to provide Skillslab training, the core team in each university selected a list of prioritized skills (from the national list) to be trained in their Skillslabs. After five years of establishment and implementation, one university trained all of the 56 skills on the national list, while four trained two-thirds to three-quarters of them, and three Skillslabs trained fewer than $40 \%$ of the 56 basic skills.

Reviewing the results of post-course feedback from students and from focus group discussions with trainers, we learned that the quantity and quality of training aids was perceived to be insufficient; some models/manikins were inappropriate for training; more consideration was needed in framing the expected requirements of students within each skill; too little time was allocated for the training of one of the eight skills investigated; and further curriculum development is needed to better integrate the skills training program into the broader curriculum.

The competency standards for general practitioners [11], and regulations on communication from the Ministry of Health in Vietnam, reflect the partnership model in doctor-patient communication [12] . However, before such a Western model is applied in Asian countries, it may need adaptations.

To identify the essential items in communication with patients that doctors should perform during a consultation, the experience and expectations of patients exiting a clinical encounter and of doctors about their own practice/skill in communication throughout Vietnam were investigated.

The results showed that most of the doctors were willing to perform all of the activities in the list of activities in doctor-patient communication reflecting partnership model. However, doctors and patients also agreed that four items had a lower priority. All four items related to fostering the relationship 
When we looked at overall patient satisfaction with the consultation as a whole, and with the doctor's communication in detail, and their relation to specific items on the communication list, it was revealed that satisfaction was significantly related to items of attentiveness and respect, but two items were notably inversely related to satisfaction: "Doctors introduces him/herself" and "Doctor asks patient to repeat main issues in treatment course". These clearly had lower priority for patients in the clinics in Vietnam.

Locally produced training materials are likely to be less expensive than commercial models, especially locally produced models developed by the teacher. Teachers who conduct Skillslab training know what features a specific training model should have and what features could be reduced in a compromise to be cost-effective. Consequently, we could increase the number of models available for each training session, thereby increasing the practicing opportunities for the students. However, even an inexpensive model will be too expensive and wasteful if it does not function well in training and assessment. Therefore, we investigated whether there were differences in the effectiveness of using locally produced, teacher-made models compared to commercially available models in training and assessing students.

The results of this study suggest that the teacher-made model was at least equal to the available commercial model in providing the opportunity for students to acquire the expected intravenous injection procedure skills. Students who practiced on the teachermade model outperformed their classmates who practiced on the available commercial model on one key item related to communication skills.

Through maximizing the number of teacher-made models for students, the number of times that students practiced the skill increased significantly. However, the results of their assessments were not significantly different in most of the items.

\section{Discussion of findings}

The results of our study demonstrate that the list prepared by the experts did not fit exactly with the everyday practice of medical skills. This finding re-emphasizes the role of other stakeholders in determining what is needed in training for medical practice [13-15].

Validation of the list of needed skills showed that most of the students observed GPs performing all of listed skills, while certain skills in the expert list were used by only a small number of GPs. If the medical schools would decide to refrain from training in such skills, not all patients would be served. Yet, it would be not a good way of using very limited resources to train skills that very few GPs will use in practice. The highest rate of use of such skills were found in the more remote provinces, where GPs may have to deal with more types of patients, having less opportunity to refer them to more specialized doctors. With the increasing number of GPs in hospitals at all levels, they appeared to be tending to specialize in selected areas. We, therefore, recommend that in parallel with the existing 
national GP training program, which is based on national needs, medical faculties consider developing a "specialty-oriented" training program, in which students may choose to have specialty-oriented skills training. This could be done intensively in the last semester of the training program; skills not directly related to their orientation specialty could be optional. Another approach could be to address the skills which are relevant for a limited number of doctors in an optional skills training program.

The fact that one university could train all 56 skills (while other Skillslabs so far only managed to train fewer than $100 \%$ of the basic skills) suggests that using a Skillslab to train the entire national list of basic skills is indeed possible in this country.

Resource priority choices may be one reason for the low proportion of recommended skills being taught in some schools. This interpretation is supported by the students' opinion that the number of training aids available even in one of the largest medical universities was insufficient to meet their learning requirements.

Thorough reviewing the results of assessment in the Skillslab, feedback from students, and focus group discussions among trainers could all help to identify not only the weaknesses of training but also ways to overcome the weaknesses. The biggest obstacle recognized by students and trainers was the limited quantity and quality of training aids.

Four main issues were identified to improve the contribution of the Skillslab to the training of medical students: 1) integration of the Skillslab training program into the existing curriculum, 2) increasing the time allocated for training certain skills, 3) ensuring that models/manikins were appropriate for the training, and 4) reconsidering the requirements for each specific skill in the skill assessment. Further efforts are needed if the medical schools in Vietnam are to make the best use of the Skillslabs to improve the quality of their graduates.

The teacher-made model studied in this thesis was a hand-made "skin like" silicone bandage which has one vein, a thin protection under the vein and a blood container. The vein can be seen and palpated on the silicone "skin" surface. The model is wrapped around the forearm of a simulated patient for practicing intravenous placement, injection of fluids, and drawing of blood. This set-up encourages the student to pay attention to the whole person, with their emotions, instead of only the arm, as is often the case with commercial models of an arm prepared for learning injection skills. It thus provides ample opportunity for the key communication with the patient while inserting the intravenous drip.

The companies producing the available commercial models seem unable, for technical and/or economic reasons, to be able to change the models' features to meet the medical/educational needs of a specific group of trainees or even a large group. Teachermade models in contrast are handmade at room temperature and pressure, so that it is relatively easy to change the shape, size, detail, color, thickness, softness, density or other features, as required by the teacher. Recently, 3D printers have become more affordable, 
so they can also be used to design prototypes of models. However, craft by hand is still a relatively inexpensive way to produce teacher-made models, at least in developing countries. The teacher-made model is flexible in adapting to specific training needs (such as the communication skill accompanying intravenous injection, in this study). Moreover, the teacher-made models not only help to address the economic limitations for developing countries, but also bring extra medical/educational benefits. This result fits with the recent attention to the benefits of attaching models to human beings to provide a more realistic experience while learning technical skills $[\underline{16}, \underline{17}]$.

Teacher-made models could be the answer for skills training in developing countries, but the sustainability of the teacher-made models also needs to be considered. The universities should have an appropriate policy to motivate teachers to participate in the design, production, improvement and use of teacher-made models. Furthermore, the research described here does not prove that all teacher-made models could be comparable with available commercial models. Every new teacher-made model needs to be critically evaluated. Using only teacher-made models could possibly limit the effectiveness of Skillslab training. There have been other reports of making and using local models, but evidence about their effectiveness in training was not reported [18] [19].

To facilitate the use of teacher-made models, the University of Medicine and Pharmacy at HoChiMinh City, Vietnam, established the Training Materials Center to develop, produce, and maintain training models, which are tailor-made for specific training needs. This center has so far produced more than 40 types of teacher-made models and equipment that are being used in skills training and assessment [20]. These products are provided not only to the eight universities participating in the project, but also to a number of newly-opened universities and colleges, and to hospitals.

By increasing the number of the teacher-made models for students, the number of times that students practiced the skill could be significantly increased. However, the results of assessments, as we reported, were not significantly different between students whose practice opportunities differed, on most of the items on the assessment checklist. This result is not consistent with the common idea of "practice makes perfect" nor with the results reported by Custers et al.[21], which suggested that increasing the number of times of practice will increase students' competence. In Custers' research students who watched either one or four models had similar performance and performed better than students who did not watch any model showing this skill quite simply. For simple skill, student rarely made mistake, increase the number of times of practice will increase the quality and speed of performing.

In our research, the standard training had supervision and feedback. Increasing number of teacher-made models, without adequate supervision, could easily lead to uncorrected errors and a false sense of competence and security [22]. Care must therefore be taken that a teacher or at least a fellow student using a checklist should be involved. If observers 
are missing from the learning experience, students' errors may go uncorrected and then be repeated throughout practice.

Furthermore, there may be an optimal combination of numbers of practice sessions, observations, and feedback. Observation and feedback seem to be a necessary addition to practice [21]. The optimal student/model/trainer ratio for each training condition and skill should be investigated in further research.

When setting up and implementing the Skillslab system in Vietnam, a South-East Asian country, communication skills training may be the most difficult addition to the training program, since most of the training material comes from Western countries [10]. Asian countries like Vietnam have many cultural difference with Western cultures [9]. In Vietnam, most of the doctors were willing to perform all of the activities which reflect the partnership model in the doctor-patient communication. However, doctors and patients also agreed that four items on the Western-inspired communication model had a lower priority for them. All of these items related to fostering the relationship. This may reflect the relatively little attention to the individual in Asian culture and the acceptance of hierarchy [23]. The patients may place themselves in a lower position than the doctors and limit their expectations (some of the doctors seemed to have the same thinking) but most of the doctors expressed their willingness to follow these four activities with the patients as partners.

It seems that clinicians and patients in Vietnam focus on clinical information and examination. However, Cegala et al. suggested that the doctor and patient should enhance mutual understanding, trust, self-efficacy, and adherence [24].

The item "Doctors introduces him/herself" was notably inversely related to satisfaction. If linked with the fact that all doctors said they needed more time for consultations, the patient may think that such activities could waste the valuable but limited time of the consultation and prefer to let it go.

We must point out that the item "Doctor asks patient to repeat main issues in treatment course" was also negatively related to patient satisfaction. Since it is not easy for patients to "repeat main issues in the treatment course," patients may feel uncomfortable when doctors ask them to do this. Likewise, doctors may feel uncomfortable questioning their patients in such a way. Yet, by doing this, the doctors know for sure whether patients understand and may remember what should be done. The health care system has to address patients' awareness of its importance and help them to become familiar with it.

Both training of physicians and improving patients' understanding of their partner positions need attention. Patients will have to be introduced to that concept and persuaded to 
participate actively. The competency standards for general practitioners [11] and regulations on communication from the Ministry of Health in Vietnam [12] reflect the partnership model in doctor-patient communication. Attention to cultural and economic differences can help to fully implement the partnership model.

The compromise between meeting local needs and achieving international standards [25] in this situation was not difficult since applying the partnership model does not harm the patient physically or mentally. Considering the limitation of time for the consultation, the doctor may choose to minimize the "building relationship."

In addition to the findings in our study, discussed above, the entire effort has yielded additional results beyond the scope of our research including: clear government policy; eight faculties/universities working together; international technical and financial assistance; eight large groups of well-trained core teams; international, national and local teacher training courses; Master of Health Professions Education training. Many dedicated teachers and hard-working support staff have contributed to the success of the nationwide implementing medical skills training program following the

\section{Skillslab approach in Vietnam.}

Innovations are not always easy to implement. In fact studies about implementation of skills training showed challenges such as that worn-out manikins may negatively affect the effectiveness of training [26]. The delivery of material in time and budget constraints were additional issues we had to contend with [27]. A research in 2017 concluded that the Skillslab approach was not effectively applied at Kenya Medical Training College due to inadequate time and frequency of Skillslab sessions, too few opportunities for practice, limited space and limited simulation equipment. Self-evaluation of students' clinical competence showed that for $50 \%$ of procedure skills, fewer than half of the students felt they had gained competence [28]. Others may have lacked competence without recognizing that problem.

Checking the innovations in medical skills training described in this thesis with Rogers' Theory of the Diffusion of Innovations (introduced in the Introduction) [29] could help us to clarify what went well and what went wrong. For Rogers [29], the adoption process involves five stages: (1) knowledge, (2) persuasion, (3) decision, (4) implementation, and (5) confirmation.

In the knowledge stage: Innovators gained appropriate awareness-knowledge, how-toknowledge, and principles-knowledge.

In the persuasion stage: The Skillslab approach has a lot of advantages $[\underline{2}, \underline{30-35}]$ but the implementation of the skills training program requires additional resources and revision of 
the standard curriculum. With international financial and technical support, innovators easily understood and used the Skillslab methodology. In the long run, after the financial support stopped, the sustainability of the Skillslabs needed to be considered. Locally-made models could help the sustainability of the innovation but the quality of these models needed to be evaluated. Cultural differences between the local setting and international examples can also be challenging, especially in training communications skills since the applicability of the available doctor-patient communication models from other parts of the world needed to be considered. Innovators must critically consider how best to persuade people to adopt the innovation, because overestimating the difficulty could lead to rejection of a worthwhile innovation. Conversely, underestimating the difficulties could lead to indiscriminate acceptance of innovation with insufficient consideration of the potential obstacles when implementing the innovation.

In the decision stage: The innovators decide whether they will accept or reject the innovation based on their consideration. The decision stage is also influenced by government policy and the participation of other universities. International financial and technical assistance can be a powerful motivator, but in some cases, could also force universities to make hasty or overambitious decisions they might later regret.

The studies in this thesis were implemented when eight state universities agree to participate in the innovation to strengthening medical skills training at eight medical faculties/universities in Vietnam by establishing medical skills training laboratories.

In the implementation stage, innovators had technical support from Maastricht University, strong commitment of the eight state universities under Ministry guidance, so that experts from the universities worked together and helped each other. There were the experiences from two existing Skillslabs, staff was given good training [1] , there was the good solution of using teacher-made models [ㅎ6], and adapting the partnership model in doctor-patient communication. There were however problems of resource constraints, and differences among the eight faculties in numbers and quality with regard to staff, infrastructure, budget and priority-setting. This inevitably resulted in differences in the speed and quality of the establishment and implementation of Skillslabs, which meant that some universities did not fully implement the skills training program [37].

As to the confirmation stage, innovators had research results on the implementation of the skills training program, with the participation of local, national, and international experts. The results showed that although some improvement was needed, in general, the eight medical faculties/universities in Vietnam were successful in setting up and implementing the medical skills training laboratories following the Skillslab approach.

The framework of Rogers' theory helps to explain the success of the project for the 
nationwide implementation of medical skills traininglaboratories, where the clear advantages, the trialability, observability and compatibility of the approach made it relatively easy to be adopted in Vietnam.

\section{Limitations of the study}

Eight Vietnamese universities worked together to set up and implement the Skillslab system. These universities strongly supported the research reported here. Most of the studies were done in eight provinces around the whole country with the participation of experts, faculty members, and students in the eight universities and doctors, as well as leaders in cooperating hospitals and health stations introduced by the universities. We tried to have high-quality experts to optimize the research tools, appropriately large sample sizes and stratification for each part of the study, and well-trained researchers in collecting data.

However, we are aware that there were certain limitations.

1) Studies conducted in Vietnam could be vulnerable to increased positive responses because of the strong desire for harmony in the culture. To reduce such bias, participation was anonymous; research assistants emphasized that they were not hospital staff, so that patients would feel less obliged to please the researchers with positive response.

2) Participants received a small amount of money for their time which might create bias as they might feel they had to give positive responses. The amounts were very small, however, and unlikely to create such a motivation in the current economic climate of Vietnam.

3) Study design and data collection also had limitations:

To answer the research question "Do students reach a higher level of technical skills when trained more often with teacher-made models?" the expectation was that the more models provided, and thus the more practice opportunities offered, the higher the technical skill level the students could reach. Therefore, we used more models, to have two students per model instead of the previous eight students per model. Unexpectedly, the results of their assessments were not significantly different from those of students using the commercial models with higher numbers of students per model, in most of the items. If we had tested different student/model ratios, we might have found the most appropriate ratio for training this skill with teacher made models. The best balance between observation and practice and the optimal student/model/trainer ratio for each training condition should be investigated in further researches.

The finding that most patients expressed overall satisfaction with their consultation and their doctor's communication may have been influenced by putting those general questions at the beginning of the face-to-face survey. At that time, the patient may not 
have been aware what activities the doctor could or should have done in a consultation. If we had put these general questions at the end of the survey after reviewing in detail what the doctor did and what might be done in the future, the overall patient satisfaction might have been lower.

Finally, the thesis did not cover all aspects considered in establishing and implementing the Skillslab system. The study on teacher-made models and on the quality of training in the Skillslab were conducted at only one university, the largest one. That might limit the generalizability of findings, although the standardization created through the project and the collaboration among universities and with the $\mathrm{MOH}$ should reduce this limitation.

\section{Conclusion and recommendations}

A Skillslab system has been set up and implemented in Vietnam. Although the level of implementation of the Skillslab training program was different from university to university, by working together, the stronger Skillslabs could be local examples that motivated and helped other Skillslabs to implement full skills training programs.

When establishing a skills training program, it is important to validate the list of basic skills to be trained in Skillslabs, but in the end, the list of skills to be trained should be decided by each university depending on their resource framework and on local conditions for practicing doctors.

Cultural differences influence the position of doctor and patient in doctor-patient communication, but applying the partnership model is possible if the doctors understand the cultural differences and patients increase their awareness of their partner role, also in the context of globalization.

Teacher-made models using locally available materials could be the answer to the sustainability of the Skillslab system in many resource-constrained settings. The teachermade models not only help to solve financial limitations but may also bring extra medical/educational effects. The universities should have an appropriate motivating policy for teachers to develop, improve, and use teacher-made models. Since the training needs are very wide and complex, teacher cannot develop all necessary models with high quality. Having a balance between teacher-made and commercial models will be needed to establish successful Skillslab training in low and middle-income countries. An adequate balance between observation and practice and the optimal student/model/trainer ratio for each training condition should be investigated in further research.

With the leadership of the government and international financial and technical support, eight faculties/universities overcame economic and cultural differences to set up and 
implement Skillslab training, a Western model, in Vietnam. The lessons learned could be helpful to other Southeast Asian countries and to other low- and middle-income countries around the world. 


\section{References}

1. Netherlands Ministry of Foreign Affairs, The case of Vietnam report of a field investigation-final report, 2007.

http://www.government.nl/./reports/./evaluation. npt.nfp-the-case-of-vietnam. . (Accessed 01 May 2013).

2. Skillslab Faculty of Health, Medicine and Life Sciences., 2012.

https://skl.mumc.maastrichtuniversity.nl/sites/intranet.mumc.maastrichtuniversity.nl /files/skl mumc maastrichtuniversity $\mathrm{nl} /$ skillslab brochure 2012.pdf. (Accessed 03 March 2020).

3. J.A. Dent, Current trends and future implications in the developing role of clinical skills centres, Medical Teacher 23 (2001) 483-489.

https://doi.org/10.1080/01421590120075724

4. T. Kozu, Medical Education in Japan, Academic Medicine 81 (2006) 1069-1075.

https://journals.Iww.com/academicmedicine/Fulltext/2006/12000/Medical_Educatio $\underline{\mathrm{n} \text { in Japan.10.aspx }}$

5. R.J. Davies, J.M. Hamdorf, Surgical skills training and the role of skills centres, BJU International 91 (2003) 3-4. https://onlinelibrary.wiley.com/doi/abs/10.1046/i.1464$\underline{410 X .2003 .04002 . x}$

6. G. Peeraer, A. Scherpbier, R. Remmen, B. De Winter, K. Hendrickx, P. Van Petegem, J. Weyler, L. Bossaert, Clinical Skills Training in a Skills Lab Compared with Skills Training in Internships: Comparison of Skills Development Curricula, Education for Health 20 (2007) 1-9.

7. P. Bradley, K. Postlethwaite, Setting up and running clinical skills learning programmes, The Clinical Teacher 1 (2004) 53-58. https://doi.org/10.1111/i.1743-498X.2004.00039.x

8. P. Stark, F. Fortune, Teaching Clinical Skills in Developing Countries: Are Clinical Skills Centres the Answer?, Education for Health 16 (2003) 298-306.

http://www.educationforhealth.net/text.asp?2003/16/3/298/109015

9. G. Hofstede, Country Comparison - Hofstede Insights, 2018. https://www.hofstedeinsights.com/country-comparison/. (Accessed 28 April 2018).

10. B.C. Schouten, L. Meeuwesen, Cultural differences in medical communication: a review of the literature, Patient Education and Counseling 64 (2006) 21-34.

11. Ministry of Health, Decision on approval for document about competence standards for general practitioners, in: M.o. Health (Ed.) Vietnam, 2015. 
https://vanbanphapluat.co/decision-no-1854-qd-byt-2015-document-aboutcompetence-standards-for-general-practitioners

12. Ministry of Health, Regulations on communication in medical examination and treatment facilities, in: Ministry of Health (Ed.) Vietnam, 2001.

https://thukyluat.vn/vb/quyet-dinh-4031-2001-qd-byt-che-do-giao-tiep-trong-cac-coso-kham-chua-benh-15cf6.html

13. M. D'Eon, R. Crawford, The elusive content of the medical-school curriculum: A method to the madness, Medical Teacher 27 (2006) 699-703.

14. L.N. Hoat, D.V. Dung, E.P. Wright, Practicing doctors' perceptions on new learning objectives for Vietnamese medical schools, BMC Medical Education 7 (2007) 19. https://doi.org/10.1186/1472-6920-7-19

15. C. Ringsted, T.V. Schroeder, J. Henriksen, B. Ramsing, P. Lyngdorf, V. Jønsson, A. Scherpbier, Medical students' experience in practical skills is far from stakeholders' expectations, Medical Teacher 23 (2001) 412-416.

https://doi.org/10.1080/01421590120043017

16. C.-a. Moulton, D. Tabak, R. Kneebone, D. Nestel, H. MacRae, V.R. LeBlanc, Teaching communication skills using the integrated procedural performance instrument (IPPI): A randomized controlled trial, The American Journal of Surgery 197 (2009) 113-118. https://doi.org/10.1016/i.amjsurg.2008.09.006

17. R. Kneebone, D. Nestel, F. Yadollahi, R. Brown, C. Nolan, J. Durack, H. Brenton, C. Moulton, J. Archer, A. Darzi, Assessing procedural skills in context: exploring the feasibility of an Integrated Procedural Performance Instrument (IPPI), Medical Education 40 (2006) 1105-1114.

https://onlinelibrary.wiley.com/doi/abs/10.1111/j.1365-2929.2006.02612.x

18. D. Widyandana, Developing low-cost mannequin for undergraduate IV line phlebotomy, Jurnal Pendidikan Kedokteran Indonesia: The Indonesian Journal of Medical Education 7 (2018) 191.

19. S. Ibnerasa, S. Daud, A. Chaudrhy, Establishing Clinical Skills Center in a Developing Country- LMDC Experience, South-East Asian Journal of Medical Education 12 (2018) 51-55.

20. U.o.M.a.P.a.H. city, Training material center, University of Medicine and Pharmacy at HoChiMinh city, Vietnam, 2020. https://ump.edu.vn/khoa-don-vi/trung-tam/311. (Accessed 23 July 2020).

21. E.J.F.M. Custers, G. Regehr, W. McCulloch, C. Peniston, R. Reznick, The Effects of Modeling on Learning a Simple Surgical Procedure: See One, Do One or See Many, Do 
One? Advances in Health Sciences Education 4 (1999) 123-143. https://doi.org/10.1023/A:1009763210212

22. D.E. Manthey, The Ideal Curriculum in: R.L. Rogers, S. Moayedi (Eds.), Medical Student Educators' Handbook2010, pp. 15-24.

23. G. Hofstede, What about Vietnam?- Country Comparison - Hofstede Insights, 2018. https://www.hofstede-insights.com/country-comparison/vietnam/. (Accessed 28 April 2018).

24. D.J. Cegala, C. Gade, S. Lenzmeier Broz, L. McClure, Physicians' and patients' perceptions of patients' communication competence in a primary care medical interview, Health Commun 16 (2004) 289-304.

https://doi.org/10.1207/s15327027hc1603 2

25. A.J. Sefton, New approaches to medical education: an international perspective, Medical principles and practice : international journal of the Kuwait University, Health Science Centre 13 (2004) 239-48.

26. D. Widyandana, G. Majoor, A. Scherpbier, Transfer of medical students' clinical skills learned in a clinical laboratory to the care of real patients in the clinical setting: The challenges and suggestions of students in a developing country, Education for Health 23 (2010) 1-6.

27. H. Khaja, Quadri, M., Rahim, M.F., Alam, A.Y., Jaffery, T., Zaidi, Z., \& Iqbal, M., The structure and function of a new Clinical Skills and Medical Informatics Laboratory (SCIL) in a developing country-a two year institutional experience, Journal Of Pakistan Medical Association 58 (2008) 612-15.

28. J. Amanya, Innovative Application of Skills Lab Methodology for Effective Teaching of Clinical Medicine at the Kenya Medical Training College, Greener Journal of Medical Sciences 7 (2017) 1-35.

29. E.M. Rogers, Diffusion of innovations, 5th ed., Free Press, New York, 2003.

30. A.I. AlHaqwi, W.S. Taha, Promoting excellence in teaching and learning in clinical education, Journal of Taibah University Medical Sciences 10 (2015) 97-101. http://www.sciencedirect.com/science/article/pii/S165836121500027X

31. P.K. Sahu, V.K. Chattu, A. Rewatkar, S. Sakhamuri, Best practices to impart clinical skills during preclinical years of medical curriculum, J Educ Health Promot 8 (2019) 57-57. https://www.ncbi.nlm.nih.gov/pubmed/31008124 https://www.ncbi.nlm.nih.gov/pmc/articles/PMC6442250/ 
32. B. O'Brien, M. Cooke, D.M. Irby, Perceptions and Attributions of Third-Year Student Struggles in Clerkships: Do Students and Clerkship Directors Agree?, Academic Medicine 82 (2007) 970-978.

https://journals.Iww.com/academicmedicine/Fulltext/2007/10000/Perceptions and Attributions of Third_Year_Student.16.aspx

33. T.P. Lam, M. Irwin, L.W.C. Chow, P. Chan, Early introduction of clinical skills teaching in a medical curriculum - factors affecting students' learning, Medical Education 36 (2002) 233-240. https://doi.org/10.1046/i.1365-2923.2002.01142.x

34. T.J. Bugaj, C. Nikendei, Practical Clinical Training in Skills Labs: Theory and Practice, GMS J Med Educ 33 (2016) 1-10. https://www.ncbi.nlm.nih.gov/pubmed/27579363

35. S.J. Matson CC, Defer T, Greenberg L, Ullian JA., Prerequisite competencies for thirdyear clerkships: An interdisciplinary approach. , Fam Med 39 (2007) 38-42.

36. T.Q. Tran, A. Scherpbier, J. Van Dalen, P.E. Wright, Teacher-made models: the answer for medical skills training in developing countries?, BMC Medical Education 12 (2012) 98 https://doi.org/10.1186/1472-6920-12-98

37. T.Q. Tran, A. Scherpbier, J. van Dalen, D. van Do, E.P. Wright, Implementing a Skillslab training program in a developing country, Education for Health 27 (2014) 243-8. 
Chapter 7

\section{Valorisation}




\section{Valorisation}

The studies in this thesis accompanied a process of nationwide implementation of skills training laboratories in Vietnam, aiming for optimal collaboration among the eight participating Universities. It can, therefore, be difficult to distinguish between the value of the implementation process and the value of the studies as separate products. Aside from the value of the studies as described below, the implementation process yielded several demonstrable effects:

- 8 functioning Skillslabs in medical universities throughout the country, with teaching material available nationwide, as well as assessment materials and described procedures;

- at least 16 Vietnamese experts in Health Professions Education, distributed evenly across the country;

- efficient as well as effective collaboration among these experts and universities;

and most importantly: the skills training program is now an official part of the medical curricula in Vietnam.

The thesis is likely to have impact on the recognition and implementation of skills training program in developing countries. The main impacts will come from:

\section{Demonstration that training the entire national list of basic skills is possible in our resource-challenged country}

This thesis described that starting with foreign funds and expertise, achieving national recognition, and developing high-quality teacher-made models, Skillslabs even in a developing country could train all the basic kills. Showing that this is possible can help to motivate other universities in Vietnam and in other low- and middle-income countries in implementing Skillslab training.

\section{Recommending presenting the skills used by a limited number of doctors in an optional skills training program}

University experts formulated the first list of basic required skills. However, we found that several skills on the expert list were actually used by only a small number of general practitioners (GP). The proportion of GPs using a specific skill depends not only on the skill but also on the location and setting of their practice. If these skills are not offered in training, some patients would be short-changed. However, the limited available resources should not be used to train skills that very few GP will need to practice. The research reported in Chapter 2 of this thesis provides a framework to establish which skills should 
be on the list of essential skills to be taught and which could be moved to an optional category.

\section{Demonstration that teacher-made models not only help to address financial issues for Skillslabs in developing countries but also bring extra medical/educational benefits.}

We described teacher-made models that are handmade at room temperature and pressure, making it easy to change their shape, size, details, color, thickness, softness, and density as required by the teacher. Teachers who are implementing Skillslab training know which features a specific training model should have and can identify which features could be reduced to make them more cost-effective. We can not only produce low price models but also develop new training models that are not available in the market. The teachermade models help not only to solve economic problems in accessing commercial models in low- and middle-income countries but can also bring about extra medical/educational benefits.

The thesis work encouraged Skillslabs in low- and middle-income countries to use teachermade models [1], explored the use of one such model quite deeply [2], and led to the development of many different teacher-made models [3]. To facilitate the use of teachermade models, the University of Medicine and Pharmacy in HoChiMinh City, Vietnam, established the Training Material Center to develop, produce and maintain training models that were designed and made to meet specific training needs [4]. The author is the director of this center. We have produced more than 40 types of teacher-made models and equipment used in skills training and assessment. The range of models covers a range of practices from basic procedure skills (e.g. intradermal injection, insertion of an intrauterine contraceptive device), examination skills (e.g. anorectal examination, auscultation), to high level technology used in continuing medical education and transfer of new technology (e.g. bronchoscopy training model, knee arthroscopy). Some of these models allow for an integrated, patient-centered approach, integrating procedural and communication skills. Our products are provided to not only our own university and the other seven involved in the project, but also to a number of newly opened universities and colleges and to hospitals. The quality of the models has been continuously improved through feedback from trainers and trainees.

Box 1 shows that the article "Teacher-made models: the answer for medical skills training in developing countries?" was cited in the book "Teaching and Learning Methods in Medicine", with the extremely positive postscript "Tran et al. have touched the most sensitive nerve..." and "It is highly motivating to learn through this study...", and "this study certainly provides guidance in this respect and acts as a model for developing countries."[1] 
Box 1: Article Teacher-made model: the answer for medical skills training in developing country? was cited in the book Teaching and Learning Methods in Medicine (Shabih Zaidi, Mona Nasir, Simulation, Teaching and Learning Methods in Medicine, Springer, Switzerland, 2015, pp. 103-4), cited here with the publisher's permission.

Article Teacher-made model: the answer for medical skills training in developing country? was cited in the book Teaching and Learning Methods in Medicine

"Tran et al. (2012) have touched the most sensitive nerve in the following study. The advantages of using simulators in skills training are generally recognized, but simulators are often too expensive for medical schools in developing countries. Cheaper, locally-made models (or part-task trainers) could be the answer, especially when teachers are involved in design and production (teacher-made model, TM). They evaluated the effectiveness of a teacher model in training and assessing intravenous injection skills in comparison to an available commercial model (CM) in a randomized, blind, pretestposttest study with 144 undergraduate nursing students. All students were assessed on both the TM and the $\mathrm{CM}$ in the pre-test and post-test. After the post-test, the students were also assessed while performing the skill on real patients. Differences in the mean scores pre- and post-test were marked in all groups. Training with TM or CM improved student scores substantially but there was no significant difference in mean scores whether students had practiced on TM or CM. Students who practiced on TM performed better on communication with the patient than did students who practiced on $\mathrm{CM}$.

These researchers believe that decreasing the ratio of students per TM model helped to increase practice opportunities but did not improve students' mean scores. The teacher-made model appears to be an effective alternative to the commercial model for training students on basic IV skills, as students showed similar increases in performance scores after training on models that cost considerably less than commercially available models. They believe that these models could be produced using locally available materials in most countries, including those with limited resources to invest in medical education and skills laboratories.

It is highly motivating to learn through this study that inexpensive tools can be made locally available. The cost of skill laboratories can be prohibitive. Many countries in Africa, Asia and Latin America want to change the modus operandi of imparting education from conventional to modern technology, albeit the cost may prohibitive. This study certainly provides guidance in this respect and acts as a model for developing countries."

\section{Our studies reinforced the importance of how training is organized in achieving desired results. Practice did not always make perfect.}

We reported how using teacher-made models helped us to have many more models for training, so that students could practice more often. However, maximizing the number of models did not improve the results of student assessment. The researcher strongly believes that different groups must be tested with different student/model ratios to find the best balance between observation and practice and the optimal student/model ratio for each 
training condition, and possibly for each skill.

\section{Providing evidence for applying partnership model in doctor-patient communication. Doctors in Vietnam reported a willingness to apply the partnership model in doctor-patient communication, which may influence doctors in other Asian countries}

Although there are many cultural differences between Vietnamese and Western cultures [5], universities in Vietnam and maybe in other Asian countries can apply the partnership model in doctor-patient communication. We found no barriers in doctors' motivation; most of the doctors expressed their willingness to perform all of the activities that reflect the partnership model in the list for doctor-patient communication.

Looking at cultural differences, when patients are not satisfied or expect different behavior from their doctor, more investigation is needed. Items of communication behavior should not be dropped from the list unless we find that patients consider them negative or if they lead to harm to the patient. Cultural difference is an important topic in doctors' training in both Western and non-Western countries; doctors can fine-tune their communication with patients based on a knowledge of cultural differences.

This finding may make it easier for universities in Vietnam and possibly other non-Western countries to adapt the partnership model in doctor-patient communication, to support patients in their role as partners, and ultimately improve the quality of health care. 


\section{References}

1. M.N. Shabih Zaidi, Simulation, Teaching and Learning Methods in Medicine, Springer, Switzerland, 2015, pp. 103-4.

2. D. Widyandana, Developing low-cost mannequin for undergraduate IV line phlebotomy, Jurnal Pendidikan Kedokteran Indonesia: The Indonesian Journal of Medical Education 7 (2018) 191.

3. S. Ibnerasa, S. Daud, A. Chaudrhy, Establishing Clinical Skills Center in a Developing Country- LMDC Experience, South-East Asian Journal of Medical Education 12 (2018).

4. U.o.M.a.P.a.H. city, Training material center, University of Medicine and Pharmacy at HoChiMinh city, Vietnam, 2020. https://ump.edu.vn/khoa-don-vi/trungtam/311. (Accessed 23 July 2020).

5. G. Hofstede, Country Comparison - Hofstede Insights, 2018. https://www.hofstedeinsights.com/country-comparison/. (Accessed 28 April 2018). 


\section{Chapter 8}

Summary 


\section{Chapter 1:}

The literature review describes the effectiveness of early introduction of clinical skills training in the medical curriculum, including the integration of clinical and basic science knowledge; students' performance is improved, and their confidence is increased. Skillslabs have been successfully developed in Western and high-income countries and have started to appear in low- and middle-income countries. Many medical schools have come under pressure to provide them for their students.

The project "Strengthening medical skills training at 8 medical faculties/universities in Vietnam", funded by the Government of the Netherlands and technical support from Maastricht University, which started in 2004, aimed to set up and implement a medical skills training program in the form of Skillslabs in medical schools in a nationwide program throughout Vietnam. The Skillslab approach has been impressively successful at Maastricht University, but its implementation across Vietnam, a developing country, was a major challenge and the results were uncertain.

The Rogers Theory on Diffusion of Innovations claimed that uncertainty is an important obstacle to the adoption of innovations. A five-stage adoption process was applied as a framework with which to track the adoption of the innovative Skillslab approach in Vietnam.

In the context of the program to set up and implement medical skills training laboratories following the Skillslab approach in Vietnam, the research in this dissertation aimed to:

4) identify which skills need to be trained in the Skillslab approach,

5) find out whether these skills could all be trained effectively under the prevalent conditions of limited resources at the time, and

6) evaluate two specific aspects of using the Skillslab approach in the conditions of Vietnam: quality of locally made models and adapting a communication model used in Western countries.

We used diverse research methods including questionnaire-based surveys, face-to-face surveys, observation, focus group discussions, self-reporting, reviews, and controlled 
experiments. For each study, we tried to have the largest possible sample size of the appropriate population at each study site.

\section{Chapter 2:}

Aimed to validate the national list of basic skills to be trained in the Skills labs. A national list of 56 basic skills had been formulated by an expert panel of faculty members from all the medical faculties/universities in the country with advice from Dutch experts, in a Delphi process. It was then validated by checking against skills commonly used in practice through self-reporting by general practitioners and observation by final year medical students.

The results revealed gaps between the skills on the list formulated by the expert panel and the actual use of these skills by graduate doctors in their daily work. The gaps were related to specific skills as well as to the region and the practice setting. The results suggest that the tendency of GPs to focus on certain areas of medicine and not on others could account for their not using some of the skills that according to the expert panel should be offered for training of all prospective general practitioners.

\section{Chapter 3:}

This study was designed to assess how close the eight main medical schools in Vietnam came to implementing the national list of 56 basic skills to be trained in the Skillslabs and to identify the facilitating factors and barriers to Skillslab use within the country's largest school. Skillslabs were established in eight medical schools with international support; models, medical and teaching equipment were supplied, learning materials were developed, and core staff and teachers were trained.

Data were collected from reports from the eight Skillslabs. Students and trainers from the largest university were surveyed for their perceptions of the quality of training on eight selected skills. Results of students' skill assessments were gathered and focus group discussions with trainers were conducted. SPSS 16 was used to analyze the quantitative data and cluster analysis was used to test for differences.

The results revealed that only one medical school was able to train all 56 basic skills on the list reached by consensus among the eight universities. Deeper exploration within the 


\section{Chapter 8}

largest school revealed that its Skillslab training was successful for most skills, according to students' post-program skills assessment and according to students' and trainers' perceptions. However, through focus group discussions we learned about weaknesses: the quantity of training aids was perceived to be insufficient; some models/manikins were inappropriate for training; more consideration was needed in framing the expected requirements of students within each skill; too little time was allocated for the training of one of the eight skills investigated; and further curriculum development was needed to better integrate the skills training program into the broader curriculum.

The fact that one medical school could teach all skills recommended for Skillslab training demonstrated that all Vietnamese schools may be similarly able to teach the basic skills of the national consensus list. It remains, however, challenging for most schools in this developing country to fully implement a national Skillslab training program.

\section{Chapter 4:}

Aimed to investigate whether the partnership model in doctor-patient communication is appropriate in Vietnam, and to identify key items in doctor-patient communication that should be included in a doctor-patient communication model for training in Vietnam.

Asian countries are making efforts to apply the partnership model in doctor-patient communication that has been used effectively in Western countries. However, notable differences between Western and Asian cultures, especially the acceptance of a hierarchical order and little attention to individuality in Asia, could mean that the application of the partnership model in Vietnam requires adaptation.

In six provinces, collaborating medical schools collected data from 480 patients using faceto-face surveys with a structured guideline following a consultation session, and from 473 doctors using a cross-sectional survey on how they usually conduct consultation sessions with patients. Data collection tools covered a list of communication skills based on Western models, adapted to fit with local legislation.

Results showed that both patients and doctors considered most elements in the list 
necessary for good doctor-patient communication. Both also felt that while actual communication was generally good, there was room for improvement. Furthermore, the doctors had higher expectations than did the patients. Four items in the Western model for doctor-patient communication, all promoting the partnership relation between them, appeared to have lower priority for both patients and doctors in Vietnam.

The communication model used in the West could be applied in Vietnam with minor adaptations. Increasing patients' understanding of their partner role needs to be considered. The implications for medical training in universities are to focus first on the key skills perceived as needing to be strengthened by both doctors and patients. In the longer term, all of these items should be included in the training to prepare for the future.

\section{Chapter 5:}

The advantages of using simulators in skills training are generally recognized, but simulators are often too expensive for medical schools in developing countries. Cheaper locally-made models (or part-task trainers) could be the answer, especially when teachers are involved in their design and production (teacher-made models).

One of the very first teacher made models was a simple model for training and assessing intravenous injection procedures. It was a hand-made "skin like" silicone bandage which has one vein, a thin protection under the vein and a blood container. The model is wrapped around the forearm of a simulated patient (could be a fellow student) for practicing intravenous placement.

Even an inexpensive model will be too expensive and wasteful if it does not function well in training and assessment. Therefore, we evaluated the effectiveness of a teacher-made model in training and assessing intravenous injection skills in comparison to an available commercial model in a randomized, blind, pretest-posttest study with 144 undergraduate nursing students. All students were assessed on both the teacher-made model and the commercial model in the pre-test and in the post-test. After the post-test the students were also assessed while performing the skill on real patients. 


\section{Chapter 8}

Differences in the mean scores pre- and post-test were marked in all groups. Training with the teacher-made model or commercial model improved student scores substantially, compared to no Skillslab training. There was no significant difference in mean scores whether students had practiced on teacher-made models or commercial models. Students who practiced on teacher-made models performed better on communication with the patient than did students who practiced on commercial models. Decreasing the ratio of students per teacher-made model helped to increase practice opportunities, but that did not improve student's mean scores. The result of the assessment on both the teachermade models and the commercial models had a low correlation with the results of the assessment on real persons.

The teacher-made model appears to be an effective alternative to commercial model for training students on intravenous injection skills, as students showed similar increases in performance scores after training on models that cost considerably less than commercially available models. These models could be produced using locally available materials in most countries, including those with limited resources to invest in medical education and skills laboratories.

\section{Chapter 6:}

In this chapter we summarize the overall findings of the study and discuss them, including the limitations. The process of change was checked against the Rogers' Theory of the Diffusion of Innovations as a framework, to help explain how the nationwide implementation of medical Skillslabs in Vietnam has moved forward.

Conclusion: A Skillslab system has been set up and implemented in Vietnam, despite the expected challenges and limitations. Although the level of implementation of the Skillslab training program was different from university to university, by working together, the stronger Skillslabs could be local examples that motivated and helped other Skillslabs to implement a full skills training program. When establishing a skills training program, it is important to validate the list of basic skills to be trained in Skillslabs, but in the end, the list 
of skills to be trained should be decided by each university depending on their resource framework and on local conditions for practicing doctors.

Cultural differences influence the position of doctor and patient in doctor-patient communication, but applying the partnership model is possible if the doctors understand the cultural differences and if patients increase their awareness of their partner role, also in the context of globalization.

Teacher-made models using locally available materials could be the answer to the sustainability of the Skillslab system in many resource-constrained settings. The teachermade models not only help to solve financial limitations but may also bring extra medical/educational effects. The universities should have an appropriate motivating policy for teachers to develop, improve, and use teacher-made models. Since the training needs are very wide and complex, teacher cannot develop all necessary models with high quality. Having a balance between teacher-made and commercial models will be needed to establish successful Skillslab training in low and middle-income countries. An adequate balance between observation and practice and the optimal student/model/trainer ratio for each training condition should be investigated in further research.

With the leadership of the government and international financial and technical support, eight medical faculties/universities overcame economic and cultural differences to set up and implement Skillslab training, a Western model, in Vietnam. The lessons learned could be helpful to other Southeast Asian countries and to other low- and middle-income countries around the world.

\section{Chapter 7:}

Presents the impacts of the study. Since the studies in this thesis accompanied a process of nationwide implementation of skills training laboratories in Vietnam, aiming for optimal collaboration among the eight participating universities, it can be difficult to distinguish between the value of the implementation process and the value of the studies as separate products. The thesis is likely to have impact on the recognition and implementation of skills 
training program in developing countries. The main impacts will come from:

1. Demonstration that training the entire national list of basic skills is possible in our resource-challenged country;

2. Recommendation to include skills used by a limited number of doctors in an optional extra skills training program;

3. Demonstration that teacher-made models not only help to address financial issues for Skillslabs in developing countries but can also bring extra medical/educational benefits; The article "Teacher-made models: the answer for medical skills training in developing countries?" was cited in the book "Teaching and Learning Methods in Medicine" by Shabih Zaidi and Mona Nasir, with the extremely positive comments: "Tran et al. have touched the most sensitive nerve..." and "It is highly motivating to learn through this study...", and "this study certainly provides guidance in this respect and acts as a model for developing countries."

4. Reinforcement of the importance of how training is organized on achieving desired results; practice did not always make perfect.

5. Evidence for applying the partnership model in doctor-patient communication in the Asian context. Doctors in Vietnam reported a willingness to apply the partnership model in doctor-patient communication, which may influence doctors in other Asian countries. 
Samenvatting 


\section{Samenvatting (Dutch)}

\section{Hoofdstuk 1:}

Bij het beschrijven van ons literatuuronderzoek belichtten we de voordelen van vroegtijdige invoering van klinisch vaardigheidsonderwijs in het Geneeskundecurriculum, zoals integratie van klinische kennis en kennis van de basiswetenschappen, verbeterde prestaties van studenten, alsook een toename van hun zelfvertrouwen. Skillslabs werden met succes in westerse landen en in landen met een hoog inkomen ontwikkeld en komen langzaamaan ook in opkomst in lage- en middeninkomenslanden. Veel medische opleidingen zijn onder druk komen te staan om hun studenten dergelijk vaardigheidsonderwijs aan te bieden.

Het project "Versterken van het medisch vaardigheidsonderwijs aan acht faculteiten/universiteiten Geneeskunde in Vietnam", dat in 2004 met financiële hulp van de Nederlandse overheid en met technische ondersteuning van de Universiteit Maastricht werd aangevangen, had als doel door middel van een landelijk opgezet plan een programma voor medisch vaardigheidsonderwijs in de vorm van Skillslabs in te richten en te implementeren in Geneeskundeopleidingen in heel Vietnam. Hoewel de "Skillslabaanpak" bijzonder veel succes had aan de Universiteit Maastricht, betekende de invoering ervan in een ontwikkelingsland als Vietnam een ware uitdaging die bovendien een onzekere uitkomst had.

In Rogers' theorie over de verspreiding van innovaties werd gesteld dat onzekerheid een belangrijk obstakel is voor de invoering van innovaties. De invoering van de innovatieve Skillslab-aanpak in Vietnam werd in vijf fasen opgedeeld, zodat we deze stap voor stap konden volgen. In het kader van dit programma om in Vietnam laboratoria voor medisch vaardigheidsonderwijs op te zetten en in te voeren conform de Skillslab-aanpak, beoogde het onderzoek in dit proefschrift:

1. in kaart te brengen welke vaardigheden er met de Skillslab-aanpak getraind moeten worden;

2. te achterhalen of deze vaardigheden allemaal naar behoren konden worden 
aangeleerd onder de toen geldende omstandigheden, d.w.z. met de beperkte middelen die ter beschikking stonden; en

3. twee specifieke aspecten van de toepassing van deze Skillslab-aanpak in Vietnamese omstandigheden te beoordelen, namelijk: de kwaliteit van lokaal vervaardigde simulatoren en de aanpassing van een uit westerse landen overgenomen communicatiemodel.

We maakten gebruik van diverse onderzoeksmethoden, waaronder vragenlijsten, individuele interviews, observaties, focusgroepgesprekken, zelfrapportages, literatuuronderzoeken en veldexperimenten. Bij elk onderzoek probeerden we een zo groot mogelijke steekproef te nemen uit de bij de onderzoekslocatie passende populatie.

\section{Hoofdstuk 2:}

In dit hoofdstuk werd getracht de nationale lijst met basisvaardigheden die in de Skillslabs onderwezen moeten worden, te valideren. Door middel van een Delphi-procedure was er een nationale lijst met 56 basisvaardigheden opgesteld door een expertpanel bestaande uit stafleden van alle faculteiten/universiteiten Geneeskunde in het land en met advies van Nederlandse experts. Vervolgens werd deze lijst gevalideerd door deze te vergelijken met in de praktijk veelgebruikte vaardigheden, zoals bleek uit zelfrapportages door huisartsen en observaties door laatstejaarsstudenten Geneeskunde.

De resultaten wezen op hiaten tussen de vaardigheden op de door het expertpanel opgestelde lijst en het daadwerkelijke gebruik van deze vaardigheden door afgestudeerde artsen in hun dagelijks werk. De hiaten hadden niet alleen betrekking op specifieke vaardigheden, maar ook op de regio en de praktijksetting. De resultaten maken aannemelijk dat de geneigdheid van huisartsen om zich op bepaalde aspecten van de geneeskunde te richten en niet op andere zou kunnen verklaren waarom zij sommige vaardigheden die volgens het expertpanel aan alle aspirant-huisartsen in de opleiding zouden moeten worden aangeboden, niet gebruiken.

\section{Hoofdstuk 3:}

Deze studie beoogde na te gaan in hoeverre het de acht belangrijkste 


\section{Samenvatting}

Geneeskundeopleidingen van Vietnam was gelukt om de nationale lijst van 56 basisvaardigheden die in de Skillslabs onderwezen moesten worden, in te voeren, alsmede in kaart te brengen welke factoren binnen de grootste Geneeskundeopleiding van het land het Skillslab-gebruik belemmeren en bevorderen. In acht Geneeskundeopleidingen werden er met internationale steun Skillslabs opgericht; er werden simulatoren, medische en onderwijsapparatuur geleverd, lesmateriaal ontwikkeld en de voornaamste stafleden en docenten werden opgeleid.

Data werden verkregen uit verslagen van de acht Skillslabs. Voorts bevroegen we studenten en opleiders van de grootste universiteit over de onderwijskwaliteit ten aanzien van acht geselecteerde vaardigheden. Daartoe verzamelden we studentbeoordelingen van de desbetreffende vaardigheden en hielden we focusgroepgesprekken met opleiders. We gebruikten SPSS 16 om de kwantitatieve gegevens te analyseren en verrichtten een clusteranalyse om eventuele verschillen bloot te leggen.

De resultaten lieten zien dat het slechts een van de acht medische universiteiten gelukt was om alle 56 via consensus verkregen basisvaardigheden op de lijst te onderwijzen. Nader onderzoek binnen de grootste universiteit wees uit dat het Skillslab-onderwijs voor de meeste vaardigheden geslaagd was, blijkens de studentbeoordelingen van de vaardigheden na afloop van het vaardigheidsonderwijs en blijkens de percepties van studenten en opleiders. De focusgroepgesprekken brachten echter ook zwakke punten aan het licht: de hoeveelheid onderwijshulpmiddelen werd als onvoldoende ervaren; enkele simulatoren/oefenmodellen waren ongeschikt voor onderwijs; per vaardigheid moest er meer aandacht worden besteed aan het formuleren van de competenties waarover studenten dienden te beschikken; er was te weinig tijd uitgetrokken voor het trainen van een van de acht onderzochte vaardigheden; en het curriculum moest verder worden ontwikkeld om ervoor te zorgen dat het vaardigheidsonderwijs beter in het bredere curriculum werd ingebed.

Het feit dat het een medische opleiding gelukt was om alle voor het Skillslab-onderwijs aanbevolen vaardigheden te trainen, toonde aan dat het voor alle Vietnamese opleidingen eveneens mogelijk zou moeten zijn om de basisvaardigheden van de consensuslijst te 
onderwijzen. Ondanks dat blijft het voor de meeste opleidingen in dit ontwikkelingsland een uitdaging om een nationaal programma voor Skillslab-onderwijs volledig in te voeren.

\section{Hoofdstuk 4:}

Het doel van dit hoofdstuk was enerzijds te onderzoeken of het partnerschapsmodel bij arts-patiëntcommunicatie bruikbaar is in Vietnam, en anderzijds te achterhalen welke voornaamste aspecten van arts-patiëntcommunicatie zouden moeten worden opgenomen in een onderwijsmodel voor arts-patiëntcommunicatie in Vietnam.

Aziatische landen doen hun best om het partnerschapsmodel dat in westerse landen met succes wordt gebruikt toe te passen bij arts-patiëntcommunicatie. Het feit dat er markante verschillen bestaan tussen de westerse en Aziatische cultuur, in het bijzonder de acceptatie van een hiërarchische structuur en minimale aandacht voor individualiteit in Azië, zou echter kunnen betekenen dat de toepassing van het partnerschapsmodel in Vietnam aanpassing behoeft.

In zes provincies verzamelden de samenwerkende Geneeskundeopleidingen gegevens van 480 patiënten via individuele interviews die na afloop van een consult en aan de hand van een gestructureerd interviewprotocol plaatsvonden, alsook van 473 artsen via een crosssectioneel vragenlijstonderzoek over hoe zij gewoonlijk een patiëntconsult voeren. De instrumenten waarmee we gegevens verzamelden omvatten een lijst van op westerse modellen gebaseerde communicatievaardigheden die aan de lokale wetgeving was aangepast.

De resultaten lieten zien dat zowel patiënten als artsen de meeste aspecten op de lijst van belang achtten voor goede arts-patiëntcommunicatie. Beiden vonden ook dat, hoewel de communicatie over het algemeen al goed bevonden werd, deze voor verbetering vatbaar was. Verder hadden de artsen hogere verwachtingen dan de patiënten. Vier punten uit het westerse model voor arts-patiëntcommunicatie, die allemaal gericht waren op versterking van het partnerschapsverband tussen hen, bleken voor zowel patiënten als artsen in Vietnam een lagere prioriteit te hebben.

Het communicatiemodel dat in het Westen wordt gebruikt, zou met enige aanpassingen in 


\section{Samenvatting}

Vietnam kunnen worden toegepast. Er moet worden nagedacht over hoe we patiënten hun partnerrol beter kunnen laten begrijpen. De gevolgen voor het medisch onderwijs aan universiteiten zijn dat de aandacht in de eerste plaats moet uitgaan naar de belangrijkste vaardigheden die in de ogen van artsen en patiënten moeten worden verbeterd. Op langere termijn zouden al deze punten in de opleiding moeten worden opgenomen om studenten op de toekomst voor te bereiden.

\section{Hoofdstuk 5:}

Hoewel de voordelen van het gebruik van simulatoren in het vaardigheidsonderwijs over het algemeen bekend zijn, zijn deze voor medische opleidingen in ontwikkelingslanden vaak te kostbaar. Goedkopere, lokaal vervaardigde oefenmodellen (of deeltaaksimulatoren) zouden in dezen uitkomst kunnen bieden, vooral wanneer docenten bij het ontwerp en de vervaardiging ervan betrokken worden (teacher-made oefenmodellen).

Een van de allereerste teacher-made oefenmodellen was een eenvoudige simulator voor het trainen en beoordelen van intraveneuze injectieprocedures. Het betrof een handgemaakt "huidachtig" siliconenverband met één ader, een dunne beschermlaag onder deze ader en een bloedreservoir. Het model werd om de onderarm van een simulatiepatiënt (bijv. een medestudent) gewikkeld voor het oefenen van intraveneuze injecties.

Zelfs een goedkoop model is echter te kostbaar en een verspilling als het niet goed functioneert tijdens de training en beoordeling. Daarom onderzochten we middels een gerandomiseerd, geblindeerd onderzoek met voor- en nameting waaraan 144 bachelorstudenten Verpleegkunde deelnamen hoe effectief een teacher-made oefenmodel voor het trainen en beoordelen van intraveneuze injectievaardigheden is vergeleken met een commercieel beschikbaar oefenmodel. Alle studenten werden bij de voor- en nameting op zowel het teacher-made oefenmodel als het commerciële oefenmodel beoordeeld. Na de nameting werden de studenten ook beoordeeld tijdens het toepassen van de vaardigheid op echte patiënten. 
De verschillen in gemiddelde scores tussen de voor- en nameting waren voor alle groepen beduidend. Vergeleken met geen Skillslab-training zorgde de training met behulp van het teacher-made oefenmodel dan wel het commerciële oefenmodel voor een aanzienlijke verbetering van studentscores. Of de studenten nu hadden geoefend op de teacher-made oefenmodellen of op de commerciële oefenmodellen maakte geen wezenlijk verschil uit voor hun gemiddelde scores. Studenten die op de teacher-made oefenmodellen hadden geoefend, daarentegen, presteerden beter op het gebied van patiëntcommunicatie dan de studenten die op de commerciële oefenmodellen hadden geoefend. Hoewel studenten meer oefenkansen kregen wanneer het aantal studenten per teacher-made oefenmodel werd verlaagd, bracht dit geen verbetering in de gemiddelde studentscores. Het resultaat van de beoordeling op zowel de teacher-made oefenmodellen als op de commerciële oefenmodellen correleerde matig met de resultaten van de beoordelingen op echte personen.

Voor het trainen van intraveneuze injectievaardigheden blijkt het teacher-made oefenmodel een geschikt alternatief te zijn voor commerciële modellen, aangezien studenten na het oefenen op modellen die beduidend minder kostten dan commercieel beschikbare modellen een vergelijkbare verbetering in prestatiescores lieten zien. Deze oefenmodellen zouden in de meeste landen kunnen worden vervaardigd met lokaal beschikbaar materiaal, ook in landen waar de middelen voor investering in medisch onderwijs en Skillslabs beperkt zijn.

\section{Hoofdstuk 6:}

In dit hoofdstuk vatten we de algemene bevindingen van het onderzoek samen en bespraken we deze, inclusief de beperkingen. Om de ontwikkeling van de nationale invoering van medische Skillslabs in Vietnam te helpen verklaren, toetsten we het veranderingsproces aan Rogers' theorie over de verspreiding van innovaties die fungeerde als denkkader.

Conclusie: ondanks de verwachte uitdagingen en beperkingen werd in Vietnam een netwerk van Skillslabs opgezet en ingevoerd. Hoewel de mate waarin de implementatie van het Skillslabonderwijsprogramma vorderde per universiteit verschilde, konden de 


\section{Samenvatting}

sterkere Skillslabs door samen te werken als lokale voorbeelden dienen die de andere Skillslabs motiveerden en hielpen om een volledig programma voor Skillslabonderwijs in te voeren. Bij het oprichten van een vaardigheidsonderwijsprogramma is het belangrijk om de lijst van basisvaardigheden die in de Skillslabs getraind moeten worden, te valideren. Uiteindelijk is het echter aan de universiteit zelf om op basis van de beschikbare middelen en de plaatselijke omstandigheden voor praktiserend artsen te bepalen welke vaardigheden er getraind moeten worden.

Hoewel cultuurverschillen de positie van de arts en de patiënt in arts-patiëntcommunicatie beïnvloeden, is toepassing van het partnerschapsmodel mogelijk, mits artsen deze cultuurverschillen begrijpen en patiënten zich meer bewust worden van hun partnerrol, ook in het kader van globalisering.

Oefenmodellen die door docenten met lokaal beschikbaar materiaal zijn vervaardigd, zouden uitkomst kunnen bieden ten aanzien van de houdbaarheid van het Skillslabnetwerk in veel settingen waar de middelen beperkt zijn. Dergelijke teacher-made oefenmodellen bieden niet alleen een oplossing voor financiële beperkingen, maar hebben mogelijk ook additionele medische voordelen of leereffecten. Universiteiten zouden daarom een passend beleid moeten voeren dat docenten motiveert om deze oefenmodellen te ontwikkelen, verbeteren en te gebruiken. Aangezien de leerbehoeften zeer uiteenlopend en complex zijn, kunnen we niet verwachten dat docenten alle benodigde oefenmodellen ontwikkelen en dat deze ook nog eens van hoge kwaliteit zijn. Om met succes Skillslabonderwijs op te zetten in lage- en middeninkomenslanden, zal er dus een balans gevonden moeten worden tussen teacher-made en commerciële oefenmodellen. Toekomstig onderzoek zou moeten proberen de juiste balans tussen observatie en praktijk en de optimale student/oefenmodel/docent-verhouding per onderwijsconditie in kaart te brengen.

Onder leiding van de overheid en met internationale financiële en technische ondersteuning hebben acht medische faculteiten/universiteiten economische en cultuurverschillen het hoofd geboden om in Vietnam Skillslab-onderwijs, een westers model, op te zetten en in te voeren. De geleerde lessen kunnen nuttig zijn voor andere Zuidoost-Aziatische landen en andere lage- en middeninkomenslanden over de hele wereld.

\section{Hoofdstuk 7:}

In dit hoofdstuk worden de gevolgen van het onderzoek gepresenteerd. Aangezien de studies in dit proefschrift gekoppeld waren aan een landelijk proces van invoering van vaardigheidsonderwijslaboratoria in Vietnam, waarbij werd gestreefd naar een optimale 
samenwerking tussen de acht deelnemende universiteiten, kan het lastig zijn de waarde van het implementatieproces te onderscheiden van de waarde die de studies als afzonderlijke producten hebben. Waarschijnlijk zal het proefschrift gevolgen hebben voor de acceptatie en implementatie van vaardigheidsonderwijsprogramma's in ontwikkelingslanden. De voornaamste gevolgen vloeien voort uit:

1. het feit dat werd aangetoond dat het onderwijzen van de gehele nationale lijst van basisvaardigheden mogelijk is in een land met beperkte middelen als het onze;

2. het advies om de vaardigheden die door een beperkt aantal artsen worden gebruikt op te nemen in een extra keuzeprogramma voor vaardigheidsonderwijs;

3. het feit dat werd aangetoond dat door de docent vervaardigde oefenmodellen niet alleen een oplossing bieden voor financiële problemen bij de oprichting van Skillslabs in ontwikkelingslanden, maar mogelijk ook additionele medische voordelen of leereffecten hebben;

Het artikel "Teacher-made models: the answer for medical skills training in developing countries?" werd in het boek "Teaching and Learning Methods in Medicine" van Shabih Zaidi en Mona Nasir, voorzien van het volgende buitengewoon positieve commentaar, geciteerd:

Tran et al. hebben de meest gevoelige snaar geraakt, en Het werkt zeer motiverend om van deze studie te leren... en deze studie reikt in dit opzicht zeker handvatten aan en dient als voorbeeld voor ontwikkelingslanden.

4. de herbevestiging van het feit dat de manier waarop het onderwijs wordt georganiseerd van belang is voor het bereiken van de gewenste resultaten; oefening baarde niet altijd kunst.

het bewijs dat toepassing van het partnerschapsmodel bij arts-patiëntcommunicatie in de Aziatische context mogelijk is. Artsen in Vietnam gaven aan bereid te zijn het partnerschapsmodel in hun communicatie met. 


\section{Curriculum Vitae}

Trung Quang Tran was born on 15 September 1960 in Saigon (Ho Chi Minh City now), Vietnam. In 1990 he received the degree of Doctor of Medicine from the University of Medicine and Pharmacy at Ho Chi Minh City, Vietnam, the largest health university in Vietnam. He worked there after graduation as an assistant lecturer in the Teacher Training Unit. In 2001, he received a Postgraduate Diploma in Public Health at the University of Medicine and Pharmacy Ho Chi Minh City, and three years later, the Master of Health Professions Education at Maastricht University, the Netherlands, on a scholarship from a World Bank project.

The author has always had a strong commitment to Medical Education. He was Coordinator of the Center of Excellence in Medical Education, University of Medicine and Pharmacy Ho Chi Minh City from 2007 to 2013, and has been Vice-director of the Medical Education Center at the same university from 2010, and Senior Lecturer in Medical Education, and then Vice-director and now Director of the Training Materials Center from 2011 to the present.

Trung was very fortunate to have the opportunity to participate in many projects on innovation in medical education. These projects gave him the chance to work with most of the medical universities and colleges in Vietnam. They also enabled him to study abroad and to visit training facilities in many other countries (Australia, China, Japan, India, Indonesia, Singapore, Philippines, Taiwan, Belgium, England, Germany, Hungary, Netherlands, USA) and to work with international organizations and their expert advisers.

Trung is passionate about training of medical skills. He acted as Coordinator of the project "Strengthening medical skills training at 8 medical faculty/universities in Vietnam" with technical support from Maastricht University and funded by The Netherlands. Recently, he has spent most of his time to develop, improve and repair training materials and models for medical skill training.

After finishing his $\mathrm{PhD}$, it is his intention to continue his work in research and development on training materials, especially developing low-cost training models to help developing countries overcome resource constraints in medical skills training. He is also keen to join the work of Maastricht University supporting developing countries to strengthen their medical skills training. 


\section{Acknowledgements}

First, I would like to express my deepest gratitude to my promotor, Prof. Dr. A.J.J.A. Scherpbier, and my co-promotors, Dr. E.P. Wright and Dr. J. van Dalen for their guidance, strong support, and motivation. They really made this miracle!

I would also like to thank the other University of Maastricht experts and especially Mr. Pie Bartholomeus, MD and Ms. Marijke Kruithof, MD, MHPE, for their commitment to skillslab training in Vietnam and for inspiring my interest in skills training and the development of the skills training models.

My great appreciation goes to my research partners Prof. Dr. Van Dung Do, Dr. Hanh Thi Nguyen, MHPE, Dr. Hoa Thu Thi Doan, MHPE, Ms. Le Anh Thi Doan, MHPE, Mr. Son Vinh, MSc, and Ms. Mai-Huyen Thi Pham, MSc. They were the most active members in data collection, data analysis, design, and layout, and for all their co-operation, I am extremely grateful.

Throughout the project and for some of the research, the participation of the members of the eight Vietnamese medical faculties/universities who joined the project "Strengthening medical skills training at 8 medical faculties/universities in Vietnam," was very important. I want to thank them for implementing these studies, and to thank the city/provincial hospitals and district health centers for hosting the data collection, and the doctors and patients who participated in the research.

I am grateful to The Netherlands Programme for Institutional Strengthening of PostSecondary Education and Training Capacity and the project "Strengthening medical skills training at 8 medical faculties/universities in Vietnam" for funding this research as well as for the support to set up the skillslab system in Vietnam.

Finally, I would like to thank my family, for motivating, supporting and sharing the family workload through all the years it took to complete this work. 


\section{SHE dissertations series}

The SHE Dissertation Series publishes dissertations of PhD candidates from the School of Health Professions Education (SHE) who defended their PhD theses at Maastricht University. The most recent ones are listed below. For more information go to: https://she.mumc.maastrichtuniversity.nl

Nishigori, H. (17-11-2020) Why do doctors work for patients? Medical professionalism in the era of neoliberalism

Oudkerk Pool, A. (06-11-2020) Competency-based portfolio assessment - Unraveling stakeholder perspectives and assessment practices

Geel van, K. (05-11-2020) Lifelong learning in radiology: all eyes on visual expertise

Stammen, L. (16-10-2020) Pursuing - High-Value, Cost-Conscious Care - The Role of Medical Education

Meulen van der, M. (15-10-2020) Assessment of physicians' professional performance using questionnaire-based tools

Matsuyama, Y. (05-10-2020) Contextual attributes fostering self-regulated learning in a teachercentered culture: learner's professional identity formation is a trigger

Rovers, S. (16-09-2020) Growing knowledge, supporting students' self-regulation in problembased learning

Bourgeois-Law, G. (03-09-2020) Conceptualizations of remediation for practicing physicians

Giuliani, M. (19-05-2020) A Critical Review of Global Curriculum Development, Content and Implementation in Oncology

Schreurs, S. (20-03-2020) Selection for medical school; the quest for validity

Schumacher, D. (19-03-2020) Resident Sensitive Quality Measures: Defining the Future of PatientFocused Assessment

Sehlbach, C. (21-02-2020) To be continued.... Supporting physicians' lifelong learning

Kikukawa, M. (17-12-2019) The situated nature of validity: Exploring the cultural dependency of evaluating clinical teachers in Japan

Kelly, M. (10-12-2019) Body of knowledge. An interpretive inquiry into touch in medical education 
Klein, D. (06-11-2019) The performance of medical record review as an instrument for measuring and improving patient safety

Bollen, J. (01-11-2019) Organ donation after euthanasia: medical, legal and ethical considerations

Wagner-Menghin, M. (25-09-2019) Self-regulated learning of history-taking: looking for predictive cues

Wilby, K. (02-07-2019) When numbers become words: Assessors' processing of performance data within OSCES

Szulewski, A. (20-06-2019) Through the eyes of the physician: Expertise development in resuscitation medicine

McGill, D. (29-05-2019) Supervisor competence as an assessor of medical trainees; Evaluating the validity and quality of supervisor assessments

Van Rossum, T. (28-02-2019) Walking the tightrope of training and clinical service; The implementation of time variable medical training 